University of South Florida

DIGITAL COMMONS

@ UNIVERSITY OF SOUTH FLORIDA
Digital Commons @ University of

South Florida

$2-1-2008$

\title{
Development of a Large Bus / Small Bus Decision Support Tool Phase 2
}

CUTR

Follow this and additional works at: https://digitalcommons.usf.edu/cutr_nctr

\section{Recommended Citation}

"Development of a Large Bus / Small Bus Decision Support Tool Phase 2," National Center for Transit Research (NCTR) Report No. CUTR-NCTR-RR-2007-09, Center for Urban Transportation Research, University of South Florida, 2008.

DOI: https://doi.org/10.5038/CUTR-NCTR-RR-2007-09

Available at: https://scholarcommons.usf.edu/cutr_nctr/164

This Technical Report is brought to you for free and open access by the National Center for Transit Research (NCTR) Archive (2000-2020) at Digital Commons @ University of South Florida. It has been accepted for inclusion in Research Reports by an authorized administrator of Digital Commons @ University of South Florida. For more information, please contact digitalcommons@usf.edu. 


\title{
Phase Two Final Report: Development of a Large Bus/Small Bus Decision Support Tool
}

\author{
Final Report
}

February 2008

Prepared for

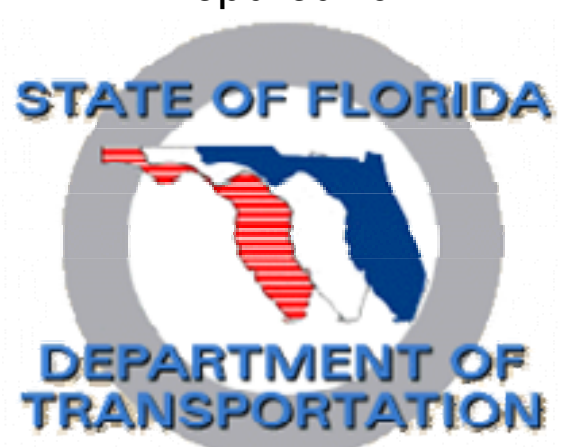

Florida Department of Transportation

Prepared by

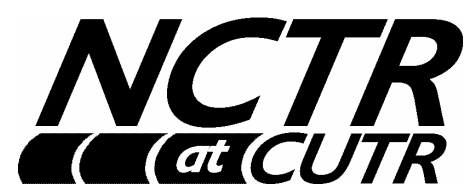

National Center for Transit Research

Center for Urban Transportation Research

University of South Florida

4202 E. Fowler Avenue, CUT100

Tampa, FL 33620

The opinions, findings, and conclusions expressed in this publication are those of the authors and not necessarily those of the U.S. Department of Transportation or the State of Florida Department of Transportation. 


\section{Development of a large Bus/Small Bus Decision Support Tool

Technical Report Documentation Page

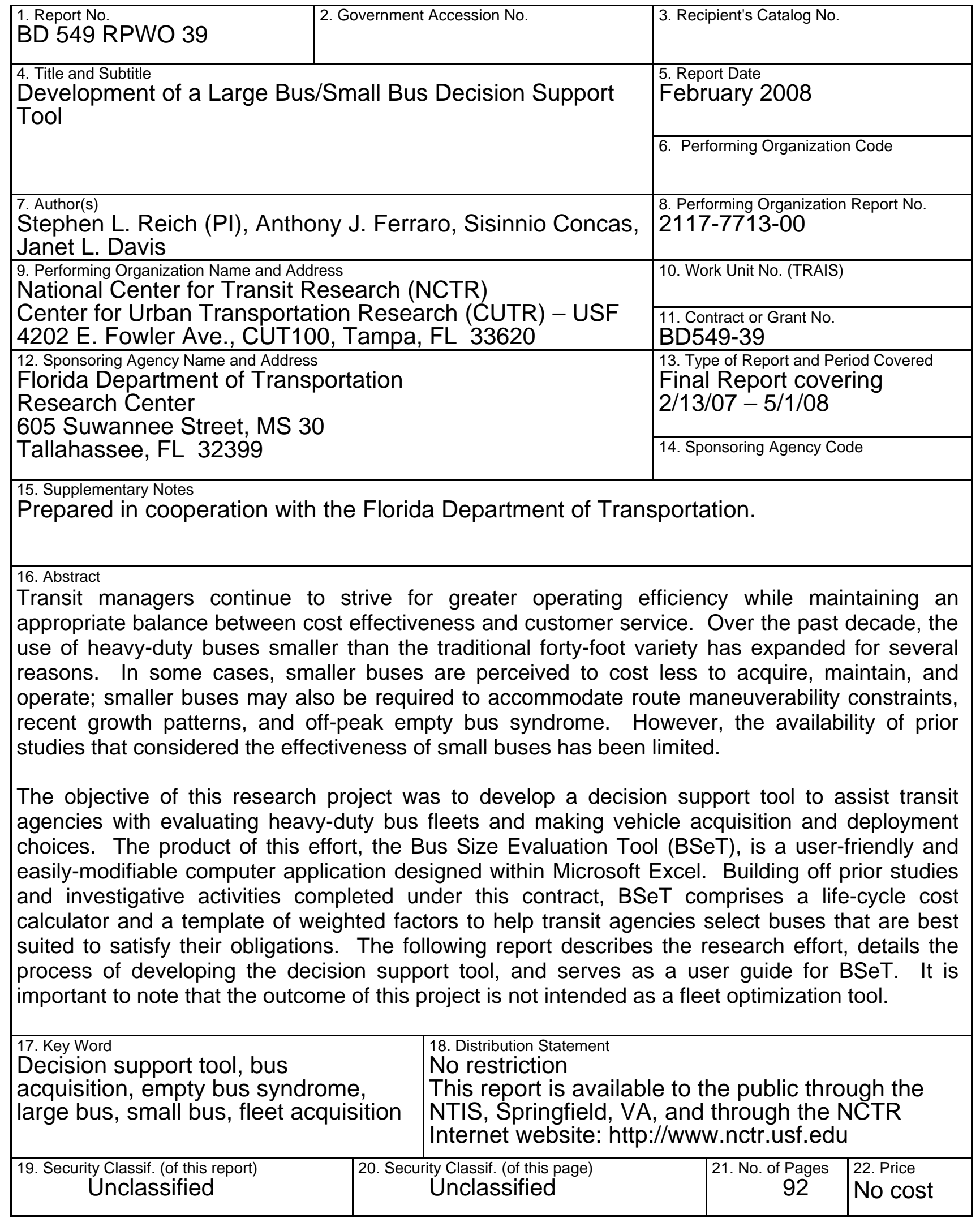

Form DOT F 1700.7 (8-72) Reproduction of completed page authorized 


\section{ACKNOWLEDGEMENTS}

CUTR would like to thank the following groups for their contributions and assistance during this project:

Florida Department of Transportation

Hillsborough Area Regional Transit Authority

Central Florida Regional Transit Authority

Jacksonville Transportation Authority

Palm Beach County Surface Transportation Department

Pinellas Suncoast Transit Authority 


\section{EXECUTIVE SUMMARY}

\section{Problem Statement}

As transit managers continue to strive for greater operating efficiency, they are obligated to maintain an appropriate balance between cost effectiveness and customer service. To this end, assorted innovations have been considered, including wider implementation of small buses. For the purposes of this study, small buses are defined as heavy-duty transit buses that are shorter in length than the traditional 40-foot vehicle. Over the past decade, the use of small buses has gained favor among many transit operators for a variety of reasons. In some cases, smaller buses are perceived to cost less to acquire, to maintain, and to operate. Smaller buses may also be required to accommodate route maneuverability constraints, recent growth patterns, and off-peak empty bus syndrome. However, the availability of prior research into the effectiveness of small buses has been limited. Studies that have considered small buses rarely attempt to identify or quantify the specific conditions under which transit decision-makers should consider replacing large buses or using small buses on new routes.

\section{Project Objective}

The objective of this research project is to develop a decision support tool that can be used to assist transit agencies with evaluating heavy-duty bus fleets and making vehicle acquisition and deployment choices. The intended product of this effort is a user-friendly, easily-modifiable computer application designed using the Microsoft Excel platform. Building off prior studies and current investigative activities, the tool comprises a life-cycle cost calculator and a template of weighted factors to help transit groups advance bus selections best suited to meet their service needs and priorities. It is important to note that the outcome of this project is not intended to be a fleet optimization tool.

\section{Research Methods and Outcome}

The investigative process involved the completion of several tasks in order to satisfy the goal of this research effort. First, prior studies were examined to determine the areas of interest most likely to impact bus acquisition and deployment decisions. The factors deemed most relevant included the following: 
- Fleet replacement \& expansion

- Load factors

- Vehicle size-related constraints
- Capital costs

- Route scheduling and design

- Customer feedback

With these variables in mind, researchers proceeded to compile a group of five Florida transit agencies to participate in the study. A key purpose of the group was to provide current and accurate data to be used for the development of the decision support tool. Specifically, data were compiled to form a composite bus fleet, which was analyzed and used to calibrate the model. Overall, the composite fleet consisted of 865 heary-duty, dieselfueled buses, including 562 large buses and 303 small buses. Fourteen model years and five manufacturers were represented, with over 80 percent of the vehicles produced by the Gillig Corporation.

Based on composite fleet data, critical assessment factors were calculated and inserted as default values for the decision support tool. Specifically, critical life-cycle variables related to usage intensity levels, variable costs, and fixed costs for small and large buses in the composite fleet are summarized in the table below.

\begin{tabular}{|lrr|}
\hline Life-Cycle Variables & Small Buses & Large Buses \\
\hline Usage intensity: & 49,434 & 49,966 \\
Average annual miles & 4.3 & 3.8 \\
\hline $\begin{array}{l}\text { Average annual miles per gallon } \\
\text { Variable costs: }\end{array}$ & $\$ 0.42$ & $\$ 0.52$ \\
Average annual per mile labor cost & $\$ 0.84$ & $\$ 0.73$ \\
Average annual per mile parts cost & $\$ 1.26$ & $\$ 1.25$ \\
$\begin{array}{l}\text { Average annual per mile maintenance } \\
\text { cost (labor + parts) } \\
\text { Average annual per mile fuel cost }\end{array}$ & $\$ 0.80$ & $\$ 0.91$ \\
\hline $\begin{array}{l}\text { Fixed costs: } \\
\text { Average vehicle acquisition cost }\end{array}$ & $\$ 297,506$ & $\$ 317,586$ \\
\hline \hline
\end{tabular}

With the critical input variables established, design of the decision support tool moved forward. Now referred to as the Bus Size Evaluation Tool (BSeT), the instrument efficiently guides the user through four analytical steps:

1. The user enters organization and analyst identification data;

2. The user inputs the current bus fleet composition, including the numbers of small and large buses by model year; 
3. The user inputs vehicle constraints, including minimum numbers of each bus size required to meet the needs of the service area and the average passenger counts among each bus size; and

4. The user responds to a series of qualitative statements.

Designed to be as straight-forward as possible, the first step of BSeT allows the user to create a distinct title for each analysis trial. Subsequent trials may be named according to specific data inputs. After the completion of several analytical tests, the user may easily compare the results by referring to the unique titles.

For the second step outlined above, the user may enter up to 12 model years of small and large heavy-duty buses. The model assumes a one-to-one bus replacement schedule by model year; however, the user has the option to enter a customized bus replacement schedule for future years. Unless otherwise modified by the user, BSeT is also designed to preserve the total passenger load capacity of the existing fleet, which is based on the number of buses by size and the number of available seats.

As outlined above in step three, BSeT is designed to account for the unique service needs and/or policy mandates of the implementing agency. In the event that a transit agency must observe specific vehicle size and quantity requirements, the model prioritizes these numbers and incorporates them into the analysis as constraints.

The fourth step shown above is critical to the analysis. The answers to these questions indicate the user's priorities regarding small or large buses. Further, few or no responses indicate no measurable differences, and the model assumes that the current fleet is representative of the user's most critical needs. Because of the importance of the qualitative analysis (step four), researchers engaged the project advisory group for vital input. Overall, the group determined four critical areas of interest for the qualifying component, including vehicle acquisition, ridership, special concerns, and feedback. For each of the nine specific qualifying statements, a seven-point Likert scale was installed as the response. As a result, each response reflects a measurable degree of need satisfied by small buses or by large buses (or indifference), and the summary total dictates the overall priorities of the user.

Although BSeT operates under basic assumptions and default values, the tool is also designed to be fully customizable. With each analysis attempt, the user may enter unique values for some or all of the critical assessment factors 
that underlie the tool. The user is also able to modify the weighting assigned to each qualitative analysis subject area.

\section{Benefits}

The outcome of this research endeavor provides FDOT with a flexible, yet robust, analysis tool that can be easily distributed to and utilized by a wide range of transit agencies. BSeT allows users to easily calculate life-cycle costs for small and large buses and compare the results. The tool goes a step beyond many prior research efforts in this area because it considers a number of qualitative factors, weights them according to expert opinion and/or user input, and incorporates their impact into the overall output findings. The outcome of the analyses may be used in support of important agency decisions regarding bus acquisition and deployment. A step-by-step BSeT user guide and critical background data are also included in the written final report. 


\section{TABLE OF CONTENTS}

ACKNOWLEDGEMENTS iv

EXECUTIVE SUMMARY v

TABLE OF CONTENTS .............................................................. ix

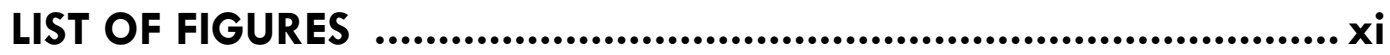

LIST OF TABLES

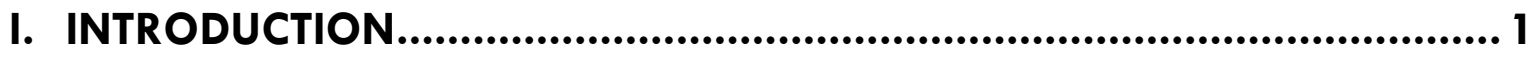

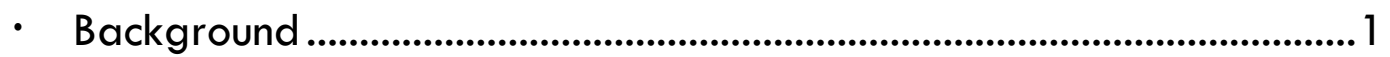

- Phase Two Overview .....................................................................2

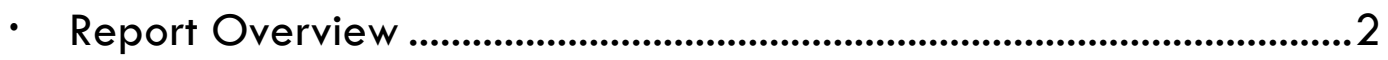

II. REVIEW of PREVIOUS STUDIES AND ASSESSMENT FACTORS ............... 5

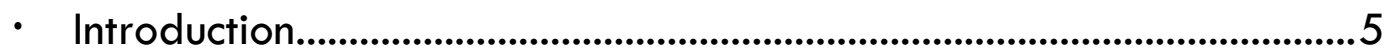

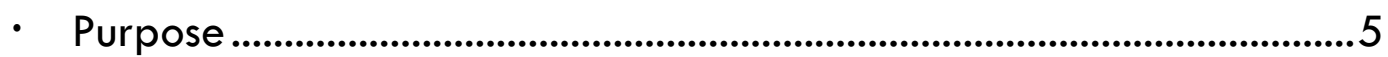

- National Transit Data ............................................................................5

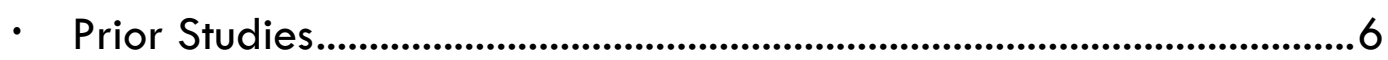

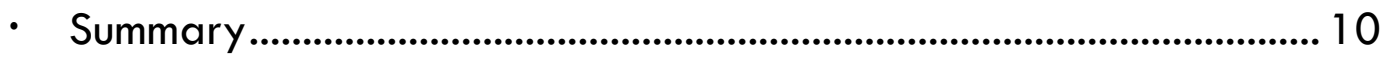

III. PARTICIPATING FLORIDA TRANSIT AGENCIES................................... 11

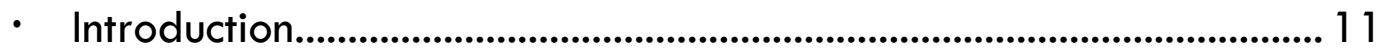

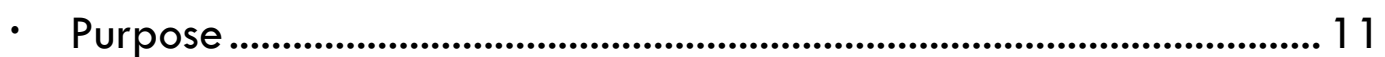

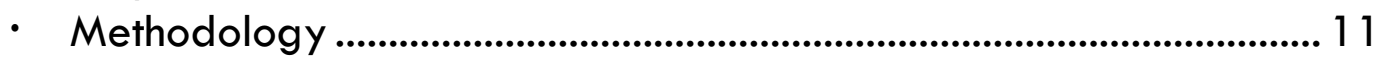

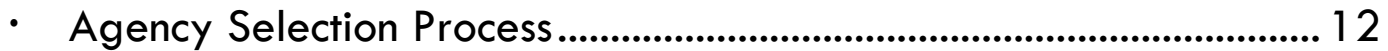

- Overview of Participating Florida Transit Agencies............................ 14

- HART: Hillsborough Area Regional Transit Authority ...................... 14

- JTA: Jacksonville Transportation Authority........................................ 15

- LYNX: Central Florida Regional Transit Authority ........................... 16

- Palm Tran: Palm Beach County Surface Transportation Dept.... 16

- PSTA: Pinellas Suncoast Transit Authority....................................... 17

- Review of Transit Agency Data and Practices.................................. 17

- Bus Fleet Compositions........................................................................ 18

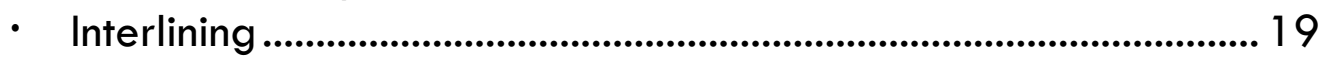

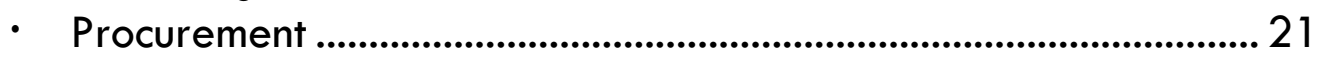

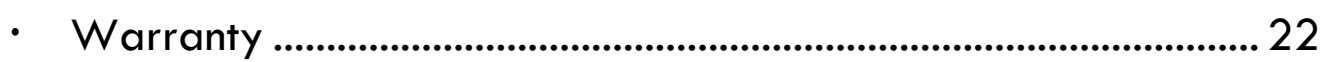

- Growth Projections ................................................................................ 23

- Fixed Routes and Service Planning Guidelines.............................. 24

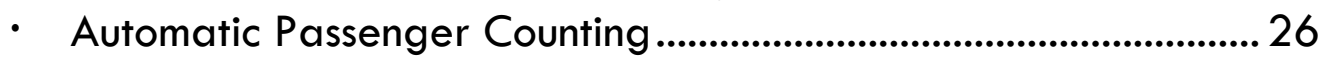

- Bus Fleet Performance and Life-Cycle Cost Data ........................... 27 
- Other Factors

- Summary

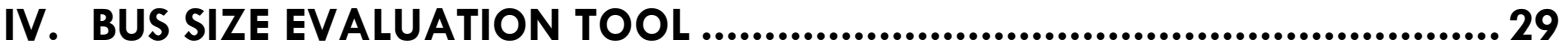

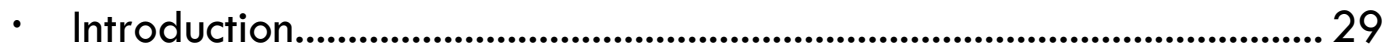

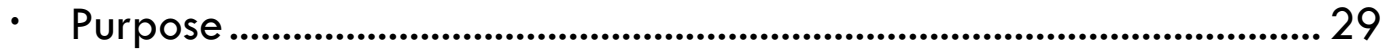

- Proposed Model .............................................................................................. 29

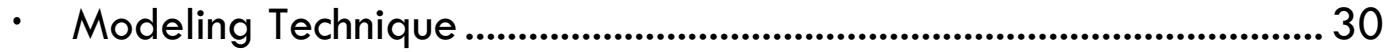

- Evaluation Criteria........................................................................................... 31

- Composite Fleet Overview................................................................... 31

- Life-Cycle Cost Factors ..................................................................... 33

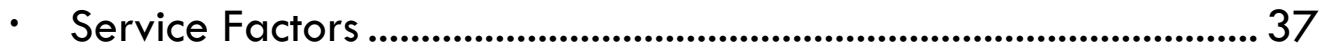

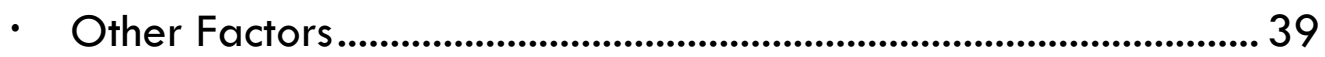

Evaluation/Decision Support Tool Implementation....................................... 41

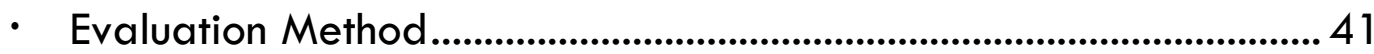

- Bus Size Evaluation Tool (BSeT) - User Guide ........................................ 45

- BSeT Analysis and Input Requirements .......................................... 47

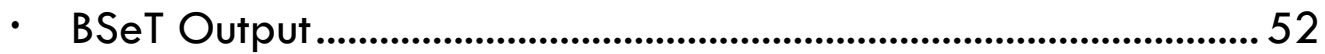

- Customizing BSeT .................................................................................... 53

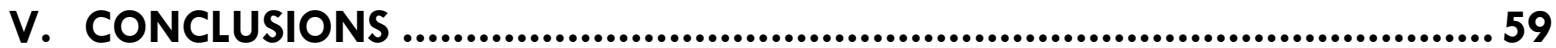

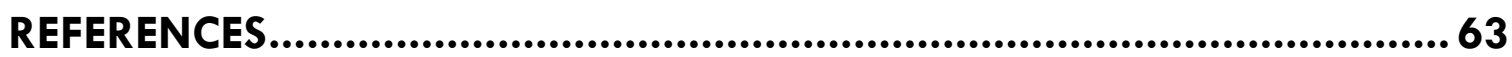

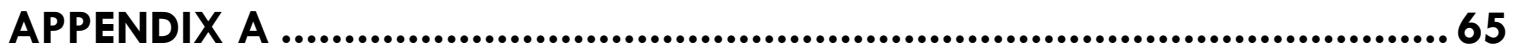

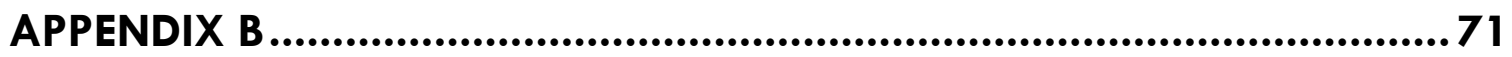




\section{LIST OF FIGURES}

Figure 4.1 Evaluation Model Flowchart ......................................................... 44

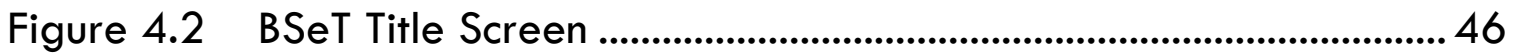

Figure 4.3 BSeT Main View and Instruction Page ............................................. 46

Figure 4.4 BSeT Analysis, Step 1: Name and Title ............................................. 47

Figure 4.5 BSeT Analysis, Step 2: Current Bus Fleet............................................ 48

Figure 4.6 BSeT Analysis, Step 3: Bus Fleet Characteristics.............................. 49

Figure 4.7 BSeT Analysis, Step 4: Qualitative Factors.....................................50

Figure 4.8 BSeT Analysis: Output Screen.......................................................... 53

Figure 4.9 Modifying BSeT Model Parameters...................................................54

Figure 4.10 Modifying BSeT Model: Cost Parameters........................................55

Figure 4.11 Modifying BSeT Model: Life Cycle Parameters.............................. 56

Figure 4.12 Modifying BSeT Model: PLF and Tolerance Parameters ............56

Figure 4.13 Modifying BSeT Model: Qualitative Factors ....................................57

Figure 4.14 Modifying BSeT Model: Custom Bus Fleet..........................................58

Figure 4.15 Modifying BSeT Model: Cancel Modifications..................................58 


\section{LIST OF TABLES}

Table 3.1 Summary of Bus Fleet Composition by Agency ............................. 18

Table 4.1 Composite Bus Fleet by Manufacturer.............................................. 32

Table 4.2 Composite Bus Fleet by Year .............................................................. 32

Table 4.3 Composite Bus Fleet Average Acquisition Costs by Model Yr ... 37

Table 4.4 Composite Bus Fleet APC Data Summary …………………............. 39

Table 4.5 Step 4: Qualitative Factors - Categories, Statements, and

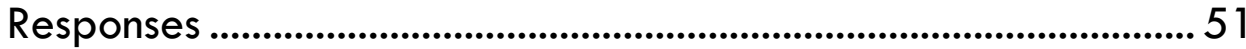




\section{INTRODUCTION}

This research project aims to develop an evaluation tool to help transit agencies make decisions about bus acquisition and deployment. The following report, completed by the Center for Urban Transportation Research (CUTR) at the University of South Florida (USF), includes an overview of relevant past research, a comparison of data and practices among selected Florida transit agencies, a description of the support tool development process, and instructions for using the tool. General concluding statements, as well as sample support tool calculations, are also presented within this document.

CUTR engaged in this research effort under a contractual agreement between the Florida Department of Transportation (FDOT) and USF. Researchers developed the scope of work through a proposal for funding by the National Center for Transit Research (NCTR). As such, CUTR organized the overall research effort around the completion of two project phases. The first phase of study (completed in June 2007) included a thorough examination of the existing Hillsborough Area Regional Transit (HART) metro bus fleet and an investigation of operating scenarios involving varying quantities of small heavy-duty transit buses. To complete phase two, CUTR utilized and built on phase one results to develop the evaluation/decision support tool.

The submission of this report represents the completion of the second and final portion of the overall research endeavor.

\section{Background}

Transit agencies face a host of challenges in the ongoing effort to improve efficiency and to balance cost effectiveness and customer service. Labor and fuel costs continue to rise, while funding streams become increasingly austere. In addition, recent population growth patterns and employer location decisions often favor lower-density areas, which commonly result in less-thanideal conditions for convenient transit service. In some cases, residential and commercial developments lack adequate space to accommodate traditional 40-foot buses. Such issues tend to form barriers to transit use. With 
policymakers generally reluctant to authorize fare hikes or tax increases, transit decision-makers must devise alternative solutions to these and other challenges.

As transit operators continue to seek out creative, economical service improvements, one option that has increasingly gained favor is expanding the use of smaller heavy-duty buses. Generally, small buses include any revenue vehicle shorter in length than the standard 40-foot public transit bus. Public policy-makers perceive that wider use of small buses will affect dramatic cost savings among the areas of acquisition, maintenance, and operation. By integrating small buses into the fleet mix, many officials also believe that the prevalence of off-peak empty bus syndrome will be reduced. However, the true impact of small bus implementations is largely undocumented, and few resources are currently available to help transit agencies determine their most effective level of small bus utilization. As such, the objective of this project is to develop a support tool to assist transit groups with the evaluation of potential vehicle acquisition and deployment choices.

\section{Phase Two Overview}

The first phase of this research project was undertaken much like an extended case study. Specifically, the phase-one effort focused on potential small bus scenarios at a single agency. The second phase expanded the investigation to comprise input from several transit properties and sought to devise a specific method to aid in fleet composition decisions. CUTR relied on research methods developed under the first research phase, as well as phase one results, to form a critical foundation for the current effort. In phase two, CUTR reexamined recent literature and other informational articles relevant to the study. Further, CUTR identified additional transit agencies for participation in the project and formed a working advisory group, which included representatives from each participating transit agency and FDOT. Then, researchers gathered information from staff interviews, observations, official documentation, and data analyses, when available. CUTR examined participating agency data, such as bus fleet statistics, operational performance and route profiles, and processed the information as necessary. As the project progressed, CUTR utilized initial data analyses to develop the bus evaluation and decision support tool. Final results, including conclusions, support tool instructions, and sample calculations, are presented in this final written report.

\section{Report Overview}

This final report includes five chapters, along with references and 
appendices. The first chapter serves as a brief introduction, and the second focuses on influential scholarly reports and summarizes the areas of interest most likely to impact transit bus acquisition and deployment decisions. In chapter three, CUTR establishes the project participants and forms an advisory group from among Florida's transit agencies, investigates critical information made available by each participant, and reports significant findings in terms of the lessons learned from the literature review and the phase one research effort. Comprising two overall components, the fourth chapter exhibits the focal point of the project. First, CUTR describes the methods employed to formulate and calibrate the decision support tool. Later, researchers launch the Bus Size Evaluation Tool and illustrate required inputs, expected outputs, and modification opportunities. The fifth and final chapter summarizes the overall research effort and presents a series of final comments. Lastly, two appendices are included. The first appendix presents supporting data referenced in chapter three, while the second appendix consists of sample analyses computed using the BSeT final version. 
(page intentionally left blank) 


\section{II. \\ REVIEW OF PREVIOUS STUDIES AND ASSESSMENT FACTORS}

\section{Introduction}

The following chapter discusses three areas of information critical to this research project. After a brief description of important national data sources, prior studies are reviewed. Next, these studies are discussed in terms of their relevance to the phase one transit bus fleet composition analysis and to the phase two effort to develop a bus evaluation/decision support tool. Later sections of the chapter consider additional model-building techniques and other applicable research methods significant to the phase two effort.

\section{Purpose}

The scope of work for phase one of this project directed CUTR to review literature, data, methods, and transit experiences relevant to smaller buses. Phase two obligated researchers to review and refine the prior study summaries in order to determine which of the assessment factors established during phase one were vital to the development of a bus evaluation/decision support tool. Specifically, the tasks completed for this chapter allowed CUTR to validate the results of phase one and to apply the lessons learned toward the second phase of research. To ensure a robust end result, researchers also documented prior studies and previous applications related to the decision tool-building process.

\section{National Transit Data}

In most cases, transit research projects involve a review of essential data maintained by the Federal Transit Administration (FTA) in the National Transit Database (NTD) and the American Public Transportation Association (APTA). For the present research effort, CUTR utilized these resources to help select Florida transit agency participants, as well as to determine critical variables 
required for use within the evaluation/decision support tool. Detailed references to national data sources are included throughout subsequent chapters of this report, where applicable.

\section{Prior Studies}

A limited amount of prior research exists on the topic of small bus transit fleet composition and comparison analysis. However, an important source of information in this area was found within the Transit Cooperative Research Program (TCRP) Synthesis 41: The Use of Small Buses in Transit Service (1). Although this study was referenced by CUTR in phase one, a more in-depth discussion is included here. Specifically, components of the synthesis are used to validate elements of the fixed-route fleet analysis completed by CUTR for the Hillsborough Area Regional Transit Authority (HART). In addition, limitations of the study are discussed, where relevant.

For TCRP Synthesis 41 , authors Hemily and King surveyed transit agencies and manufacturers, interviewed transit managers and staff, and presented four case studies. Critical information documented in the study included specific uses of small buses, reasons for small bus purchases, user experiences, and relevant issues and technologies. In this study, the term small buses encompassed 57 types of smaller transit vehicles from van cut-aways to heavy-duty 30 -foot buses. Paratransit vans, rural service vehicles, and replica trolleys were not included in the study (such vehicles were also excluded from the CUTR analysis).

Survey results indicated that close to 60 percent of North American transit agencies operated small buses and overall, small buses comprised about 20 percent of urban-area transit bus fleets. Results also showed that larger transit agencies generally operated a lower percentage of small buses, while smaller agencies operated a larger share. The authors reported that interest in small buses had steadily grown due to a number of reasons, including: growth of suburban areas, limited accessibility, noise and vibrations caused by larger buses, public opinion (including empty bus syndrome) and the desire for greater cost-effectiveness with service in low-demand areas or during low-demand hours. In fact, "matching capacity to demand" and "maneuverability on small streets" were the most common reasons given for small bus purchases. Eighty-five percent of respondents reported positive experiences with small buses, and the number of transit agencies that had increased the use of small buses in recent years surpassed the number that had reduced small bus use. 
According to TCRP Synthesis 41, Altoona Bus Testing and Research Center (ABTRC) findings demonstrated that small heavy-duty buses averaged slightly better fuel economy than large buses (CUTR also observed this condition at HART). This observation is not entirely unexpected because manufacturers generally build and equip smaller heavy-duty buses similarly to larger models. Although one case study reported fuel economy among small buses to be 39 percent higher than large buses, no evidence to substantiate this claim was provided. The study also found that vehicle manufacturers increasingly develop small bus models to complement their larger vehicle offerings.

Other aspects of TCRP Synthesis 41 were relevant to the investigation at hand. For example, Hemily and King recommended that transit agencies exercise caution when attempting to utilize small buses during peak demand periods or in areas where demand exceeded capacity. They pointed out that transit customers become unhappy during extended periods of overloaded capacity, and the authors reinforced the overall importance of passenger loading issues. The report discussed the interlining process and pointed out that the use of a complex array of small and large buses tends to impede the design and maintenance of interliner schedules. Additionally, the authors mentioned the potential for small bus service to be branded and marketed for greater visibility and to generate a positive image of the service. Increased political support for a transit agency might also be among the results of such efforts.

Hemily and King indicated common concerns related to small buses, such as reliability and maintenance costs, as well as customer acceptance and acquisition costs. Although larger transit agencies maintained a lower proportion of small buses, they tended to be somewhat less satisfied with them than smaller agencies. Specifically, some agencies experienced excessive passenger loading on small buses during peak periods, while others found the vehicles to be less reliable than large buses. Unfortunately, the research did not specify which types of small buses were most likely to generate such concerns. In general, the availability of information directly related to operator, mechanic, and public opinions of small buses was also limited. However, agencies did report positive customer response to services specifically designed for operation by smaller buses.

Some of the critical small-bus purchase decision factors identified in TCRP Synthesis 41 were not necessarily relevant to the CUTR study. For example, the most important factor cited was the lower wage rate for small bus operators; however, this was not an issue for HART because the agency maintained salary parity among all operators. Maneuverability was also 
given as a reason that agencies consider small buses, but HART tested all fixed-routes to ensure complete operability regardless of bus size. While agencies were concerned about public acceptance of smaller vehicles, the overall availability of market research in this area was minimal.

The synthesis report tended to combine issues, concerns, performance measures, et cetera across all small buses rather than outlining information by bus type. Further, issues specific to smaller heavy-duty buses were generally not presented. For example, while overall motivations for the acquisition of smaller buses were outlined, details related to procurement and deployment of the heavy-duty varieties were limited. In addition, the synthesis effort did not include a decision-making tool for use by agencies when considering the purchase of small buses. However, the authors pointed out that the development of such a tool was warranted, and they called for greater insight into specific vehicle performance measures. Further study of the costeffectiveness of small bus services was also suggested.

A second highly relevant prior study was TCRP Report 61: Analyzing the Costs of Operating Small Transit Vehicles - User's Guide STVe (Small Transit Vehicle economics) (2). Specifically, the KFH Group, Inc., Littleton C. MacDorman, and Laidlaw Transit Services, Inc. developed a Microsoft Excel tool to assist transit decision-makers with the selection of small transit vehicles. In fact, the report served as both the narrative of the research effort and an instruction manual for the program. The STVe tool incorporated actual cost data with capital, operating, and maintenance costs and allowed users to process such variables to determine cost-effective vehicle procurement solutions. The project also identified several non-financial factors that may impact bus purchasing decisions.

Sensitive to the difficult nature of drawing comparisons among a wide variety of small transit vehicles, STVe model-builders designed the tool to consider a full range of cost details. Because the operating characteristics of small transit vehicles vary considerably, TCRP Report 61 also considered nonfinancial and non-quantifiable factors. The study did not include a series of conclusions and recommendations. However, the authors included a glossary of relevant terms, as well as examples of the STVe in practice and interpretations of the sample results.

Because of the scarcity of transit research related to small buses, TCRP Report 61 served as an important reference in the phase one report produced by CUTR. While the focus on small transit vehicles and the construction of a cost analysis tool were overarching influences drawn from the KFH Group product, other elements contained in the study also proved 
important. For example, the authors pointed out that smaller transit vehicles were more likely to be considered for use in lower density areas and smaller cities. According to the study, recent commercial and residential growth tended to be low density, and smaller transit vehicles were the most appropriate choice to provide service in such areas. Much of the HART service area fits this profile, and the project was driven by the desire for fuller off-peak buses.

Fleet standardization, a practice in which many transit agencies engage to create homogeneous bus fleets, was also discussed in TCRP Report 61. This practice seeks to reduce vehicle acquisition, training, and maintenance costs, as well as to facilitate replacement part purchases. Although researchers were unable to determine whether or not HART officially adopted the policy, the agency was fully engaged in the practice of fleet standardization at the time of the study. TCRP Report 61 study included a brief discussion of lowfloor vehicles, which comprise a significant portion of the HART bus fleet.

A series of classification schemes was developed for TCRP Report 61, which were generally similar to identifiers used during the phase one CUTR effort. For example, the report presented eight vehicle classifications (including two types of heavy-duty vehicles), while only two classes were relevant to the CUTR project. Additionally, both studies referred to three types of transit service levels; however, the details of these classifications were somewhat different, and CUTR used specific fixed-route terminology provided by HART. Based on HART service characteristics, CUTR also combined classification schemes for the purposes of the phase one study.

The terms of the phase one research effort did not instruct CUTR to develop a complex transit vehicle comparison model. Specific concerns focused on operating scenarios with various combinations of heavy-duty buses. In contrast, TCRP Report 61 was designed to compare many types of smaller transit vehicles. However, several critical variables were common to both studies, and CUTR's reliance on these variables was reinforced by their significance within the earlier report. Specifically, vehicle purchase price and service life expectancy, as well as costs for fuel, labor, parts, and other maintenance needs, were factors in both research efforts. Non-financial points, such as vehicle-related size constraints, vehicle maneuverability, ride quality, fuel type, vehicle aesthetics, and noise levels, were considered by CUTR but ultimately dismissed because they were not among the determining factors at HART. 


\section{Summary}

As the work intended for phase two involved the development of a bus acquisition decision support tool, CUTR relied on TCRP Report 61 as a key reference. In this case, the STVe tool served as a critical guideline, including financial and non-financial elements, as well as passenger loading factors; however, CUTR's effort is only applicable to heavy-duty, 12-year service life small buses. In addition, while the TCRP Report 61 tool allowed for comparison between small buses, the tool developed by CUTR will be designed to specifically compare small and large heavy-duty transit buses.

Like the TCRP effort, CUTR intended to develop the evaluation/decision support tool using Microsoft Excel and to include step-by-step instructions for using the finished model and interpreting the results. As in prior studies, CUTR also designed the research process to draw input from an advisory group consisting of regional transit agency representatives.

Overall, prior studies revealed the following topics as most likely to impact decisions regarding bus acquisition and deployment:

- Replacement/Expansion - Specifically, are newly acquired buses intended to replace buses about to be retired or to expand the existing fleet? Further, what are the service needs based on the type of service and special needs of the area?

- Load Factor - What are the passenger capacity needs that must be accommodated by each vehicle?

- Vehicle Size-related Constraints - What general or specific conditions impact the ability of a bus to operate throughout the service area? Do conditions require or restrict the use of specific bus types?

- Capital Cost - How do acquisition costs affect purchasing and/or deployment decisions?

- Route Scheduling and Design - How do specific agency practices, such as interlining, scheduling, etc., contribute to decisions related to vehicle acquisition and deployment?

- Customer Feedback - To what degree, if any, do the opinions of bus riders impact bus acquisition and deployment efforts?

Researchers intended to utilize these topics as a guide for further investigation of participating transit agencies. Results are documented in Chapter III. 


\section{III. \\ PARTICIPATING FLORIDA TRANSIT AGENCIES}

\section{Introduction}

In essence, Chapter III serves as a cornerstone for this research effort. Following a brief description of the overall investigative plan, the process of selecting four additional Florida transit agencies to participate in the project is explained in detail. Later, an overview of each participant is presented, and current practices are reported in terms of each critical assessment factor. Data gathered during this process were vital to the development of the evaluation/decision support tool, which is presented in Chapter IV.

\section{Purpose}

The original scope of work for this project directed CUTR to review NTD and APTA data, to help select Florida transit agencies to be included in the project, and to form a project advisory group that consisted of key personnel from each participating agency. Once established, researchers coordinated with the group to gather critical data for development of the evaluation/decision support tool. The large pool of assessment data, including life-cycle maintenance costs and passenger load counts, was necessary to ensure a robust calibration for the research product.

\section{Methodology}

CUTR observed a careful plan of action to complete this segment of the research effort. A portion of the research design was based on methods determined during the first phase of study, while new strategies were required to complete other components of the project. First, researchers identified a group of transit agencies for participation in the project, helped to narrow the field and to suggest appropriate candidates, and then, formed a working advisory group, which included representatives from each participating agency and FDOT. Based on the close working relationship fostered with HART planners during phase one, CUTR initiated contact with planning staff at the additional phase two transit agencies. These individuals advised researchers as to the most appropriate contacts within their 
respective organizations. As the advisory group expanded, researchers maintained frequent contact with each and gathered vital information through staff interviews, direct observations, official documentation, and critical data analyses, when available. As data were made available, CUTR examined items such as bus fleet statistics, operational performance figures and route profiles, and processed the information, as necessary. Critical assessment factors are reviewed later in this chapter, while specific data analysis results are provided in Chapter IV.

\section{Agency Selection Process}

As stated earlier, this research project was designed to build upon the methods and results determined under an earlier study. Specifically, while the previous research phase focused on one Florida transit agency, the present phase was designed to bring up to four additional organizations into the study. As such, the next step in the process was to determine which Florida transit groups were the most eligible candidates for further study. Beyond simply meeting basic criteria, prospective candidates had to be willing to participate in the research process, to contribute to it, and to fulfill data and information requests in a timely manner. To meet this challenge, the FDOT project manager enlisted CUTR to assist in the selection of Florida transit agencies to participate in this research effort.

Initially, CUTR reviewed the NTD to identify Florida agencies that directly operated a transit bus fleet from 2001 through 2005. Based on these criteria, any organizations limited to demand response and/or purchased services during the time period were eliminated from consideration. In total, 21 agencies were identified in the NTD, and all but one agency reported directly-operated transit service in 2005 (see Appendix A, Table A.1).

While the NTD provided significant data regarding individual agency fleets and fleet operating characteristics, it contained little, if any, specific information regarding the nature of the vehicles that made up the fleet. Because a critical assessment factor involved fleet composition by bus type, i.e., 40-foot buses and less-than-40-foot buses, CUTR turned to the APTA Fleet Database for additional information. APTA published information for 13 of the 21 agencies that reported to the NTD in 2003 and for 12 of the 20 agencies that reported to the NTD in 2005 (see Appendix A, Table A.2).

Due to incomplete data, the following nine agencies were eliminated from consideration for the study because none reported specific fleet information for 2005:

- Bay County Council on Aging Bay Coordinated Transportation 
BCCOA)

- City of Tallahassee (Star Metro)

- Council on Aging of St. Lucie. (CT)

- Escambia County Area Transit (ECAT)

- Indian River County Council on Aging, Inc. (IRCCOA)

- Lakeland Area Mass Transit District (Citrus Connection)

- Lee County Transit (Lee Tran)

- Pasco County Public Transportation (PCPT)

- Polk County Transit Services Division-Polk County BOCC (PCTS)

Two agencies of significant size were excluded based on minimal use of buses less than 40 -feet in length:

- Broward County Mass Transit Division (BCT) -0.0 percent ( 0 small buses out of 275 total buses)

- Miami-Dade Transit (MDT) - 9.6 percent (70 small buses out of 732 total buses) ${ }^{1}$

Four agencies were eliminated because smaller buses comprised most or all of the revenue fleet:

- County of Volusia, dba: VOTRAN (VOTRAN) - 100.0 percent (47 small buses out of 47 total buses)

- Manatee County Area Transit (MCAT) - 100.0 percent (20 small buses out of 20 total buses)

- Sarasota County Area Transit (SCAT) - 100.0 percent (36 small buses out of 36 total buses)

- Space Coast Area Transit (SCAT) - 87.5 percent ( 14 small buses out of 16 total buses)

As a result of the descriptive statistics compiled above, six candidates for the phase two research effort remained, including:

- Palm Beach County Palm Tran, Inc. (Palm Tran) 66.4 percent (85 small buses out of 128 total buses)

- Central Florida Regional Transportation Authority (LYNX) - 17.9 percent (47 small buses out of 263 total buses)

- Gainesville Regional Transit System (RTS) - 36.9 percent (38 small buses out of 103 total buses)

- Hillsborough Area Regional Transit Authority (HART) - 59.3 percent (99 small buses out of 167 total buses)

\footnotetext{
1 Although MDT assets include a high number of less-than-40-foot buses, CUTR's intimate knowledge of the agency's overall experience with these vehicles also factored into the decision to exclude this fleet from consideration for the study.
} 
- Jacksonville Transportation Authority (JTA) - 15.4 percent (25 small buses out of 162 total buses)

- Pinellas Suncoast Transit Authority (PSTA) - 68.1 percent (96 small buses out of 141 total buses)

CUTR examined agency descriptions, census data, modal characteristics, and service efficiency as reported in the 2005 NTD (see Appendix A, Table A.3 and Table A.4). Researchers also compared 2005 with 2003 NTD data reported by each of the six candidate agencies. Further review of modal characteristics, service efficiency, and fleet composition indicated that each potential agency experienced growth and other changes in a variety of areas.

CUTR presented the results of the agency selection analysis to the FDOT project manager. As the focus of phase one, HART was automatically included among the phase two participants. Of the remaining transit agencies, LYNX, JTA, and PSTA all compared most favorably to HART. While Palm Tran and RTS were both somewhat smaller in size than the other four transit authorities, researchers felt that the analysis would benefit by including both organizations in the second research segment. Specifically, the inclusion of a county-operated agency (Palm Tran) or a city-operated group (RTS) would allow for additional points of view and enhance the value of the project. In the end, Palm Tran was selected for consideration by the FDOT project manager, and the project moved forward with the remaining five participants.

\section{Overview of Participating Florida Transit Agencies}

In addition to HART, the following Florida transit agencies were selected to participate in this research effort: JTA, LYNX, Palm Tran, and PSTA. In addition to a general review of each participant, CUTR researchers visited selected representatives from each agency and compiled detailed information related to each assessment factor identified in Chapter II. As such, the remaining sections of this chapter introduce each participating agency and present general background information for each. Later sections describe specific aspects of transit operations, data, and other practices relevant to the development of the bus evaluation/decision support tool.

\section{HART: Hillsborough Area Regional Transit Authority}

In 1979, HART was created to plan, finance, acquire, construct, operate, and maintain mass transit facilities and supply transportation assistance in Hillsborough County, Florida. Jurisdictions served by the authority include the City of Tampa, Hillsborough County, and the City of Temple Terrace. 
Appointees from each service jurisdiction comprise a 12-member board of directors, which governs HART and appoints an executive director. HART offers multiple modes of service to meet the varied transport needs of the diverse community, including: local and express fixed-route buses, an historic electric streetcar, vanpool and guaranteed ride home, door-to-door paratransit, employer/subscription minibus, circulator service in selected areas, and travel planning assistance. In addition, all HART buses are 100 percent wheelchair and bicycle accessible. The agency retains over 600 employees, and approximately 550 positions are represented by the Amalgamated Transit Union Local 1593.

In addition to the 196-vehicle fixed-route bus fleet, HART maintains a number of transit assets, including 4,500 bus stops, 18 park-and-ride facilities, eight transfer centers, and two transit centers. At the time of this writing, the HART system consisted of 51 routes, including trolley routes and a 2.4-mile streetcar line. HART carried approximately 30,000 weekday passengers on the fixed-route bus service and another 1,200 average daily streetcar passengers. The agency reported slightly more than ten million passenger trips in 2005, which represented its highest total ever and an increase of 13 percent over 2004. In fact, HART greatly exceeded the national bus ridership growth trend of 0.4 percent from 2004-2005. The trend continued into 2006 with an eight percent ridership increase during the first six months of the year.

\section{JTA: Jacksonville Transportation Authority}

In 1971, the Jacksonville Expressway Authority, which formed 16 years earlier to build bridges and expressways in Duval County, merged with several private bus companies to form the Jacksonville Transportation Authority (JTA). The authority maintains multi-modal transportation responsibilities, including public transit services and the construction and design of bridges and highways. In fact, JTA is the only major Florida city authority to manage roadways and bridges in addition to public transit. As such, officials regard JTA as an integrated transportation network. Among the public transit systems offered by JTA are metro bus service; ChoiceRide, an employer-focused transit alternative; JTA Connexion, a door-to-door transit service for the disabled, elderly, and transportation disadvantaged; Skyway, an automated transit system linking the central business district with parking facilities; three downtown trolley lines; and, a downtown stadium shuttle service. The authority contributes to future transportation planning and studies rapid transit alternatives such as light rail, bus ways, HOV lanes, commuter rail, and additional road construction. 
A core component of JTA, the metro bus system operates an active fleet of 258 vehicles that travel 8.5 million annual revenue miles along 56 fixed routes. Over 80 percent of JTA buses are 40 feet in length, and the fleet consists of vehicles from 7 different manufacturers. JTA buses carried approximately ten million passenger trips in 2005, and specific services include flyer and express bus routes, and interliner service, which combines routes to eliminate the need for riders to transfer or pay two fares. To support bus services, the authority retains 320 bus operators and 110 maintenance employees.

\section{LYNX: Central Florida Regional Transit Authority}

Although its roots can be traced as far back as the 1931 Orlando Transit Company, the modern era of public transit in central Florida began in 1992 with the adoption of the "LYNX" moniker. LYNX is the official name of the Central Florida Regional Transportation Authority, which provides public transit service in Orange, Seminole, and Osceola counties. Since 1992, LYNX has experienced an upward trend in ridership growth, studied the implementation of light rail, and expanded service into Lake County.

The governing body of LYNX is a five-member board of directors that consists of one representative from Orange, Seminole, and Osceola counties, as well as a representative from the City of Orlando and FDOT District Five. The LYNX chief executive officer reports directly to the board.

The main service area of LYNX includes the central Florida counties of Orange, Seminole, and Osceola, including the City of Orlando. Specifically, the service area encompasses 2,538 square miles and a population of approximately 1.6 million people. The fixed-route route system is designed as a radial network, but it has progressed into a multi-destination network. Overall, the bulk of service is provided within Orange County, and the dominant geographic feature within the LYNX service area is a multitude of water bodies. In recent years, LYNX extended limited service into Lake County. Express service is also offered to western Volusia County. In addition to traditional fixed-route transit bus service, LYNX provides paratransit (ACCESS LYNX) and the LYNX Commuter Assistance network.

\section{Palm Tran: Palm Beach County Surface Transportation Dept.}

Palm Tran began operational service for Palm Beach County, Florida, in 1973. Most Palm Tran transit bus services are concentrated along the eastern edge of the large county. In addition to metro bus service, the agency also maintains Palm Tran Connection, a door-to-door paratransit service for the disabled, elderly, and transportation disadvantaged, and the 
Lake Region Commuter Route, an on-demand bus route that serves the western portions of the county. Palm Tran also operates feeder routes for the regional Tri-Rail transportation system.

The Palm Tran bus fleet includes 128 vehicles that travel along 37 fixed routes. Specifically, smaller buses (less than 40 feet) comprise two thirds of the Palm Tran fleet, while the remaining third are 40-foot vehicles. The agency utilizes buses from two different manufacturers.

In fiscal year (FY) 2006, Palm Tran completed over nine million passenger trips, which represents a 12 percent increase over 2005. As Palm Beach County continues to experience above-average population growth (exceeding 1.13 million total residents as of the 2000 U.S. census) and Palm Tran ridership continues to increase, the agency added routes, modified routes to improve connections, and acquired additional buses. For example, the agency contracted to procure 31 new buses in 2007.

\section{PSTA: Pinellas Suncoast Transit Authority}

The history of transit service in Pinellas County can be traced to the first streetcar line that ran in 1903; bus service operated by the St. Petersburg Municipal Transit System (SPMTS) began in 1926. In the modern era, the Central Pinellas Transit Authority, which began operation in 1973, partnered with SPMTS, and after voters approved a permanent merger, the organizations became PSTA in 1984. The agency has the distinction of serving the most densely populated county in Florida.

The board of directors consists of 15 appointees from throughout the service area, including three appointees each from the cities of Clearwater and St. Petersburg. PSTA operates over 200 vehicles across more than 40 routes, which serve 21 of 24 municipalities and unincorporated areas in the county. Routes are arranged as a hub-and-spoke system and center around three major hubs within the cities of St. Petersburg and Clearwater. The agency employs over 600 people and provides local and express bus service, as well as trolley routes, park-and-ride facilities, commuter lines, circulator routes, and demand-response service. Almost 12 million annual riders travel approximately nine million miles on PSTA.

\section{Review of Transit Agency Data and Practices}

This chapter introduced five Florida transit agencies selected to participate in this research effort. The following sections provide further details related to transit practices at each organization that may affect or be impacted by bus size decisions. The critical assessment factors addressed below were 
determined based on phase one findings and relevant prior studies as reported in Chapter II of this report. Specifically, CUTR documented information compiled from each agency regarding eligible fleet composition, interlining, procurement, warranty, projections for ridership growth, bus fleet guidelines and performance, service planning practices, automatic passenger counting methods, life-cycle cost data, and other relevant information, where necessary. Analyses performed on selected factors for input into the evaluation/decision support tool are described in greater detail in Chapter IV.

\section{Bus Fleet Compositions}

This section provides a brief overview of participating transit agencies' bus fleet compositions. As stated earlier, only data related to diesel-fueled, heavy-duty transit buses were considered for this study. As such, data from all other revenue vehicle types, including trolleys, hybrids, cut-aways, and compressed natural gas vehicles were excluded. Further, this section also explains any inconsistencies between fleet totals reported earlier in the agency overview sections and the numbers reported below.

The following fleet composition data were compiled directly from information provided to CUTR by participating transit agencies. Data from these vehicles formed the basis of the calibration dataset used to develop the bus decision support tool. Overall, the study utilized data from 865 buses, including 562 40-foot buses and 303 less-than-40-foot buses (see Table 3.1).

Table 3.1 Summary of Bus Fleet Composition by Agency

\begin{tabular}{|l|c|c|c|}
\hline Agency & Total Buses' $^{\prime}$ & $\mathbf{4 0}^{\prime}$ buses & <40' buses \\
\hline HART & 182 & 87 & 95 \\
\hline JTA & 163 & 138 & 25 \\
\hline LYNX & 188 & 172 & 16 \\
\hline Palm Tran & 147 & 61 & 86 \\
\hline PSTA & 185 & 104 & 81 \\
\hline Totals' & $\mathbf{8 6 5}$ & $\mathbf{5 6 2}$ & $\mathbf{3 0 3}$ \\
\hline
\end{tabular}

1 - Totals indicate buses eligible for the study not the total number of revenue vehicles in each fleet. 
Specifically, 163 buses comprised the eligible JTA fleet, including 13840 foot buses and 25 less-than-40-foot buses. For LYNX, 188 buses, including 172 40-foot buses and 16 less-than-40-foot buses, were part of the study. Palm Tran data consisted of 147 total buses (61 40-foot, 86 less-than-40foot) and the PSTA fleet included 104 40-foot buses and 81 less-than-40foot buses (185 total vehicles.) For HART, CUTR relied on data gathered during the phase one research effort, which represented 8740 -foot buses and 95 less-than-40-foot buses (182 total vehicles).

\section{Interlining}

Interlining is a scheduling method that assigns a transit vehicle to operate trips on more than one route. Specifically, a bus arrives at a common terminal location after completing a route, and then it proceeds to complete a second and different route. The practice seeks to afford greater convenience because passengers are allowed to travel longer distances without having to transfer to another bus. Dwell times and layovers at terminals are also reduced or eliminated. In some cases, the use of interlining is limited to specific time periods during the day. For example, a bus may operate only one route during peak hours, while interlining during off-peak periods.

The scope of work for the first phase of this project called for an investigation of interlining practices, including the relationship to assigned bus size. In response, CUTR gathered information about interlining from planners and route designers. Overall, four of the five Florida transit agencies that participated in the second phase of this project utilized interlining to varying degrees. The following section provides an overview of interlining at each agency.

Interlining is especially applicable to the transit hub system in effect at HART. The agency found that bus operator dwell times at transit hubs approached 30 minutes in some cases. As a result, HART adopted the practice of interlining to keep buses moving, thereby, improving efficiency. Although HART recognizes no official criteria for interlined routes, buses assigned to interlined routes must be able to accommodate the maximum passenger load across both routes. Because there are only eight route endpoints in the system, HART planners were able to assign interlined routes with a high degree of precision. Planners determine interlined routes based on scheduling factors, passenger transfer tendencies, and optimal conditions for reduced headway times. In addition, drivers help to identify likely route candidates for interlining. HART currently interlines a total of 15 routes. In 
most cases, two routes are interlined with each other; however, there are some instances where three or more routes are interlined.

According to HART planners, the agency has recently tended to make less use of interlining because roadway traffic has had a negative impact on driving time, making schedules more difficult to coordinate. However, interlining has improved efficiency related to driver dwell time. Drivers reportedly have positive feelings about the practice, and they appreciate the opportunity to participate in the planning process.

Among 44 JTA routes, 16 are interlined. Planners reportedly preferred the practice because JTA does not allow for transfers; full fare is required for each route segment. As such, the objective of interlining at JTA was to extend roundtrips to three hours, which would reduce the need for transfers and afford riders greater convenience and lower costs. JTA uses only one number/name to refer to interlined routes. Over time, planners found that neither operators nor supervisors preferred interlining because of the long one-way trip time and the limited, if any, layover time at the middle of routes. A recent on-board survey revealed that over 60 percent of customers felt interlined routes had a positive effect and allowed for greater convenience in reaching their final destination. While some customers liked the practice, others protested, claiming that route delays during one segment of the interlined route negatively impacted riders that only traveled on a different segment. In fact, JTA planners found that some pairings were not as efficient as originally intended. Interlined routes are examined up to three times each year, and they are revised as necessary. For example, interlined routes found to carry many more passengers on one segment than a subsequent segment may be split into two separate routes. JTA planners also reported that in the future, the utilization of interlining is likely to diminish.

LYNX and PSTA also engage in interlining to varying degrees, while Palm Tran does not interline any routes. With a minimal number of spare buses available, approximately 36 LYNX routes are interlined. The agency reported substantial efficiency gains as a result of the practice. PSTA also saves vehicles by interlining up to nine routes; the agency is less concerned about operator dwell times because it observes a clock/face schedule, which calls for routes to begin at selected quarter hour points. PSTA identified concerns associated with interlining, such as operating different sized buses across interlined routes and different characteristics among vehicles. 


\section{Procurement}

CUTR found that practices related to new vehicle acquisitions are generally similar among the participating transit agencies. Each organization routinely purchased buses through the state contract, and most actively pursued a policy of fleet standardization. Specifications and acquisition rationale are also comparable. Study participants mostly rely on operational concerns, rather than specific formulas, to determine the mix of small and large transit buses. In some cases, procurement decision challenges are common to each agency, while other issues are unique to specific properties.

Fourteen Florida transit agencies, including each participating agency in this project, are able to procure heavy-duty transit buses from the Gillig Corporation through the state contract, which expires in January 2009. Terms and conditions of the overall contract are generally established by the agencies. Although core requirements do not vary, contract participants may use a cafeteria menu from Gillig to select specific features and components for their bus purchase. The contract also helps transit groups approach fleet standardization, which is an attempt to limit the number of manufacturers represented in the vehicle inventory. Ideally, a fully standardized fleet would include buses from only one manufacturer.

Administratively, the size of buses slated for purchase is mostly determined by the buses they are intended to replace. Specifically, most new vehicles are the same size as the vehicles slated for retirement. Within each participating agency, planners and maintenance managers contribute to procurement decisions. Maintenance staff generally preferred standard 40foot buses, while schedulers like to have a variety of bus sizes at their disposal in order to maximize efficiency and to meet particular route needs. However, because acquisition costs for 40-foot and less-than-40-foot buses are usually similar, both groups generally defer to the larger models. Executive staff and other ranking officers may also provide critical input regarding the overall length of vehicles that are to be purchased. Special needs also influence the sizes and types of buses that transit agencies purchase. For example, JTA may acquire up to three articulated buses per year over the next three years, HART requires 40-foot vehicles on new express routes, and LYNX uses compressed natural gas buses for its downtown fixed guideway service.

The presence of physical barriers and constraints, as well as other unique route conditions that may limit turning radii and vehicle access, are among the strongest operational concerns that drive acquisition decisions related to small buses. In fact, some project participants cite these factors as the only 
reasons why smaller buses are acquired and included in their operating fleets. For example, although PSTA claimed to be mostly phasing them out, smaller buses are still required to traverse older bridges, access new developments, and accommodate other developed private properties. Heavy passenger loading on LYNX and Palm Tran routes also limits the use of smaller buses to areas with maneuverability and access concerns. JTA cited concerns about vehicle width, impacts on residential neighborhoods, and vehicle weight issues (especially as related to maintenance) as common reasons for including smaller buses in the fleet.

\section{Warranty}

Differences in service and maintenance characteristics between small and large buses have the potential to impact maintenance costs, and thus an analysis needed to be completed for this investigation. For example, warranty terms that are variable by bus type could be a major cause for cost differentiations. As such, CUTR documented relevant warranty-related experiences among participating agencies and differences, if any, between small and large bus warranties.

Overall, buses produced by the same manufacturer are covered by the same warranty, regardless of length. Specifically, the first year of vehicle operation is protected by bumper-to-bumper coverage. The structural integrity of the vehicle is covered for 12 years $/ 500,000$ miles. In general, warranty coverage for component parts varies by part and manufacturer, but similar parts receive the same coverage. For example, engine and transmission warranties cover five years $/ 300,000$ miles. Other examples include wheelchair lifts (one year $/ 50,000$ miles), drive axles (2 years/100,000 miles), and air conditioning units (3 years/unlimited miles).

In general, no major warranty-related issues or differences between small and large buses were reported by the study group, and agencies were typically satisfied with Gillig vehicles. Newer vehicles comprised large portions of participating agency fleets, so no major problems had been discovered at the time of this writing. Further, minimal differences were found among historical experiences. JTA officials claimed that vehicle weight had a limited impact on warranty component performance. However, most observed differences, such as longer brake life on smaller buses, were not warranty-related issues. According to PSTA, low floor buses generally experience tire wear sooner than standard floor models. The agency makes a conscious effort to rotate buses in order to maintain similar mileage accumulation across each model year fleet. 


\section{Growth Projections}

Transit agency decisions regarding the quantity and characteristics of revenue fleet vehicles are likely to be affected by projected growth, as well as prior experiences. As such, CUTR documented applicable historical patterns, recent trends, and anticipated expansions in ridership and services among the study participants.

According to HART planners, the agency served 8.1 million riders in FY2003. By 2007, ridership was expected to grow to approximately 11 million riders. Initial FY2007 counts indicated growth by three percent over the previous year. Planners anticipated a one percent increase for FY2008, and no increase for FY2009. It is important to note that these numbers are estimates, and they may vary as HART has experienced record ridership levels during recent years. However, past projections were found to be relatively consistent with actual outcomes.

After experiencing decreases in both passengers and passenger miles throughout most of the 1990s, JTA has seen these numbers increase during the current decade. Specifically, ridership reached a low in FY2001 before rebounding with a slight increase the following year and a major increase in FY2003. Passenger miles steadily increased since 1998 and reached an alltime high by FY2004. Overall, growth averaged eight percent over the past nine years, and despite a two and one-half percent drop during FY2007, planners project annual increases of approximately two percent over the coming years.

At LYNX, ridership has steadily increased over the past decade. For example, overall ridership increased by 3.1 percent in FY2004 and gained another 5.7 percent in FY2005. Based on this trend, the agency anticipates significant growth to continue for the foreseeable future. Although substantial additions to service have not been made in recent years, expected population growth and related vehicle needs are outlined in various planning documents. Specifically, the FY2008-2017 LYNX Transit Development Plan suggests that a total fleet of 418 vehicles (342 in maximum service) would be necessary to maintain pace with future averages. In addition, a long range transportation plan completed by METROPLAN ORLANDO calls for LYNX to amass a fleet of 571 vehicles (472 in maximum service) by 2020 .

Service enhancements and growing demand drive continuing ridership increases at Palm Tran. The agency utilized revenues from a local fuel tax levied in 1996 to double the number of routes and nearly triple the number of buses. By FY2000, Palm Tran provided approximately 6.5 million fixed- 
route passenger trips. The number of trips rose to 8.3 million in FY2005, and more than 10 million trips are anticipated for FY2007. Upward trends are expected to continue, with some estimates envisioning over 25 million passenger trips by 2016 . Increasing demand for services may only be tempered by budget limitations, which have recently caused some service expansion plans to be put on hold.

PSTA has also experienced notable ridership gains over the past ten years and expects growth to continue into the future. Average yearly increases were close to 4.5 percent during that span, and overall ridership for FY2005/2006 surpassed 11 million passenger trips. Major urban corridors generally exhibited the most dramatic upswings. On some routes, service enhancements led to ridership increases of up to 25 percent. Fleet and fare structure improvements are also credited with contributing to ridership growth.

\section{Fixed Routes and Service Planning Guidelines}

Each participating agency classified most bus routes as local, circulator, or express. Local routes provide frequent stops throughout the service area. Express routes involve a limited number of stops, travel at higher speeds, and usually carry commuting passengers over longer distances. Circulator routes are confined to specific areas and generally utilize smaller transit vehicles, such as vans or trackless trolleys. (Because of the variety of non-traditional transit vehicles used, circulator routes were not included in the analysis).

Each participating agency operated mostly local routes. HART operated the highest number of express routes (ten). JTA, LYNX, and PSTA included only a few express routes among their fixed-route systems. Officially, Palm Tran operated no express routes, however; one limited stop route was somewhat similar to an express route. It is important to note that the limited stop route is not an express route because it does not travel on interstate highways and it has more stops than a traditional express route. LYNX service to the Disney area was also notable because route designs were somewhat of a hybrid between local and express, but the agency classified these routes as local.

Within this research project, the discussion of service planning guidelines includes the following topics: the number and types of fixed routes operated by heavy-duty buses, physical seating capacity by bus type, formal and/or informal standards for acceptable passenger capacity by bus and route type, methods used to accommodate excessive passenger loads, seasonal or other causes for passenger load fluctuations, relevant customer feedback, and other factors that may impact service delivery. CUTR demonstrated the 
importance of these factors during phase one, as well as in Chapter II of this report. As such, researchers queried phase two participants about relevant practices and reported the results below.

Overall, none of the project participants had implemented official service planning rules. During phase one, HART reported that a formal document was under development, and although no official rules were in place, the agency did observe specific capacity guidelines according to route type and bus size. In fact, the policies followed by HART were likely the most defined among any group in the study group.

As reported in phase one, HART observed a separate tolerance for both local and express routes. Specifically, the agency allowed passenger loads on local routes to reach 125 percent of the bus seating capacity, while express routes were limited to 100 percent. Based on this formula, HART local routes were allowed to reach a maximum load of 44 passengers on a 40-foot bus with 35 seats and 29 passengers on a less-than-40-foot bus with 23 seats. Express routes maintained passenger load limits according to the total number of seats on the bus. PSTA reported no formal loading standards, and the agency generally followed the original equipment manufacturer (OEM) specifications for capacity. For example, new buses have 40 seats and additional capacity for 40 standees. JTA relied on similar OEM guidelines for loading restrictions. The agency would tolerate standees on express routes; however, this was not a regular occurrence, if at all. LYNX and JTA would also observe a 100 percent seating capacity limit on express routes, but regular loading did not normally approach this level. Palm Tran had no formal load factors in place.

Instances of excessive passenger loads were addressed according to the frequency of occurrence along each route. In general, agencies made an effort to assign the appropriate size bus to handle the anticipated passenger load. For example, HART assigned large buses to routes that exceeded the tolerable capacity limit of small buses. In cases where a larger bus is already assigned to the route, another bus, commonly referred to as a plug bus, is placed into service to handle the extra passengers. Plug buses are dispatched based on availability rather than size. PSTA and LYNX also deployed plug buses, when necessary, in cases of riders standing for longer than 15 minutes or to avoid leaving passengers behind. The plug bus immediately follows the primary bus along the route. Both Palm Tran and JTA reported use of plug buses to be rare.

For routes that routinely exceed acceptable capacity levels, agencies usually engaged further action. In such cases, participants reviewed passenger 
counts and assigned route surveyors to observe passenger counts. For example, HART engaged such remedial steps even in cases where the tolerable capacity limit was exceeded just once during service hours. However, agencies generally agreed that the use of a plug bus is usually the least costly short term option. In cases of repeated high loads, long-term solutions, including the possibility of adding a bus or reducing headways, are investigated. Problem routes are also addressed three or more times per year during the mark-up or bid process, which reassigns routes, implements new service and eliminates other service, as necessary.

\section{Automatic Passenger Counting}

Automatic passenger counter (APC) devices have gained wide acceptance among transit agencies over the past two decades. APC technology has proved to be a reliable and accurate method to collect and analyze transit ridership data, and as such, APC data are highly sought after for research purposes. Although specific techniques and equipment vary, each system records the number of people boarding and alighting at each stop, creates a time point for each count, and maintains an ongoing tally of riders. As vehicles return from service, APC data are transmitted wireless or manually downloaded to a central computing system, validated, and then, used by agency planners, schedulers, and other staff, as necessary. The accompanying software is capable of generating a variety of reports, depending on the needs of the agency.

Within this project, four of the five participating transit agencies employed APCs to varying degrees. Specifically, JTA had approximately 70 APCs deployed among its bus fleet, while LYNX had 31 APCs and PSTA, which had only recently acquired the technology (March 2007) had 25 APCs in place. $A P C s$ in use among these three agencies were permanently installed into vehicles, which were rotated throughout all routes in the system. On the other hand, the ten APCs utilized at HART were temporarily installed and rotated among each bus in the fleet. At the time of this writing, Palm Tran had yet to implement APCs.

For phase one of this project, HART used APC data and software to generate a Stop Summary Report for each route. CUTR retained this dataset for phase two and asked each APC-equipped participant to generate similar reports based on their own APC observations. The Stop Summary Report is especially applicable to this study because it provides an average passenger count at each stop made over the course of the entire service day. Further, reports commonly include several observations for each stop and time point, depending on the overall time span of the report. This factor serves to 
increase the strength of the stop summary dataset. A discussion of the APC data analysis is found in Chapter IV of this report.

\section{Bus Fleet Performance and Life-Cycle Cost Data}

As a critical component of phase one, CUTR completed an in-depth life-cycle cost analysis of the HART fixed-route heavy duty bus fleet. These factors were also a fundamental element of the evaluation/decision support tool developed under the phase two effort. For purposes of this study, life-cycle cost and fleet performance data needs include life-to-date ${ }^{2}$ fixed and variable costs, annual mileage, fuel efficiency, and fuel costs. Fixed costs involved vehicle acquisition costs, while variable costs included maintenance costs such as labor, parts, and outside repairs.

CUTR gathered life-cycle cost data for each participating agency fleet, sorted the information, and discarded ineligible vehicles (trolleys, hybrids, and other non-heavy-duty diesel buses). In total, data from 865 buses, including 303 small buses and 562 large buses were compiled. To prepare the dataset for calibration of the evaluation tool, researchers engaged a multi-step process. First, the average annual mileage for each vehicle was calculated. Next, per-mile variable costs for labor and parts were calculated. Outside costs, in-house rebuild costs, and other miscellaneous costs that were reported by only selected participants were discarded in order to preserve continuity. Fuel efficiency, reported as average miles-pergallon, was also documented. Specific results of this analysis and further description of the evaluation/decision support tool calibration task are described in the next chapter.

\section{Other Factors}

At this point, a brief discussion of other potential assessment factors, especially those not applicable to the study at hand, is warranted. For example, prior studies described bus operator salaries as a key determinant of transit agency interest in small buses. Specifically, some organizations paid operators different salaries, according to the size of the vehicle driven. However, this factor was not relevant to this investigation because each participating Florida transit agency maintained salary parity among all drivers, regardless of vehicle size operated.

Another assessment factor revealed during the literature review involved customer opinion of smaller buses. In some cases, transit customers reportedly

2 Life-to-date (LTD) refers to the time elapsed from the time that the bus was purchased and placed into service to the date the inventory was prepared. For this study, inventories were prepared between September-October 2007. 
maintained low opinions of the vehicles. However, no significant indications of customer resistance to smaller buses were documented. At most, anecdotal evidence was mentioned briefly.

\section{Summary}

The intent of this chapter was two-fold: to explain the process of selecting Florida transit agencies for the study and to describe those agencies ultimately included in the project. Specifically, CUTR developed a methodology to select appropriate Florida transit groups to participate in the bus evaluation/decision support tool development project. Once the participants were in place, researchers documented existing conditions and practices at each organization, paying particular attention to critical assessment factors revealed during the review of prior studies (including the phase one effort of this study). Among the most important variables were bus fleet composition, service planning methods, passenger counts and loading criteria, vehicle performance and maintenance cost data, anticipated agency and area growth patterns, and specific agency policies regarding warranty, interlining, and route design. The findings described in this chapter formed the foundation for input and calibration of the evaluation/decision support tool, which is presented in Chapter IV. 


\section{BUS SIZE EVALUATION TOOL}

\section{Introduction}

The following chapter chronicles the development of the bus evaluation/decision support tool that was the intended outcome of this research effort. First, the conceptual framework and modeling technique that underlie the tool are introduced. Next, the evaluation criteria that drive the tool are described. Vital service and cost factors, which were established earlier in this report and based largely on the phase one results, are brought forward and presented in terms of the tool under development. Later, the bus evaluation/decision support method is designed, and step-by-step input requirements are described. Lastly, potential user modifications to tool are illustrated.

\section{Purpose}

The overall intent of this research project was to utilize the outcome of the HART fixed-route fleet analysis study (phase one) along with lessons learned from previous studies and the outputs of earlier stages of this effort (phase two) to develop an analysis tool to assist in bus size decisions regarding procurement and deployment. At a minimum, CUTR intended that the tool consist of a life-cycle cost calculator and a matrix with weighted factors that would be used by transit agencies to aid in the choice of the appropriate vehicle. Using the Microsoft Excel platform, researchers sought a userfriendly tool designed to facilitate the input of data and updates. Ideally, the resulting computer model will yield a distinct fleet composition output; however, it is important to note that the outcome of this project is not intended to be a fleet optimization tool.

\section{Proposed Model}

In order to achieve the stated purpose of this research project, CUTR proposed a straightforward approach to developing the evaluation/decision support model. The evaluation structure followed a basic design that would assure consistent measurement and comparison of relevant factors and inputs. 
The approach was largely based on a framework proven to be an effective method of predictive analysis. ${ }^{3}$ Specifically, the tool would be calibrated using a dataset large enough to provide significant default values for each variable. The model would also be fully customizable, allowing the user to override some or all of the default values. However, a fail-safe system is intended to protect users from inadvertent or otherwise unwanted changes to the default values. Afterwards, the user is guided through a series of inputs, and the model performs a series of calculations to yield recommended fleet compositions.

In order to build the model described above, researchers followed a careful plan of action. First, the modeling technique was established, and evaluation criteria were determined. Critical assessment factors, which would be used to calibrate the model and serve as default values, were identified and calculated, as necessary. With the vital analytical elements in place, the model design was fine-tuned to include all necessary and relevant components. At this point, the evaluation tool was created using the appropriate modeling software. From there, researchers developed stepby-step instructions for using and customizing the tool and performed sample calculations. The remaining sections of this chapter recant the model development process in detail.

\section{Modeling Technique}

As stated above, the intended outcome of this research effort was a userfriendly evaluation/decision support tool. The objective was to create a model that would produce robust results, yet allow for even novice-level computer operators to generate useful outputs. As such, the model was designed to guide users through a step-by-step process, prompting the entry of readily-available transit data. In addition to agency-specific information, the model would account for constraints as defined by the user. For example, minimum fleet composition requirements would be entered, and answers to qualifying questions would influence vehicle allocation results. The tool would also take into consideration passenger loading factors and vehicle capacity limits.

The following sections establish the evaluation criteria and describe the critical assessment factors used to evaluate bus fleets and assist with decisions regarding vehicle size procurement and deployment.

3 TRIMMS - Trip Reduction Impacts for Mobility Management Strategies, CUTR, March 2007. 


\section{Evaluation Criteria}

With the basic modeling framework in place, the next step in the evaluation tool development process was to establish critical inputs. Overall, cost concerns and service issues would likely be the overriding motivations for transit agencies to utilize the finished product of this research effort. As such, the evaluation criteria were categorized as life-cycle cost factors (including maintenance and performance data) and service factors (including passenger loading and acceptable vehicle capacities). Other qualitative factors were also considered and included, where feasible.

The following sections describe the sources of data and explain the relevance to the evaluation/decision support tool development. Specifically, researchers examined data gathered from participating agencies, associated current inputs with phase one results, and described preliminary calculations required to complete the model development process. For example, researchers had to calculate life-cycle costs, including costs per mile, before data could be used to calibrate the model and serve as default values.

\section{Composite Fleet Overview}

To establish critical assessment factors required for the evaluation/decision support tool, CUTR formed a composite heavy-duty transit bus dataset that consisted of HART data from phase one and all other data received from phase two participants. In total, the composite fleet comprised 865 heavyduty buses, including 562 large buses and 303 small buses, from five Florida transit agencies. Selected comparative analyses were completed for the composite fleet. For example, although five manufacturers were represented, the overwhelming majority of vehicles within the composite fleet were produced by the Gillig Corporation (see Table 4.1).

Table 4.2 showed that vehicles within the composite fleet ranged in age from less than one year to over 12 years. The distribution by bus model year was fairly even, with the exception being that one third of small buses were 10 years old. Overall, the comparisons illustrated that the sample fleet would provide a strong calibration element for the evaluation tool. 
Table 4.1. Composite Bus Fleet by Manufacturer

\begin{tabular}{|c|r|r|r|r|r|r|}
\hline \multirow{2}{*}{ Manufacturer } & \multicolumn{2}{|c|}{ Large Buses } & \multicolumn{2}{c|}{ Small Buses } & \multicolumn{2}{c|}{ Total Buses } \\
\cline { 2 - 7 } & Count & Percent & Count & Percent & Count & Percent \\
\hline Gillig & 465 & $82.7 \%$ & 258 & $85.1 \%$ & 723 & $83.6 \%$ \\
\hline Nova & 55 & $9.8 \%$ & - & - & 55 & $6.4 \%$ \\
\hline Flxible & 25 & $4.4 \%$ & - & - & 25 & $2.9 \%$ \\
\hline New Flyer & 15 & $2.7 \%$ & 45 & $14.9 \%$ & 60 & $6.9 \%$ \\
\hline Orion & 2 & $0.4 \%$ & - & - & 2 & $0.2 \%$ \\
\hline Totals & 562 & $100 \%$ & 303 & $100 \%$ & 865 & $100 \%$ \\
\hline \hline
\end{tabular}

1 - Totals indicate buses eligible for the study not the total number of revenue vehicles across all study participant fleets.

Table 4.2. Composite Bus Fleet by Year

\begin{tabular}{|c|c|c|c|c|c|c|}
\hline \multirow[b]{2}{*}{ Bus Model Year } & \multicolumn{2}{|c|}{ Large Buses } & \multicolumn{2}{|c|}{ Small Buses } & \multicolumn{2}{|c|}{ Total Buses ${ }^{1}$} \\
\hline & Count & Percent & Count & Percent & Count & Percent \\
\hline 1993 & 5 & $0.9 \%$ & - & - & 5 & $0.6 \%$ \\
\hline 1995 & 20 & $3.6 \%$ & - & - & 20 & $2.3 \%$ \\
\hline 1996 & 45 & $8.0 \%$ & 10 & $3.3 \%$ & 55 & $6.4 \%$ \\
\hline 1997 & 48 & $8.5 \%$ & 101 & $33.3 \%$ & 149 & $17.2 \%$ \\
\hline 1998 & 28 & $5.0 \%$ & - & - & 28 & $3.2 \%$ \\
\hline 1999 & 48 & $8.5 \%$ & 22 & $7.3 \%$ & 70 & $8.1 \%$ \\
\hline 2000 & 16 & $2.8 \%$ & 31 & $10.2 \%$ & 47 & $5.4 \%$ \\
\hline 2001 & 77 & $13.7 \%$ & 29 & $9.6 \%$ & 106 & $12.3 \%$ \\
\hline 2002 & 37 & $6.6 \%$ & 30 & $9.9 \%$ & 67 & $7.7 \%$ \\
\hline 2003 & 13 & $2.3 \%$ & 18 & $5.9 \%$ & 31 & $3.6 \%$ \\
\hline 2004 & 84 & $14.9 \%$ & 25 & $8.3 \%$ & 109 & $12.6 \%$ \\
\hline 2005 & 39 & $6.9 \%$ & 18 & $5.9 \%$ & 57 & $6.6 \%$ \\
\hline 2006 & 68 & $12.1 \%$ & 12 & $4.0 \%$ & 80 & $9.2 \%$ \\
\hline 2007 & 34 & $6.0 \%$ & 7 & $2.3 \%$ & 41 & $4.7 \%$ \\
\hline Totals' & 562 & $100 \%$ & 303 & $100 \%$ & 865 & $100 \%$ \\
\hline
\end{tabular}

1 - Totals indicate buses eligible for the study not the total number of revenue vehicles across all study participant fleets. 


\section{Life-Cycle Cost Factors}

Chapter II of this report referenced prior studies, including the phase one report that focused on HART bus fleet scenarios, to illustrate life-cycle cost variables essential to the vehicle decision-making process. Such factors are critical to bus procurement and deployment choices. In Chapter III, researchers expanded the study group to include four additional Florida transit agencies and gathered life-cycle cost data from each new project participant. The next step in the process was to link previous results with current data to provide a benchmark within the evaluation/decision support tool framework. To accomplish this, preliminary analyses of composite bus fleet life-cycle cost were necessary.

For a more complete, historical perspective, researchers summoned methods developed during the phase one effort to calculate life-to-date (LTD) average annual figures for the combined heavy-duty, diesel-powered bus fleets of the five participating agencies. LTD is a descriptive period of time that starts when a bus is acquired and placed into service, and it continues until the time that data are programmed into the analysis. Specifically, the following variables related to usage intensity levels, variable costs, and fixed costs were considered for small and large buses:

- Average annual miles

- Variable costs:

- Per mile labor costs

- Per mile parts costs

- Per mile outside repair costs (if reported)

- Per mile fuel cost

- Fixed costs:

- Bus acquisition cost

Before moving forward, it is important to recall the following assumptions relevant to the life-cycle cost analysis:

- A small bus is assumed to be any heavy-duty, diesel-powered bus less than forty feet in length;

- A large bus is assumed to be any heavy-duty, diesel-powered bus that is forty or more feet in length;

- The midpoint of life (or mid-life) of buses in the analysis is 6 years, and the complete service life of buses is 12 years;

- Any route can be served by a small bus at any given time; and,

- Operating costs (driver pay, training expenses, etc.) are the same for small and large buses. 
The following sections describe each input variable, illustrate necessary calculations, and present preliminary findings, where applicable.

Average annual miles - A basic component of the life-cycle cost analysis is fleet use intensity. Fleet use intensity is defined as LTD average annual miles driven, which were calculated using the following formula:

LTD Average Annual Miles $=$ Total Miles Driven LTD $/ \#$ of Years LTD

First, CUTR calculated the LTD average annual miles for each vehicle in the composite fleet. This metric was a necessary first step in order to determine subsequent assessment factors, such as per mile labor and parts costs. Next, researchers determined the overall average annual mileage among all small buses and all large buses.

As a result of this analysis, the following values were chosen as default LTD average annual mileage values for use in the evaluation/decision support tool:

- LTD average annual miles for large buses: 49,966

- LTD average annual miles for small buses: 49,434

Per mile labor costs - Maintenance labor costs are considered variable costs. The LTD average annual per mile labor costs were calculated using the following formula:

LTD Average Annual Per Mile Labor Cost $=$ Average Annual LTD Labor Cost/ LTD Average Annual Miles

Researchers calculated the average annual per mile labor cost for each vehicle in the composite fleet and then determined overall averages specific to the groups of small and large buses. As a result of the analysis, the following values were identified as the default LTD average annual per mile labor costs for the evaluation/decision support tool:

- LTD average annual per mile labor cost for large buses: \$0.52

- LTD average annual per mile labor cost for small buses: $\$ 0.42$

Per mile parts cost - Parts are another variable maintenance cost critical to the evaluation/decision support tool. The LTD average annual per mile parts costs were calculated using the following formula: 
LTD Average Annual Per Mile Parts Cost $=$ Average Annual LTD Parts Cost/ LTD Average Annual Miles

Researchers calculated the average annual per mile parts cost for each vehicle in the composite fleet, and then determined overall averages specific to small and large buses. As a result of the analysis, the following values were identified as the default LTD average annual per mile parts costs for the evaluation/decision support tool:

- LTD average annual per mile parts cost for large buses: $\$ 0.73$

- LTD average annual per mile parts cost for small buses: $\$ 0.84$

Per mile outside repair costs - Outside repairs generally refer to any repairs performed by a third party, rather than by in-house maintenance staff. Despite the number of participants and the number of vehicles in the study, only one agency included outside repair costs as a key component of its maintenance data. As a result, CUTR excluded outside repair costs from among the critical assessment factors used in the decision support tool. However, the tool was designed to be flexible and to support user modifications. As such, potential users could add outside repair costs back into the model, when necessary. Modification techniques are included later in this report.

Per mile fuel costs - The final variable cost required for the evaluation/decision support tool model is average per mile fuel costs. The LTD average per-mile fuel costs are calculated using the following formula:

\section{Average Per Mile Fuel Cost $=$ Average Fuel Price ( $\$ /$ gallon) $/$ Fuel Efficiency (miles/gallon)}

To calculate the average annual per mile fuel costs, the following definitions/assumptions are necessary:

- Average Fuel Price $=$ average diesel fuel price for Florida

- Fuel Efficiency = LTD Annual Average Miles/LTD Annual Average Fuel Consumption

The formula shows that, ideally, the average per mile fuel cost should account for both fuel efficiency and fleet usage intensity. Trends reported in phase one indicated that fuel efficiency generally declines as vehicles age (older vehicles consume more fuel, on average, per mile). CUTR examined the composite bus fleet database for direct fuel costs and measures of fuel 
efficiency. In many cases, participating transit agencies did not report historical fuel consumption data. Fuel economy performance also varied across reporting periods. For example, some vehicle records included a year to date miles per gallon average, while others were reported for shorter or longer time periods. However, because each vehicle did have a miles per gallon average associated with it, CUTR decided that the sample size was large enough to overcome slight reporting differences.

It is reasonable to assume that the average fuel efficiency of a single bus within a specific model year is very similar to the average fuel efficiency for the entire group of vehicles within the model year. This assumption is strengthened when the group of buses was produced by the same manufacturer, and they were of the same or similar model type and were acquired under the same requisition order. Further, the initial data review showed that miles per gallon figures were generally consistent with past experiences (for example, phase one findings indicated that smaller buses outperformed larger buses by about 1.0 miles per gallon or less). As such, researchers calculated the average annual miles per gallon across the small and large bus fleets.

As a result of the analysis, the following values were identified as the default LTD average annual miles per gallon for the evaluation/decision support tool:

- LTD average annual miles per gallon for large buses: 3.8

- LTD average annual miles per gallon for small buses: 4.3

Average Florida fuel costs were determined to be $\$ 3.45$ per gallon at the time of this writing. As such, the final results of the fuel efficiency analysis were as follows:

- LTD average annual per mile fuel costs for large buses: \$0.91

- LTD average annual per mile fuel costs for small buses: $\$ 0.80$

Bus Acquisition Costs - The purchase price of transit vehicles is considered a fixed cost. The average acquisition costs of large and small buses in the composite fleet are reported in Table 4.3. Assuming the costs were reported in actual dollars, the cost figures were adjusted to current 2007 dollars. ${ }^{4}$

\footnotetext{
${ }^{4}$ Throughout the analysis, acquisition costs are reported in actual 2007 dollars. Whenever necessary, dollar figures were transformed into 2007 dollars using the Consumer Price Index inflation calculator as designed by the Bureau of Labor Statistics (http://data.bls.gov/cgibin/cpicalc.pl)
} 
Researchers calculated the average acquisition cost for each model year fleet by vehicle size. Each average was normalized to 2007 dollars, and the average total model year cost by fleet was calculated. Lastly, the total costs for all vehicles were calculated by vehicle size, and the average costs per vehicle by vehicle size fleet were calculated.

As a result of the analysis, the following values where identified as the default average bus acquisition costs for the evaluation/decision support tool:

- Average Bus Acquisition Cost - Large Buses: \$317,586

- Average Bus Acquisition Cost - Small Buses: \$297,506

Table 4.3. Composite Bus Fleet Average Acquisition Costs by Model Year

\begin{tabular}{|c|c|c|c|c|c|c|}
\hline & \multicolumn{3}{|c|}{ Large Buses } & \multicolumn{3}{c|}{ Small Buses } \\
\cline { 2 - 7 } $\begin{array}{c}\text { Bus Model } \\
\text { Year }\end{array}$ & Count & $\begin{array}{c}\text { Average } \\
\text { Unit Cost (at } \\
\text { procurement) }\end{array}$ & $\begin{array}{c}\text { Average } \\
\text { Unit Cost } \\
(2007 \text { dollars) }\end{array}$ & Count & $\begin{array}{c}\text { Average } \\
\text { Unit Cost (at } \\
\text { procurement) }\end{array}$ & $\begin{array}{c}\text { Average } \\
\text { Unit Cost } \\
(2007 \text { dollars) }\end{array}$ \\
\hline 1996 & 45 & $\$ 241,165$ & $\$ 321,148$ & 10 & $\$ 221,230$ & $\$ 294,601$ \\
\hline 1997 & 48 & $\$ 248,901$ & $\$ 324,015$ & 101 & $\$ 231,943$ & $\$ 301,939$ \\
\hline 1998 & 28 & $\$ 266,863$ & $\$ 342,069$ & 0 & - & - \\
\hline 1999 & 48 & $\$ 253,220$ & $\$ 317,568$ & 22 & $\$ 251,955$ & $\$ 315,981$ \\
\hline 2000 & 16 & $\$ 252,243$ & $\$ 306,055$ & 31 & $\$ 250,930$ & $\$ 304,462$ \\
\hline 2001 & 77 & $\$ 268,022$ & $\$ 316,202$ & 29 & $\$ 247,592$ & $\$ 292,100$ \\
\hline 2002 & 37 & $\$ 278,481$ & $\$ 323,428$ & 30 & $\$ 261,522$ & $\$ 303,732$ \\
\hline 2003 & 13 & $\$ 258,319$ & $\$ 293,327$ & 18 & $\$ 248,651$ & $\$ 282,349$ \\
\hline 2004 & 84 & $\$ 289,316$ & $\$ 320,003$ & 25 & $\$ 255,779$ & $\$ 282,909$ \\
\hline 2005 & 39 & $\$ 296,087$ & $\$ 316,760$ & 18 & $\$ 258,698$ & $\$ 276,761$ \\
\hline 2006 & 68 & $\$ 302,081$ & $\$ 313,073$ & 12 & $\$ 276,422$ & $\$ 286,481$ \\
\hline 2007 & 34 & $\$ 299,145$ & $\$ 299,145$ & 7 & $\$ 294,806$ & $\$ 294,806$ \\
\hline \hline $\begin{array}{c}\text { Totals } / \\
\text { Averages }\end{array}$ & $\mathbf{5 3 7}$ & - & $\$ 317,586$ & 303 & & - \\
\hline
\end{tabular}

\section{Service Factors}

The preceding section demonstrated essential cost considerations that influence bus procurement and deployment choices. In the following section, the focus shifts to a second and no-less-important area of concern regarding transit fleet decisions. While the life-cycle costs described earlier are fundamental economic concerns, transit agencies also depend on a satisfied customer base, and they strive to maintain a high demand for service. As 
such, service-related variables also play a vital role in vehicle assessment and selection decisions.

As described in Chapter III, four additional Florida transit agencies were brought into the project for phase two. CUTR collected service data from each new participant, including route data and automatic passenger counts. ${ }^{5}$ Using similar analysis methods completed in phase one, researchers examined critical passenger loading factors to determine a service factor benchmark within the evaluation/decision support tool framework. Relevant passenger loading calculations are described below.

The objective of the passenger load analysis in phase one was to determine the optimal number of large buses and small buses under existing and hypothetical route assignment characteristics. Specifically, CUTR assembled a series of operating scenarios and simulated passenger loading under the sample conditions. Researchers applied HART loading standards, including those based on the actual number of seats (PLF) and those based on the tolerable percent rider capacity by bus and route type (TOL.) CUTR found that the tolerable load factor, or TOL, was vital to the analysis because it was based on agency policy and the actual number of passengers rather than on a physical constraint (the number of seats.) For phase two, CUTR originally intended to combine passenger count data from the composite fleet, determine acceptable loading capacities for the composite fleet, and arrive at default values for PLF and TOL. However, as reported in Chapter III, HART was the only participating agency to maintain a tolerable load policy. As a result, CUTR examined PLF as a critical assessment factor for the composite fleet, while TOL was limited to an optional, qualitative factor. ${ }^{6}$

Based on the number of seats, the passenger load factor (PLF) is an indication of the vehicle occupancy percentage at each observation point along a bus route. The APC system automatically calculates the PLF within the route observation dataset using the following formula:

\section{PLF $=($ Average Passenger Load/Actual Number of Seats on the Bus $) * 100$}

\footnotetext{
5 At the time of this project, Palm Tran had not implemented APCs, so no APC data were received from the agency. In order to maintain continuity, CUTR excluded Palm Tran manual passenger count data from consideration.

6 For the evaluation/decision support tool, CUTR maintained the HART standards as default values for tolerable loading. Specifically, the acceptable number of passengers carried on local routes is equal to $125 \%$ times the number seats on the bus, while the acceptable number of passengers carried on express routes is equal to $100 \%$ times the number of seats on the bus.
} 
In this case, the average passenger load is equal to the total number of passengers observed onboard the bus at a given observation point divided by the number of observations at that point. Within the composite bus fleet, almost 440,000 APC observations were recorded along 162 routes (see Table 4.4). Close to 80 percent of counts were recorded on large buses, which ran approximately 72 percent of the routes in the dataset. The analysis illustrated that less than one percent of the observations exceeded a passenger load factor of one. Of those that did, just about 98 percent of excessive loading instances were recorded on large buses.

Table 4.4. Composite Bus Fleet APC Data Summary

\begin{tabular}{|l|c|c|c|c|}
\hline Bus Type & Routes & $\begin{array}{c}\text { Total } \\
\text { Observations }\end{array}$ & $\begin{array}{c}\text { Total Instances of } \\
\text { PLF }>/=100 \%\end{array}$ & $\begin{array}{c}\text { Percent of Observations } \\
\text { PLF }>/=100 \%\end{array}$ \\
\hline Large & 116 & 345,206 & 3,884 & $1.13 \%$ \\
\hline Small & 46 & 94,220 & 90 & $0.10 \%$ \\
\hline \hline Totals & 162 & 439,426 & 3,974 & $0.90 \%$ \\
\hline
\end{tabular}

To arrive at default values for the evaluation/decision support tool under development, CUTR reviewed seating capacity statistics for each bus in the eligible composite fleet and calculated the average number of seats for large buses and small buses. As a result of the analysis, the following values were identified as the default average seating capacities for the evaluation/decision support tool:

- Average number of seats - Large Buses: 40

- Average number of seats - Small Buses: 29

\section{Other Factors}

By this point, critical assessment factors related to life-cycle costs and service variables had been established. Prior studies, as well as the review of participating transit agencies completed earlier in this study, revealed that additional non-financial, or qualitative, factors may also influence bus acquisition and/or deployment decisions. Earlier research indicated that such factors are difficult to measure, so they are commonly excluded from modeling analysis. However, this research effort would be remiss to ignore these factors completely.

Initially, researchers considered a broad scope of other factors. Areas of concern included: specialized needs of specific transit service areas, intended type of service for new vehicles, declining passenger capacity among newer 
bus models, maneuverability, obstacles, and other size restriction concerns, vehicle width and weight, interlining and other scheduling practices, customer acceptance and feedback, rising manufacturing costs, and growing interest in alternative fuel vehicles. CUTR drew on the knowledge and expertise of the project advisory group to refine and categorize the set of other variables. In the end, four general areas of interest incorporated nine qualitative factors into the evaluation/decision support tool. The final categories and topics were as follows:

- Vehicle acquisition

- Overall agency vehicle priority

- Vehicle most likely to meet agency-specific operating needs

- Vehicle most adaptable to new technologies

- Ridership

- Prevalence of routes with excessive passenger loading

- Anticipated service demand changes

- Special concerns

- Vehicle maneuverability limitations

- Accommodation of recurring special events

- Feedback

- Public opinion

- Driver opinions

While each category listed above was found to be relevant, project advisors stressed that some factors were more significant than others in terms of vehicle acquisition and deployment choices. As such, the group weighted each qualitative category, and CUTR installed the results into the evaluation/decision support tool as default values. Specific factor weighting results are discussed in greater detail later in this chapter. 


\section{EVALUATION/DECISION SUPPORT TOOL IMPLEMENTATION}

\section{Evaluation Method}

The following section presents the analytical framework underlying the sketch planning tool application. The following acronyms are used:

$$
\begin{aligned}
\text { TF } & =\text { Total Fleet } \\
\text { TFC } & =\text { Total Fleet Capacity } \\
\text { TOL } & =\text { Passenger tolerance } \\
\text { SB } & =\text { Small Bus } \\
\text { LB } & =\text { Large Bus } \\
\text { BASE } & =\text { Base Case } \\
\text { CONST } & =\text { Constrained } \\
\text { UNCONST } & =\text { Unconstrained }
\end{aligned}
$$

The model developed under this research effort functions according to the following progression:

1. The user provides information regarding the current and programmed bus requisition schedule. The total number of current and projected small and large buses is determined using the following calculation:

$$
T F_{B A S E}=S B_{B A S E}+L B_{B A S E}
$$

2. Through the qualitative analysis, the user is asked to specify the minimum required number of small and large buses. ${ }^{7}$ The fixed quantity of buses represents a constraint. At this stage, the model splits the projected bus schedule into:

a. Constrained Share - This is equal to the minimum required number of small and large buses.

b. Unconstrained Share - This is the remainder of small and large buses that are to be allocated by the tool.

The result provides an initial new fleet requisition schedule that is equal to:

$$
T F_{\text {NEW }}=S B_{\text {CONST }}+S B_{\text {UNCONST }}+L B_{\text {CONST }}+L B_{\text {UNCONST }}
$$

\footnotetext{
7 For example, agency policy may dictate that only large buses run a certain type of route, or maneuverability constraints limit some routes to small buses only.
} 
3. Through a series of qualifying questions, the unconstrained share is allocated either to small or large buses.

4. Next, the model computes the required number of either small or large buses that maintains the original total bus fleet capacity. This is done by using the passenger tolerance method, as described in Step 5.

5. The final requisition schedule is estimated, which provides the simulated number of small and large buses:

$$
T F_{S I M}=S B_{\text {CONST }}+S B_{S I M}+L B_{\text {CONST }}+L B_{\text {SIM }}
$$

Passenger tolerance analysis - As described above, once Step 3 has been defined, the following formula is applied to compute the unallocated share of small or large buses:

Compute the current total bus fleet capacity, adjusted by the passenger tolerance factor:

$$
T F C_{B A S E}=\underbrace{\left(\frac{S B_{A P C}}{S B_{S C}}\right)}_{S B_{P L F}} S B_{T O L}^{B A S E}+\underbrace{\left(\frac{L B_{A P C}}{L B_{S C}}\right)}_{L B_{P L F}} L B_{T O L}^{B A S E}
$$

Compute the simulated total bus fleet capacity:

$$
T F C_{S I M}=\underbrace{\left(\frac{S B_{A P C}}{S B_{S C}}\right)}_{S B_{P L F}} S B_{T O L}^{S I M}+\underbrace{\left(\frac{L B_{A P C}}{L B_{S C}}\right)}_{L B_{P L F}} L B_{T O L}^{S I M}
$$

where:

$S B_{A P C}=$ Small bus average passenger count across all routes

$L B_{A P C}=$ Large bus average passenger count across all routes

$S B_{S C}=$ Small bus seating capacity

$L B_{S C}=$ Large bus seating capacity

$S B_{T O L}=$ Small bus passenger tolerance

$L B_{T O L}=$ Large bus passenger tolerance

$S B_{P L F}=$ Small bus passenger load factor

$L B_{P L F}=$ Large bus passenger load factor

Note that the passenger tolerance is equal to a multiplier of the PLF. For example, if the $\mathrm{PLF}=100 \%$ and the $\mathrm{TOL}=1.25$, then the adjusted $\mathrm{PLF}=125 \%$. 
Once the qualitative factor analysis of Step 3 assigns the unallocated share to either small or large buses, then the model automatically computes equations ( 1 ) and (2) and measures the difference between (2) and (1). This difference, divided by the average bus seating, gives the simulated number of marginal small or large buses required to maintain current total fleet capacity levels

$$
\Delta B U S_{i}=\frac{\left(T F C_{S I M}-T F C_{B A S E}\right)}{S C}
$$

where:

$\Delta B U S_{i}=$ incremental number of either small or large bus required to maintain current total fleet capacity.

The evaluation modeling process is further illustrated by Figure 4.1. 
Figure 4.1. Evaluation Model Flowchart

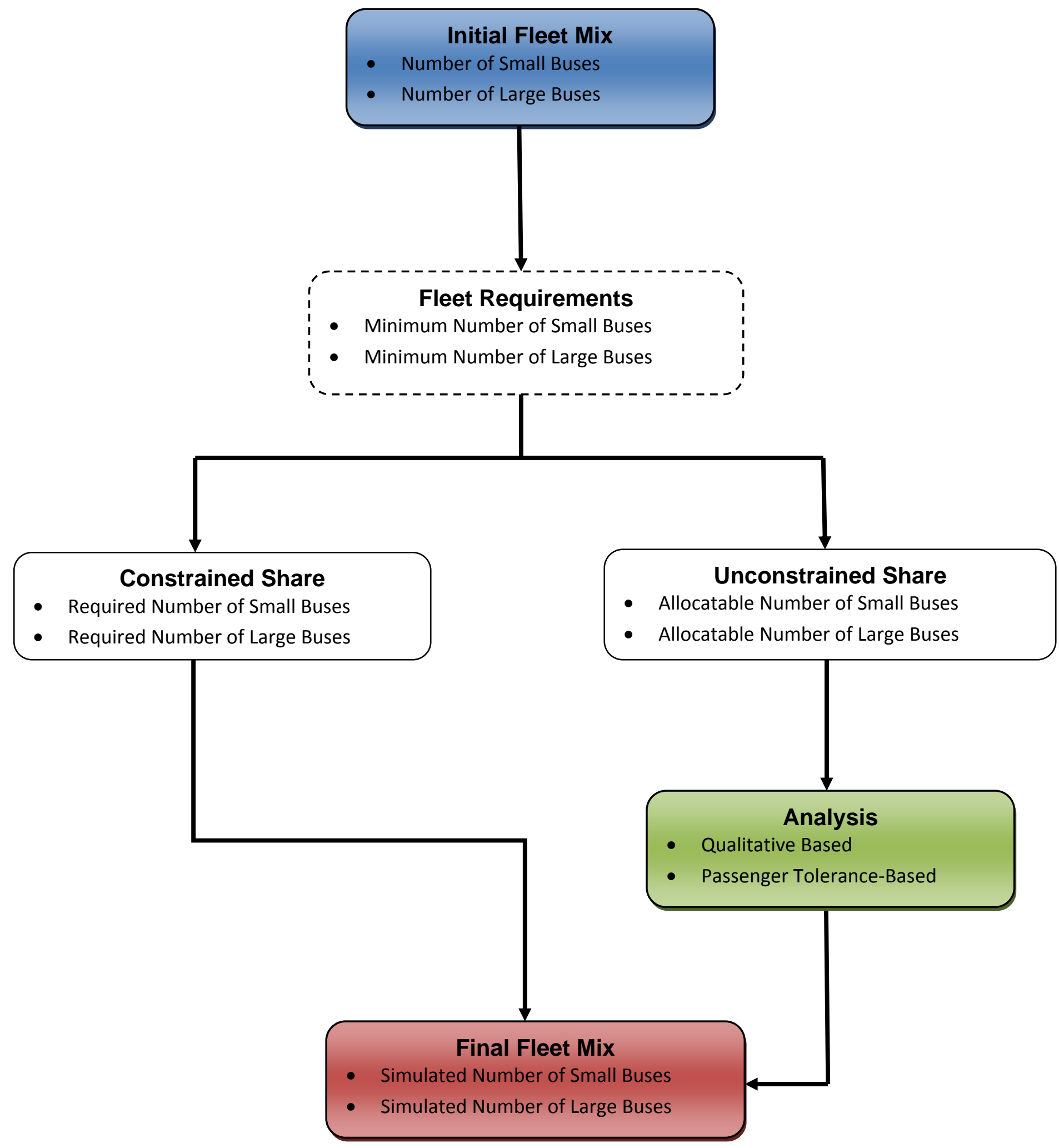




\section{Bus Size Evaluation Tool (BSeT) - User Guide}

The analytical process described in the previous section, and constituting the model framework, led to the development of a sketch planning tool that works within a Microsoft Excel platform. ${ }^{8}$ The sketch planning takes the acronym of BSeT or Bus Size Evaluation Tool. The following section describes $B S e T$, identifies the required inputs for utilizing the tool, the results it produces, and its customization capabilities.

Upon opening the program, a security warning about macros appears. The user must enable macros in order for the program to launch properly. Next, a splash screen is activated which displays the program name (Figure 4.2). Within five seconds, the graphic disappears to reveal the BSeT start page. A series of buttons are displayed (Figure 4.3), each with a function described in the instruction box:

Run Analysis: Clicking this button initiates the four-step evaluation.

View Results: Clicking this button toggles the user back and forth between the start and results pages.

Modify Model Parameters: BSeT is a flexible tool that allows the user to change the default values by clicking this button.

Custom Bus Schedule: By clicking this button, BSeT allows users to input a unique bus requisition schedule.

Toggle Help: Clicking this key turns off the instruction box; clicking it again causes the instruction box to reappear (see Figure 4.3).

8 The tool is designed to operate as a macro written using Visual Basic language. Simply put, a macro is a set of instructions that are recorded and allow a visual interface to be implemented, which permits a more user-friendly analysis. 


\section{Figure 4.2. BSeT Title Screen}

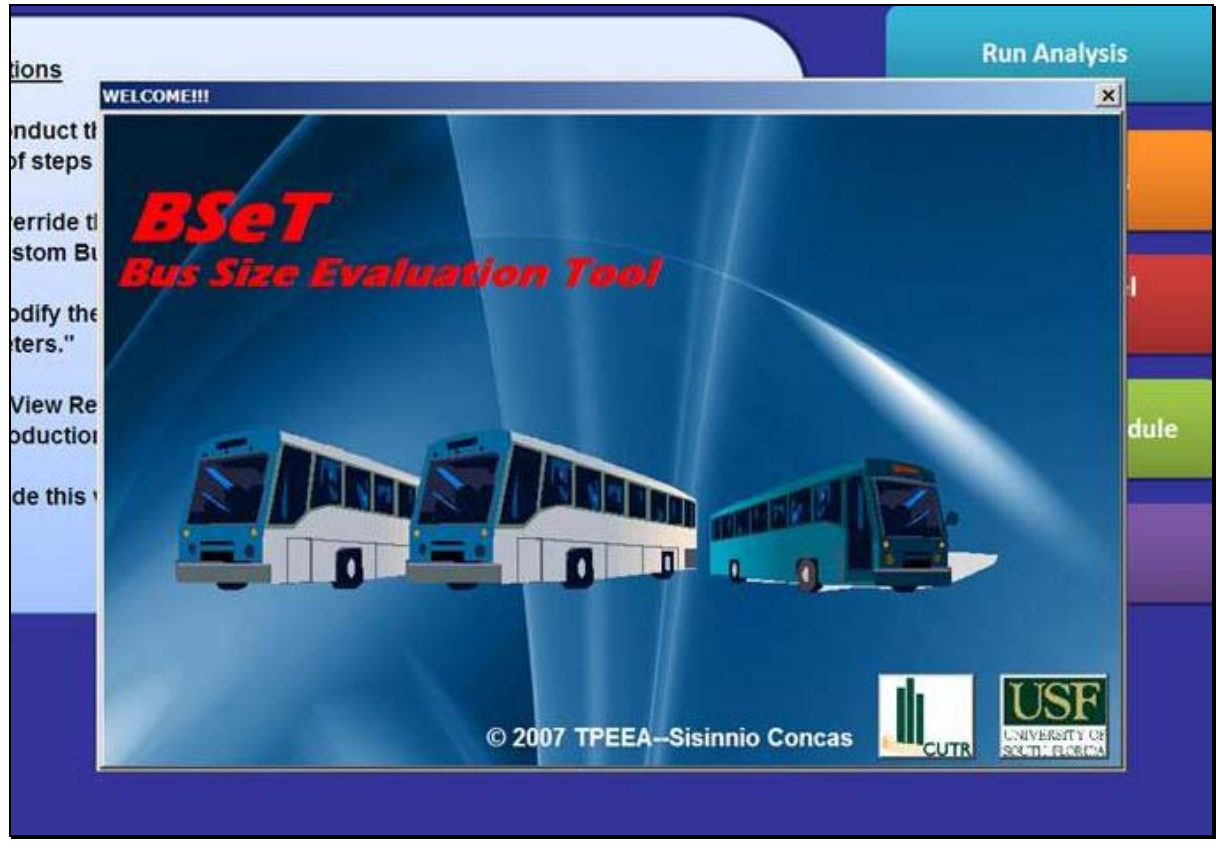

Figure 4.3. BSeT Main View and Instruction Page

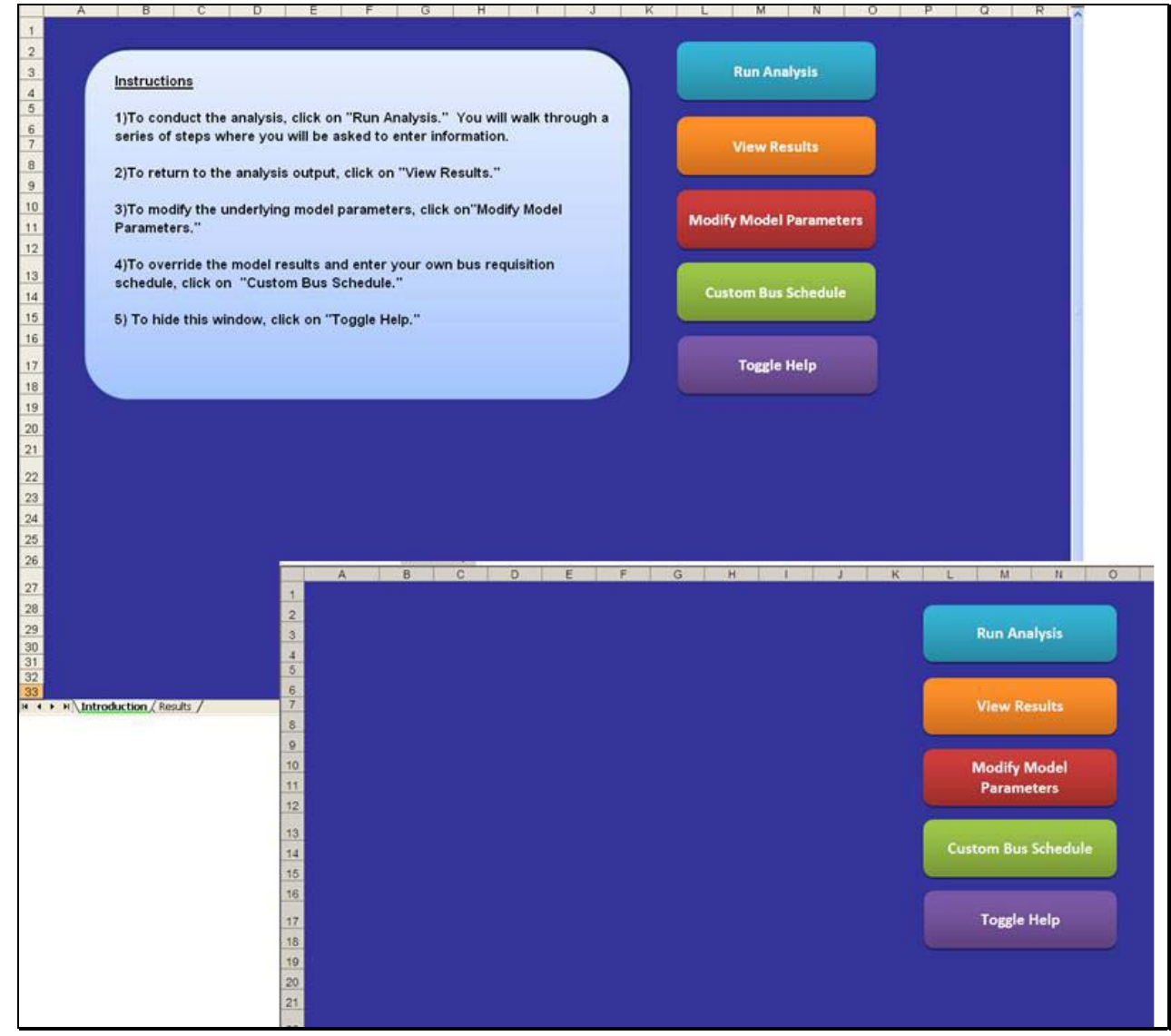




\section{BSeT Analysis and Input Requirements}

The analysis is conducted by clicking the "Run Analysis" key. This action immediately brings up a four-step module. The first module asks for basic inputs, including the agency and analyst names, as well as the year of the analysis (see Figure 4.4). Tool designers anticipated that BSeT users would likely run the model several times, in order to create different scenarios. As such, the tool also provides the opportunity for the user to give each run a unique name so that results can be easily compared. Once the information is entered the user clicks the "Next" button.

Figure 4.4. BSeT Analysis, Step 1: Name \& Title

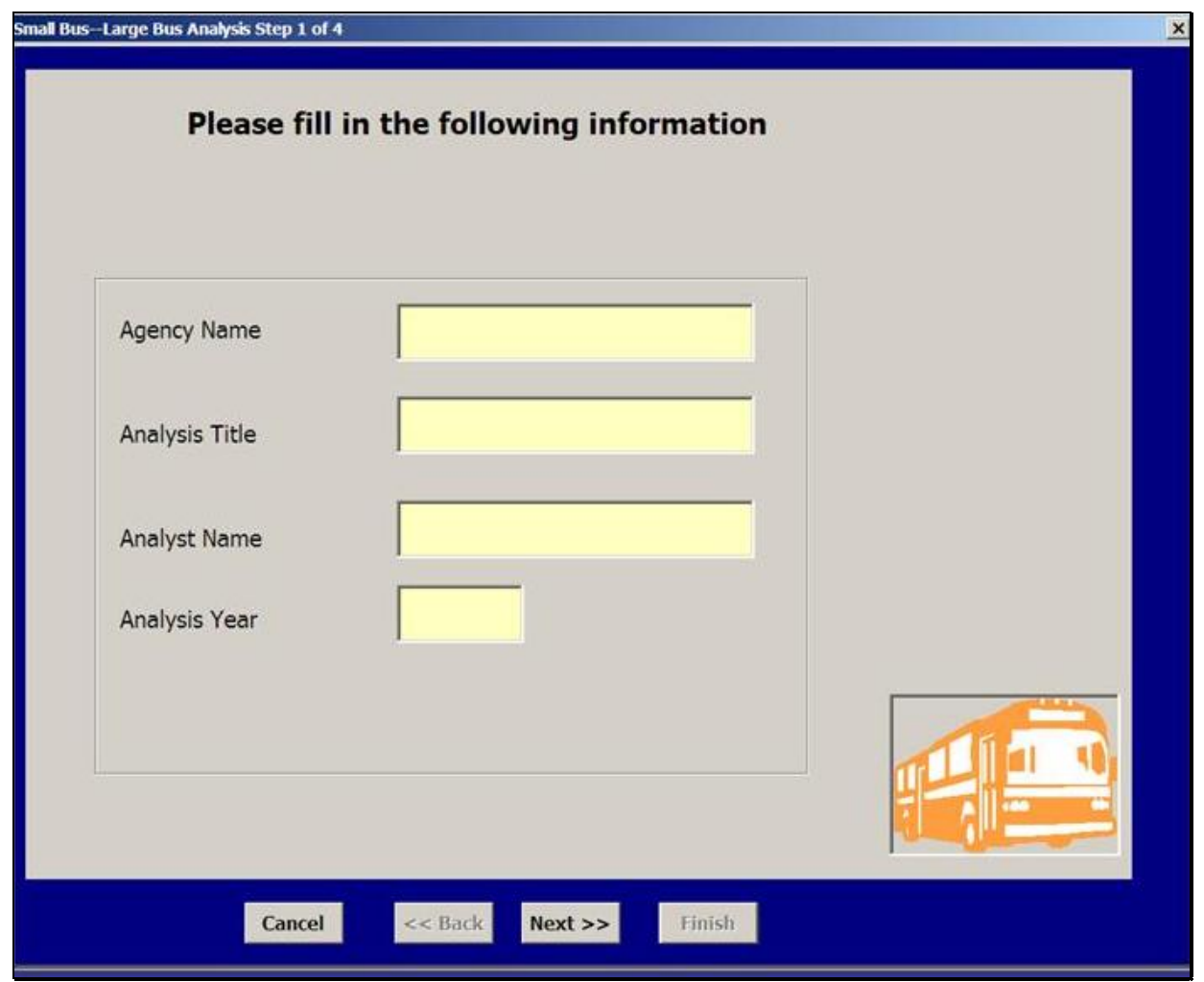

In the second step, displayed in Figure 4.5, the user is given the opportunity to enter the number of large buses in the current fleet by model year, then to enter the number of small buses. ${ }^{9}$ Step 2 provides space for twelve years worth of vehicles, dating back from the analysis year. In the event that the fleet under analysis does not contain any vehicles from a specific model year, the user may leave the space blank. Upon completing the current bus fleet,

\footnotetext{
9 Recall that for the purposes of this study, a large bus refers to any 40-foot or longer heavy-duty transit bus and a small bus refers to any heavy-duty transit bus that is less than 40 feet in length.
} 
Figure 4.5. BSeT Analysis, Step 2: Current Bus Fleet

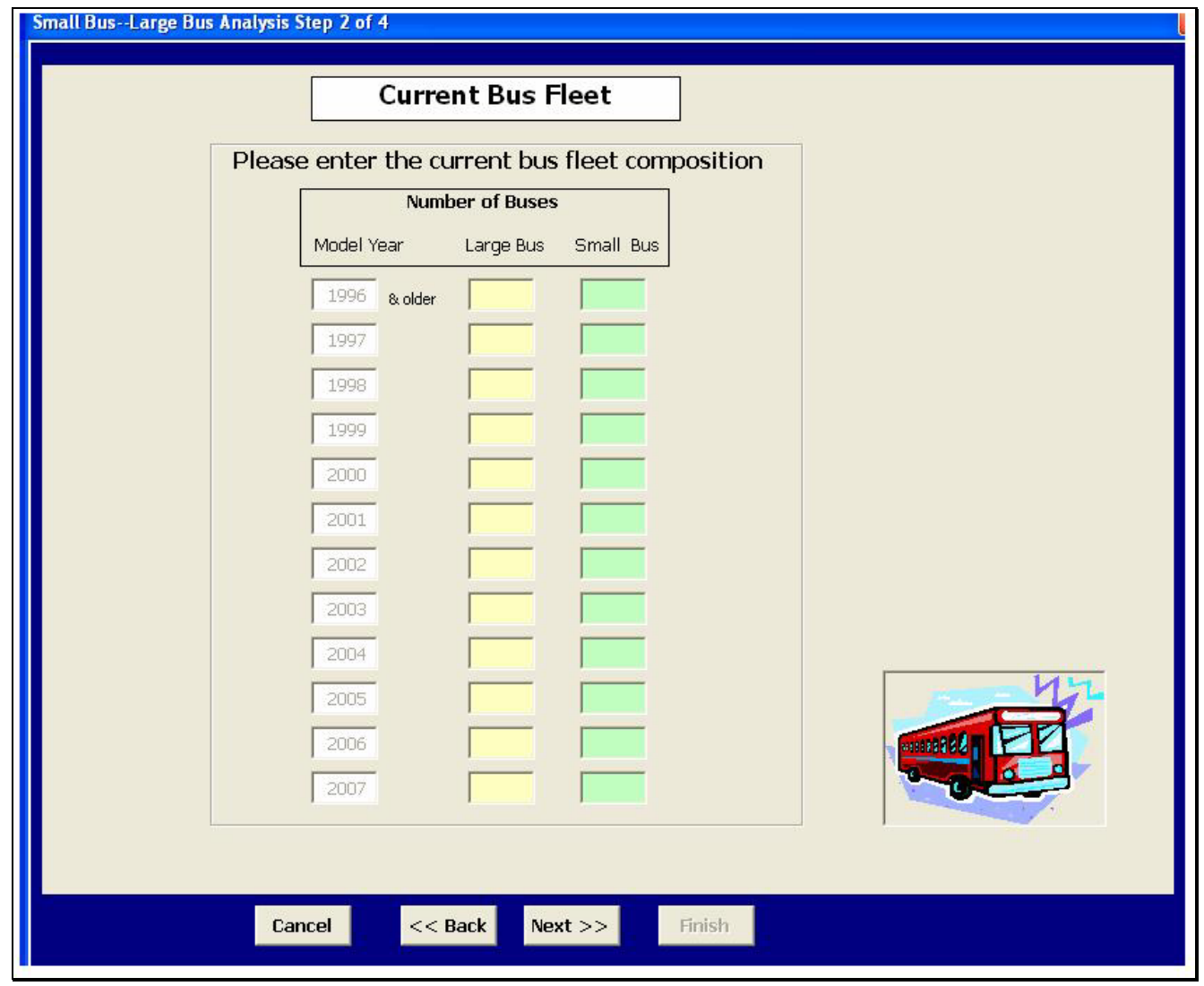

the user is directed to click the "Next" button in order to proceed with the analysis.

In this third step, the user is asked to enter information about bus fleet characteristics (see Figure 4.6). The analyst is required to enter the minimum numbers of large and small buses necessary to meet agency needs. For example, agency policy might dictate that only large buses may be used on express routes, so the minimum number of large buses would include the total buses necessary to meet express route service. In the event that no such constraints exist, the user must enter a zero in each box in order for the tool to provide an outcome at the end of the final step.

To further strengthen the analysis, the user has the option to enter average passenger count data for small and large buses. While agencies may not have such metrics immediately available, these figures are easily determined from passenger count data, especially data provided by APCs. If data are unavailable, the tool uses the default values. When finished entering the bus fleet characteristics, the user clicks "Next" and is taken to the fourth, and final, step in the analysis. 
Figure 4.6. BSeT Analysis, Step 3: Bus Fleet Characteristics

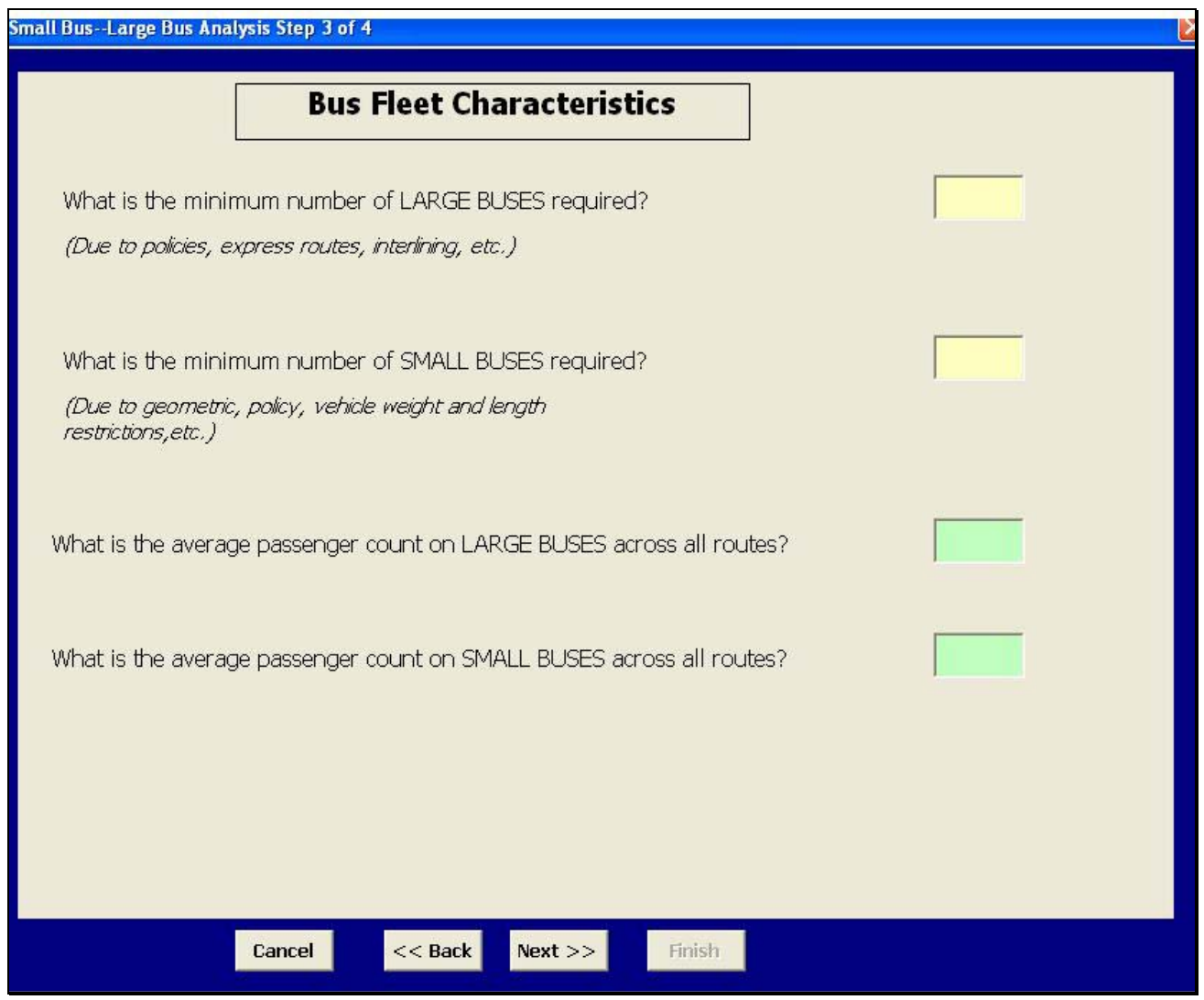

The last step of the BSeT analysis requires the analyst to respond to a series of qualitative factors (see Figure 4.7). The purpose of this step, which is critical to the analysis, is to determine the overall extent to which small or large buses are an appropriate option, given the priorities of the agency. The model is designed to interpret each response as an indication of a need for small buses or for large buses, or that no differences between the two are apparent.

A series of four tabs is incorporated into the tool for this step. Each tab is dedicated to a critical, qualitative topic related to bus selection and deployment. The first qualifying subject area is designed to determine the user's priorities regarding bus size, if any, related to vehicle acquisition. The next qualitative subject area is concerned with ridership, while the third addresses special concerns. The final qualitative factor reveals general public opinion and bus operator feedback regarding bus size. A fifth tab includes a general description of the rating scale.

Overall, nine specific statements are distributed among the four qualitative category tabs (see Table 4.5). Responses to each statement are designed 
Figure 4.7. BSeT Analysis, Step 4: Qualitative Factors

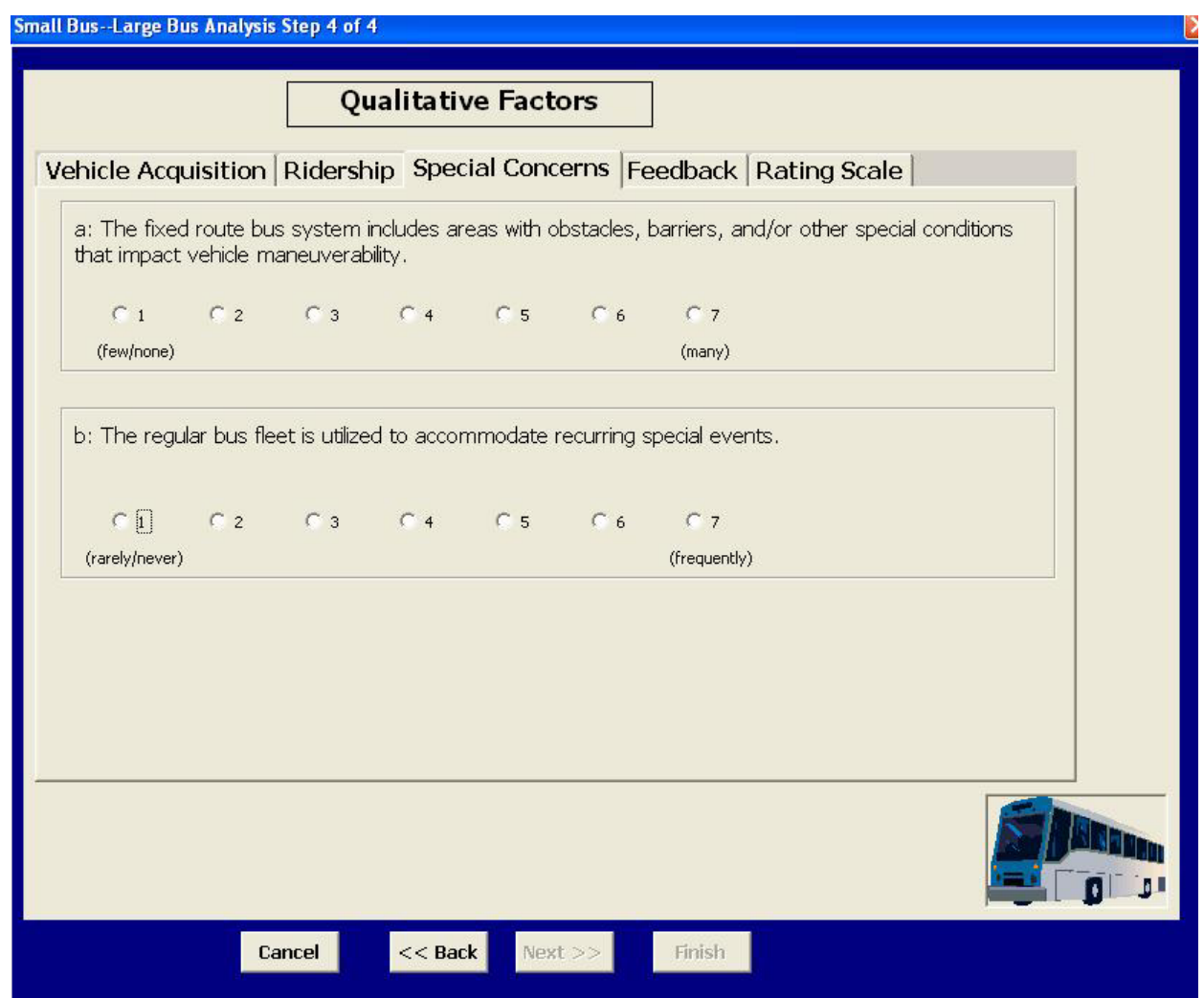

around a seven-point Likert scale, and each response selection corresponds to the degree to which the user's priorities are met by small or large buses. The response scale for seven of the nine qualifying statements (those within the first, second, and fourth categories) utilizes the common bipolar method. Specifically, the selections " 1 " and " 7 " are strong indications for small or large buses, respectively. The user indicates moderate need for small or large buses by selecting "2" or "6" and slight need for small or large buses by selecting " 3 " or " 5 ". The selection of " 4 " indicates that the user is indifferent.

The two qualifying statements included under the "Special Concerns" category are somewhat different from the seven statements described above. Here, each statement addresses an issue that is commonly dealt with by implementing one size of bus or another. For example, small buses are generally deployed to overcome instances of reduced maneuverability, and large buses are generally deployed to accommodate large crowds generated by recurring special events. As such, the response scale following each statement is designed to indicate the user's degree of need for the specific bus type. 


\section{Table 4.5. Step 4: Qualitative Factors - Categories, Statements, and Responses}

\section{Vehicle Acquisition}

a: In the event of bus fleet expansion, indicate which bus type best meets the agency's overall priorities.

(small buses) $1 \quad 2 \quad 3 \quad 3 \quad 4 \quad 5 \quad 6 \quad 7$ (large buses)

b: Indicate which bus type is most likely to meet the specific operating needs and conditions of the agency.

(small buses) $1 \quad 2 \quad \begin{array}{lllllll}1 & 2 & 4 & 5 & 6 & 7 & \text { (large buses) }\end{array}$

c: Indicate which bus type is more adaptable to technological upgrades and retrofits.

$\begin{array}{llllllll}\text { (small buses) } 1 & 2 & 3 & 4 & 5 & 6 & 7 & \text { (large buses) }\end{array}$

\section{Ridership}

a: Indicate the general prevalence of bus routes that consistently experience significant periods of excessive passenger loading.

$\begin{array}{lllllllll}\text { (few routes) } & 1 & 2 & 3 & 4 & 5 & 6 & 7 \text { (many routes) }\end{array}$

b: When anticipating future conditions, indicate the degree to which overall demand for service is expected to grow or decline.

$$
\text { (decline) } \begin{array}{llllllll}
1 & 2 & 3 & 4 & 5 & 6 & 7 & \text { (grow) }
\end{array}
$$

\section{Special Concerns}

a: The fixed route bus system includes areas with obstacles, barriers, and/or other special conditions that impact vehicle maneuverability.

$$
\text { (few/none) } 1 \quad 2 \quad 3 \quad 4 \quad 5 \quad 6 \quad 7 \text { (many) }
$$

b: The regular bus fleet is utilized to accommodate recurring special events.

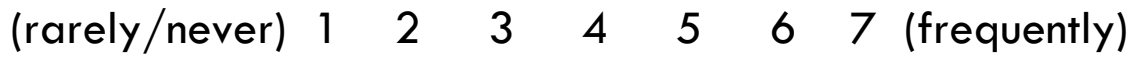

\section{Feedback}

a: Based on your experience, indicate the degree to which the public has expressed a favorable opinion of one bus type over another.

$\begin{array}{llllllll}\text { (small buses) } & 1 & 2 & 3 & 4 & 5 & 6 & 7 \\ \text { (large buses) }\end{array}$

b: Based on your experience, indicate the degree to which operators have expressed a favorable opinion of one bus type over another.

$\begin{array}{lllllllll}\text { (small buses) } & 1 & 2 & 3 & 4 & 5 & 6 & 7 & \text { (large buses) }\end{array}$ 
Because the relevance of each qualitative category varies in terms of overall bus acquisition and deployment choices, the four areas were weighted according to input received from the project advisory group. The following measures were installed as the default weight for each category:

I. Vehicle acquisition $-30 \%$

II. Ridership $-35 \%$
III. Special concerns $-25 \%$

IV. Feedback - 10\%

Like other parameters, the model allows for the modification of qualitative factor weighting assignments, as necessary.

As mentioned earlier, the simplicity of the model allows the user to complete several trials. As such, the analyst has the option to input a variety of answers to various qualitative factors in order to view and compare the impact of each arrangement.

Upon completion of step four, the user clicks "Finish" to display the BSeT analysis results. At any time during the completion of analysis steps one through four, the user may choose to cancel the analysis or to go back to the previous analysis step.

\section{BSeT Output}

After all required input steps are completed and the user has clicked on the "Finish" button, the analysis is then complete, and the results are presented. 10 The BSeT model output screen, shown in Figure 4.8, displays the original state followed by the result of the analysis. Users are able to easily compare initial conditions with the impact of the variables that were entered. ${ }^{11}$ In the upper left quadrant of the screen, the agency name, analysis title, analyst name, and year are shown. Below that, analysis results are shown beside the base case. Specifically, fixed and variable cost calculation outputs, including fuel, maintenance, operating, and acquisition costs, are displayed.

To the right, final results and comparisons are highlighted in a yellow box. Here, analysts are able to compare average annual costs per mile for small and large buses. Total vehicle replacement costs are also indicated. To better understand the analysis tool and interpret the results, a step-by-step application example is provided in the appendix of this report.

\footnotetext{
10 It is important to note that the numbers displayed in Figure 4.8 are not the result of a specific analysis or example application. The output sample serves only as a demonstration of the tool layout.

11 At this time, the model is a beta version with illustrative qualification questions only. The project advisory group will convene to approve a series of qualifying factors. The finalized BSeT analysis output will be largely influenced by answers to the qualifying questions.
} 
Figure 4.8. BSeT Analysis: Output Screen ${ }^{12,13}$

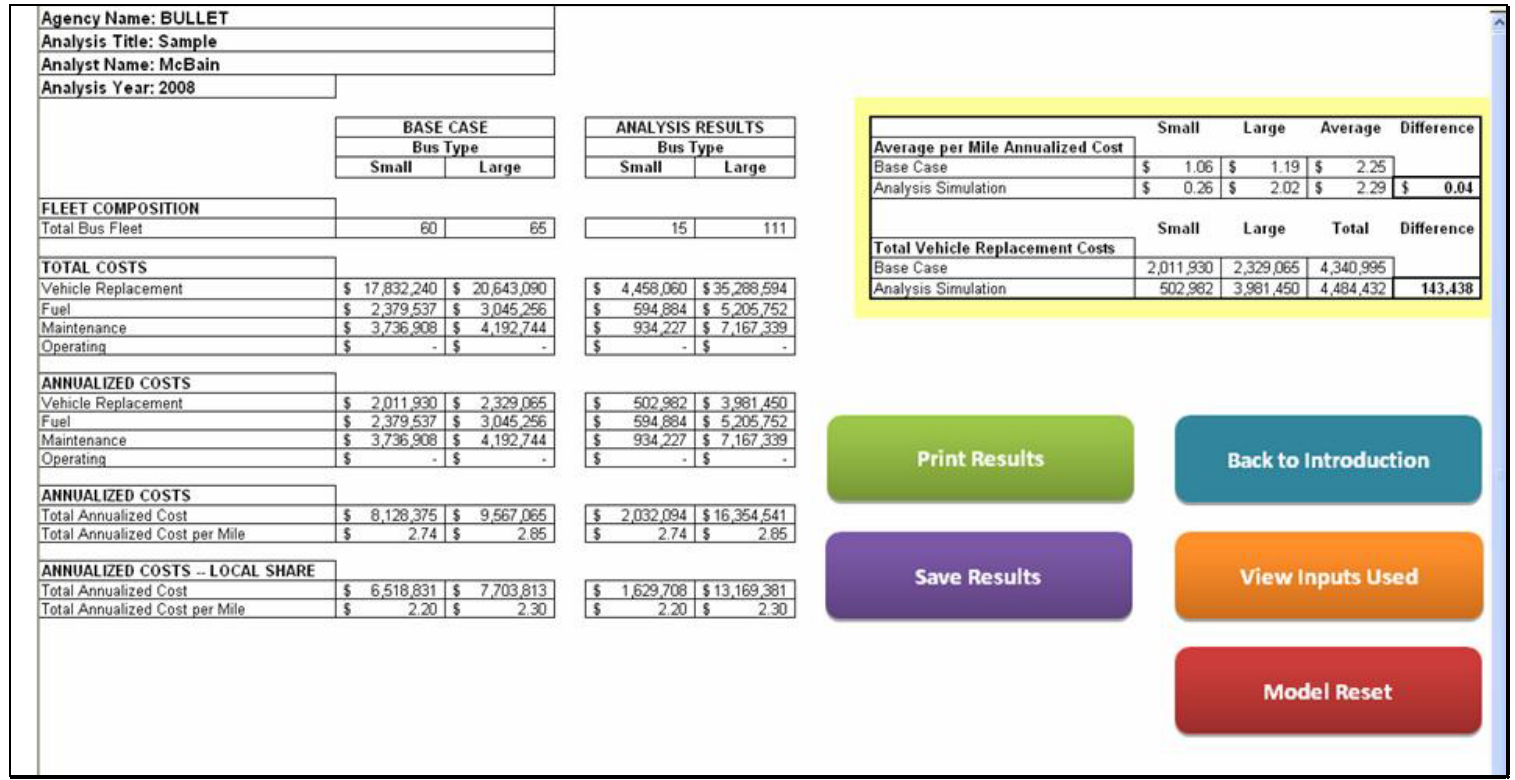

Five action buttons are located within the lower right quadrant of the BSeT output screen. Their labels and functions are listed below:

Print Results: clicking this button sends the output screen to the local printer where a hard copy of the output is generated.

Save Results: clicking this button allows the user to save the file under a unique file name.

Back to Introduction: clicking this button returns the user to the introductory screen.

View Inputs Used: clicking this button displays a summary of all data entered by the user.

Model Reset: clicking this button clears the inputs and results so that the user may initiate a new analysis.

\section{Customizing BSeT}

BSeT was designed to be fully customizable, offering adequate flexibility to accommodate the diverse needs of end users. Specifically, the tool permits the following parameters and assumptions to be fully modified:

- Cost parameters

\footnotetext{
12 Figure 4.8, the BSeT Analysis: Output Screen is presented for illustrative purposes only. The numbers included in the graphic are based on a purely hypothetical scenario.

13 For enhanced image clarity, the size of the five action buttons has been slightly increased in Figure 4.8.
} 
- Life cycle parameters

- Passenger loading factors

- Bus fleet requisition schedules

Within each parameter, all critical assessment factors are customizable. In fact, end users are encouraged to adjust the tool to best accommodate their specific needs and conditions. However, the modification option can also be used simply to view the default values for each variable. The following section describes the modification process in greater detail.

To begin customizing the model, all the user has to do is find the main BSeT screen and click on the button labeled "Modify Model Parameters." A failsafe box appears immediately, ensuring that the user intends to make changes (see Figure 4.9). After clicking on the "Yes" button, the model parameters screen appears (see Figure 4.10).

Figure 4.9. Modifying BSeT Model Parameters

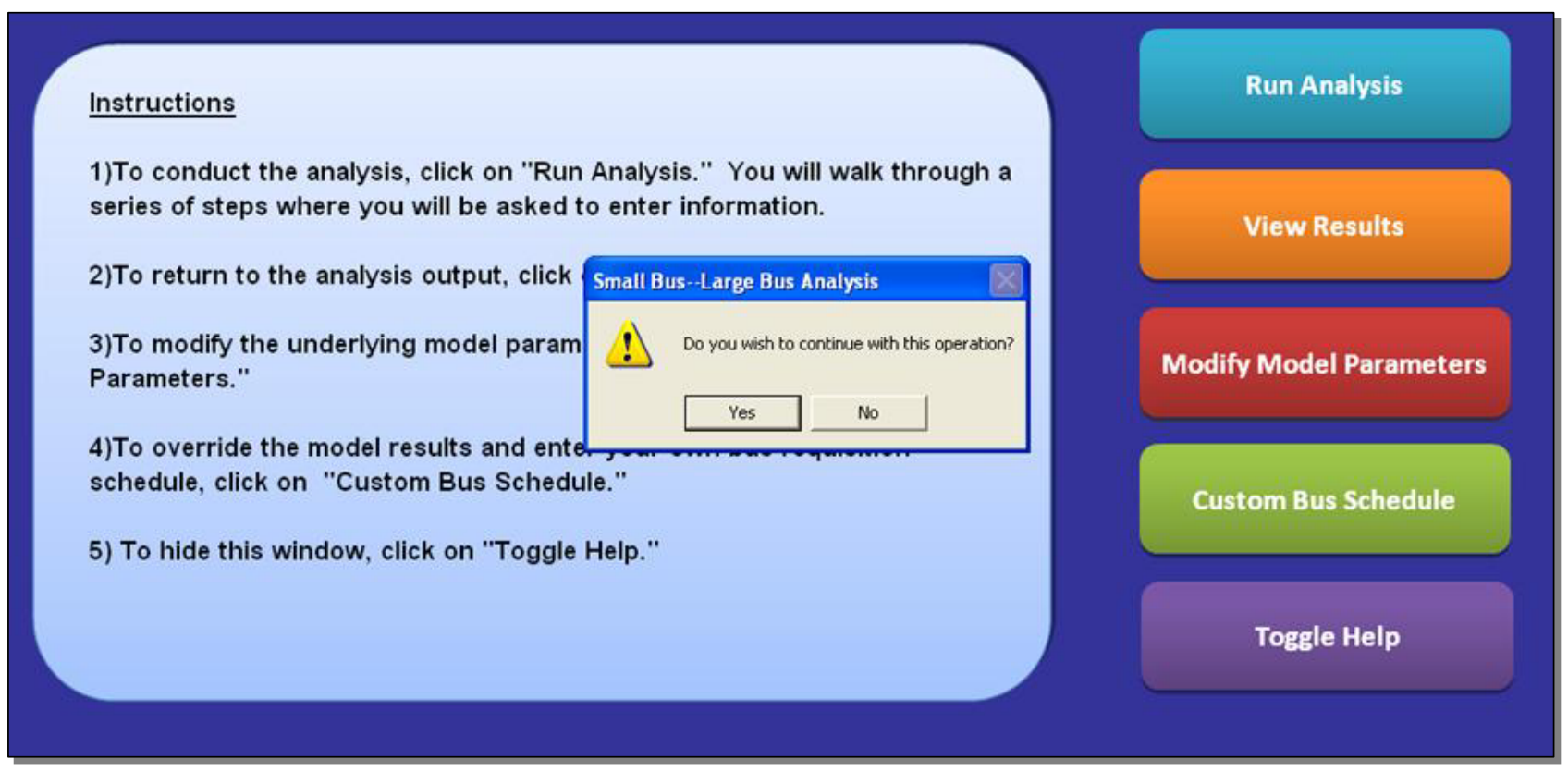

With the model parameters page open, the user will notice three available tabs. Within each tab, the default values ${ }^{14}$ are visible. The defaults cannot be changed; however, they are overridden when custom information is entered for the analysis.

\footnotetext{
14 Default values for life-cycle costs and service factors were determined earlier in this chapter through analysis of the composite bus fleet. In cases where composite fleet data were unavailable (such as PLF and tolerance), CUTR relied on data from the phase one research effort.
} 


\section{Figure 4.10. Modifying BSeT Model: Cost Parameters}

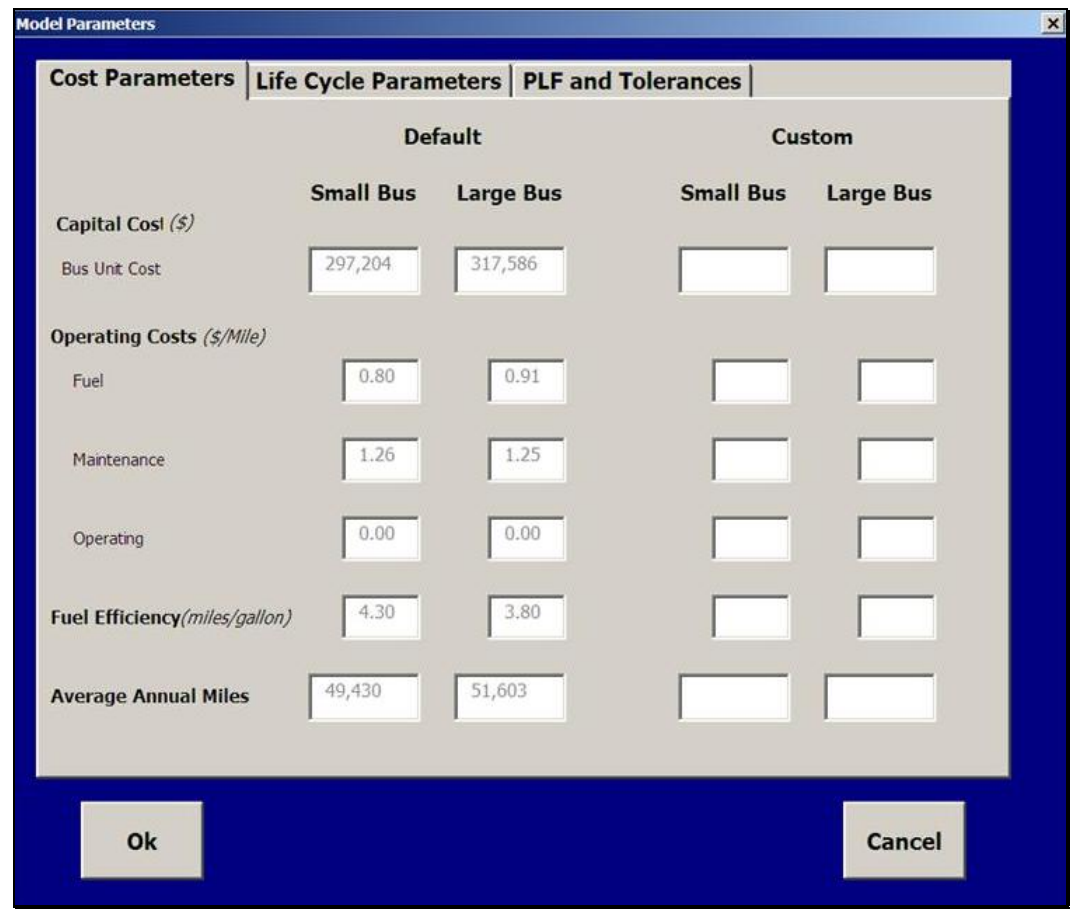

The first tab to be modified includes cost parameters. Here, fixed and variable costs are displayed for both small and large buses. The average annual costs per mile for fuel, maintenance, ${ }^{15}$ and operations are shown, along with the vehicle procurement costs and average annual miles. The user has the option to modify some or all of the parameters.

The second modifications tab focuses on life cycle parameters (see Figure 4.11). Once again, the defaults cannot be changed, but the custom entries override the default values. Specific variables that can be customized include the cost share percentage, expected vehicle life, and average annual operator salary.

Figure 4.12 illustrates the third modifiable area of model parameters, which allows passenger loading variables by bus type to be customized. BSeT users are able to enter specific measures related to bus seating capacity and average passenger counts. This modification area is especially useful for multiple analyses and comparative purposes. For example, the user may enter various seating capacity figures in order to examine different vehicles or vehicle configurations. Analysts may also enter a unique percent for acceptable vehicle capacity. Again, the user is able to experiment with various degrees of tolerance and then, to compare the results.

15 The parameters for operating costs-maintenance represent the sum of average annual maintenance labor costs per mile and average annual parts costs per mile. 
Figure 4.11. Modifying BSeT Model:

Life Cycle Parameters

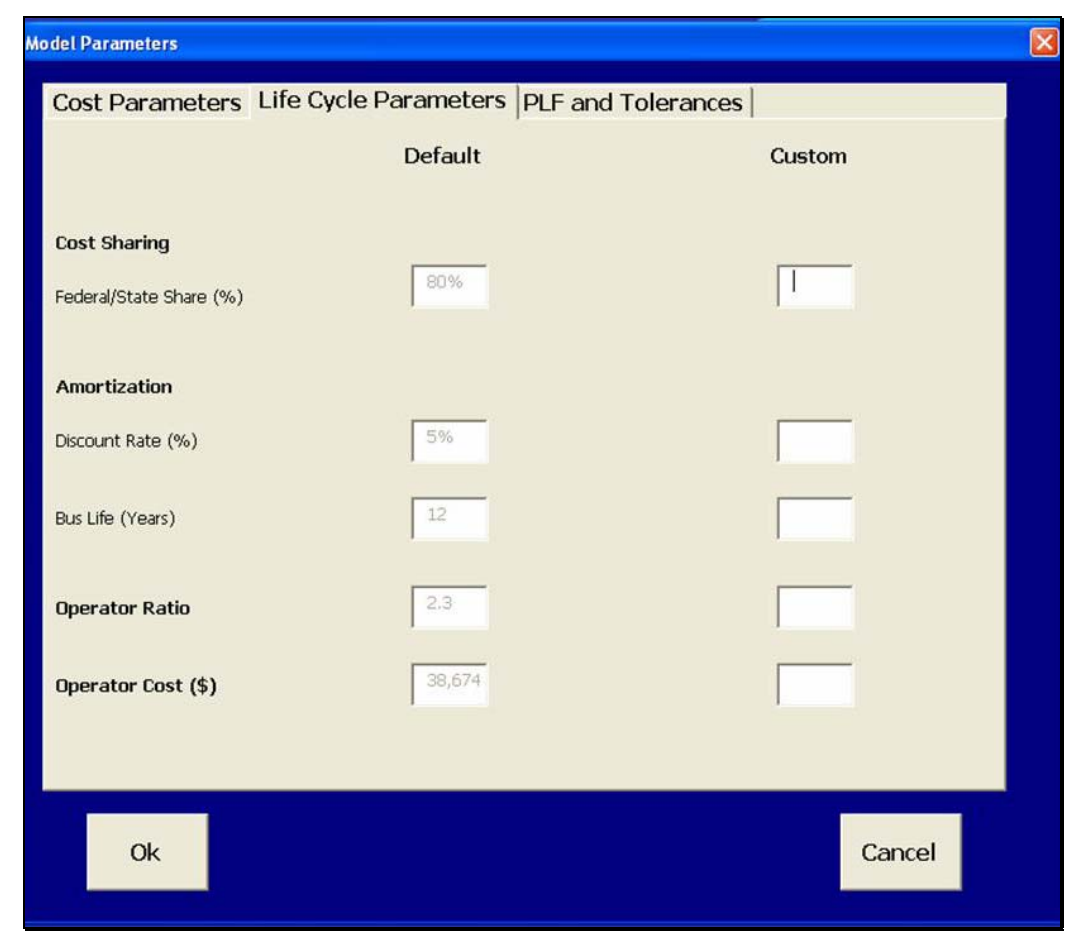

Figure 4.12. Modifying BSeT Model:

PLF and Tolerance Parameters

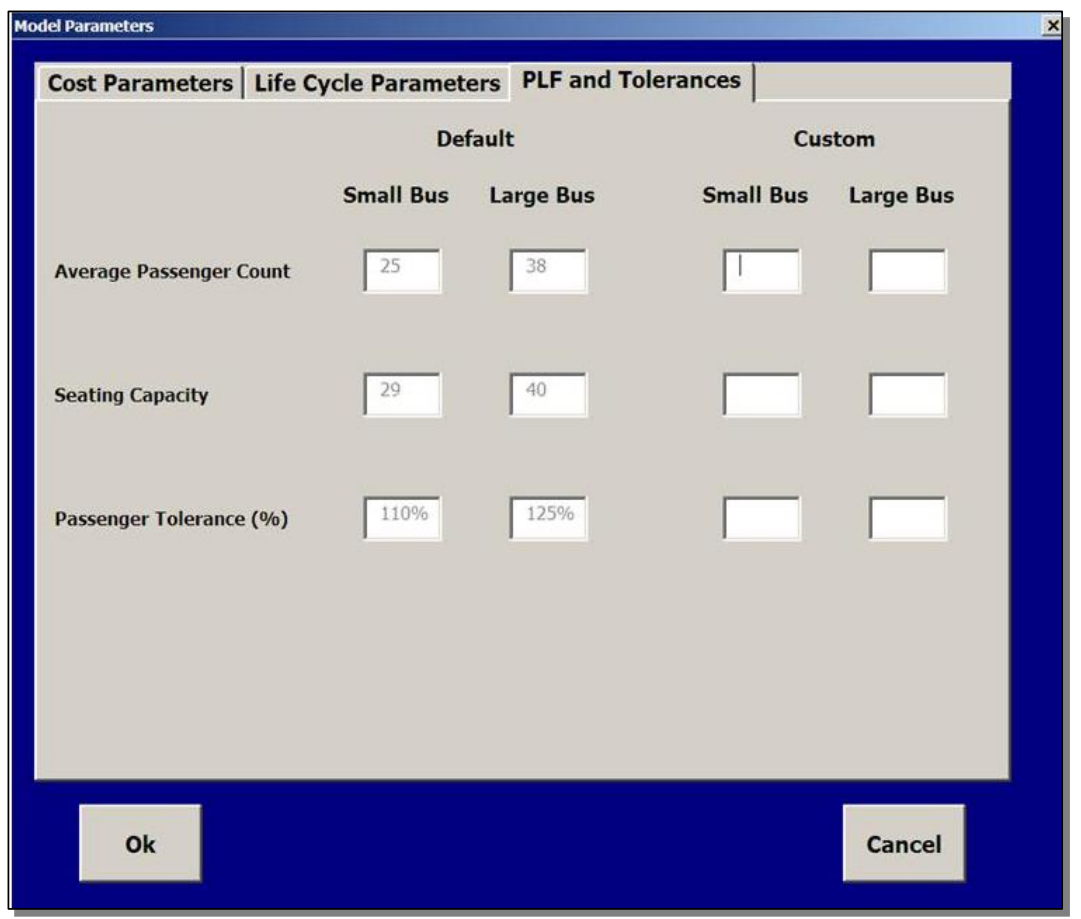


Figure 4.13 illustrates the fourth modifiable area of model parameters. Here, the weighting scale of the qualitative factors may be customized. BSeT users are able to enter specific percentages related to each of the four qualitative subject areas. As with other modifiable areas, the default values cannot be changed, however, any custom entries will override the default values. If the user intends to modify the qualitative factor weighting distribution, a value must be placed in each box, and the sum of the values must equal 100 percent. Further, the model will not allow a zero value for any factor. In the event that the user wishes to reduce the weight of one or more factor areas to very small percentage, he/she must use a very small decimal number (such as $.001 \%$ ).

Figure 4.13. Modifying BSeT Model: Qualitative Factors

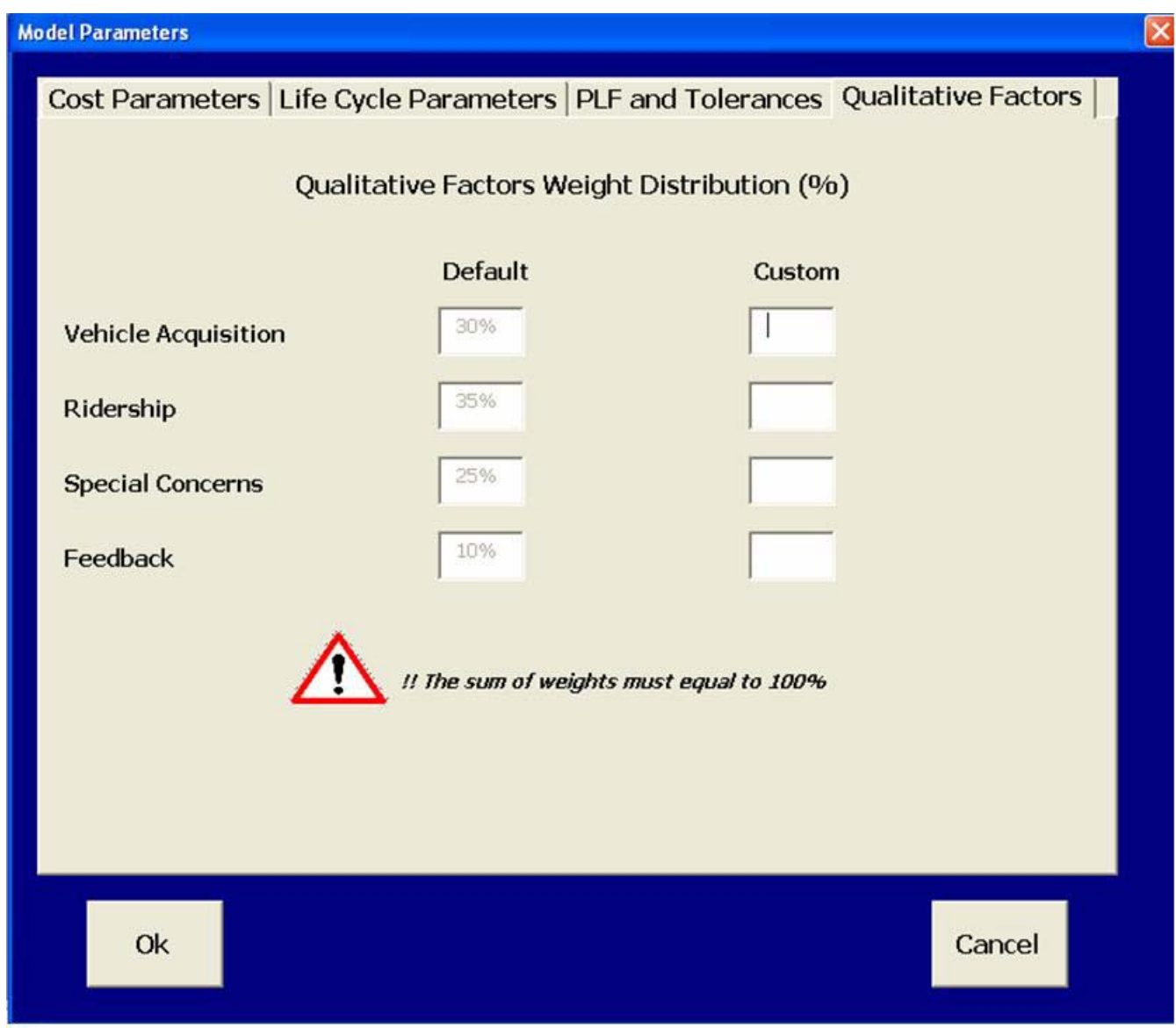


Another modifiable area, which is available under a separate button on the BSeT main page, concerns the existing bus fleet and the anticipated requisition schedule (see Figure 4.14). Here, the user is able to enter specific quantities of existing fleet buses by year, as well as the anticipated replacement schedule by year.

\section{Figure 4.14. Modifying BSeT Model: Custom Bus Fleet}

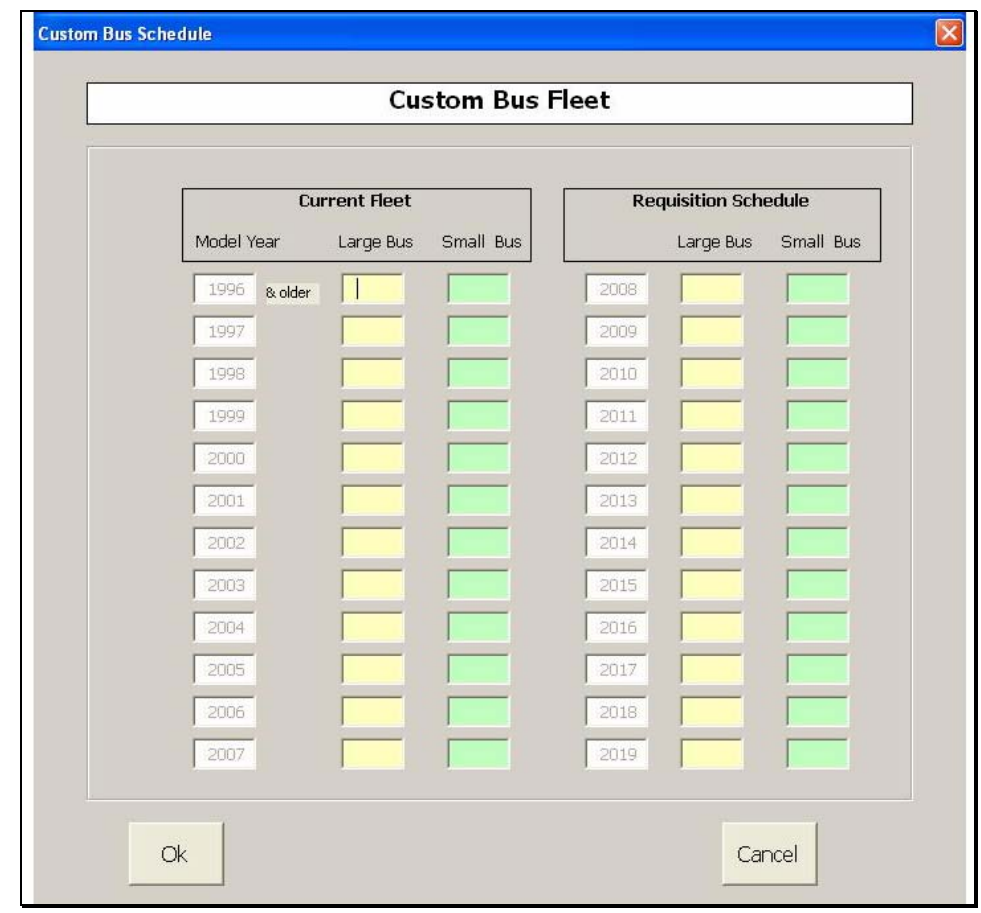

At any time, the user may cancel the modifications by clicking on the "Cancel" button, and then responding in the affirmative to the failsafe question (see Figure 4.15). Further, all of the modifications can be cancelled and the default variables restored by clicking on the "Model Reset" button, which is available on the output screen (please refer to Figure 4.8).

Figure 4.15. Modifying BSeT Model: Cancel Modifications

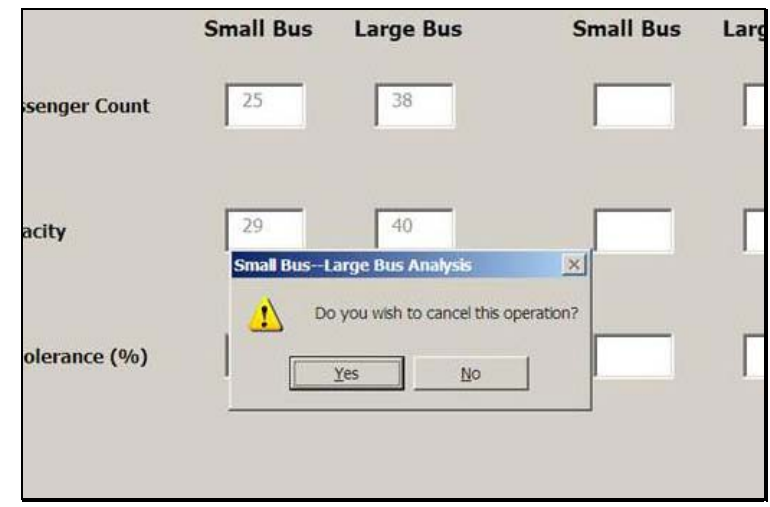




\section{CONCLUSIONS}

The preceding report chronicled the development of a decision support tool for use by transit agencies to aid in the acquisition and deployment of heavy-duty, diesel-powered buses. First, prior studies were reviewed and relevant assessment factors were determined. Next, a working group of representatives from selected Florida transit agencies was established to provide practical knowledge and expertise, as well as critical oversight and composite data, to the research effort. Later, the evaluation technique was developed and refined, and the decision support tool was created. Formally dubbed the Bus Size Evaluation Tool (BSeT), the tool's operation and analysis method were described in detail.

This research approach is consistent with prior life-cycle cost analyses completed for large and small heavy-duty transit buses. For the purposes of this study, large buses are defined as heavy-duty, diesel-fueled buses that are 40 feet in length, and small buses are defined as heavy-duty, dieselfueled buses that are less than $40 \mathrm{feet}$ in length. The model did not include alternative-fuel vehicles or non-standard, less-than-12-year lifespan vehicles. Life-cycle cost variables considered by this application include variable costs per mile, including per mile maintenance cost (labor + parts) and per mile fuel cost; fixed costs, including vehicle acquisition cost; and usage intensity data, including average annual miles. Further, the tool incorporates service and other factors to generate a more accurate and relevant outcome. Specifically, the model maintains user-defined constraints for small and large buses, and unless otherwise modified, the tool assumes that the user seeks to preserve existing fleet capacity, regardless of the actual vehicle mix generated by the analysis.

A fundamental strength of this model is the ability of the end-user to modify any or all of the internal parameters according to agency-specific data. The robustness and flexibility of the tool allows for widespread application among transit operators.

By addressing other, non-quantifiable factors, the outcome of this research effort surpasses previous decision support tool development efforts. BSeT includes a series of qualitative subject areas that serve to define and weight the user's priorities related to bus size. However, the tool also provides an 
analysis output in the event that no advantage of one type of bus over another is indicated.

Although the concluding remarks section of a research effort designed to generate a cost analysis tool such as BSeT is generally different from a traditional research report, several notable points are worthy of review at the close of this project. These items are outlined below:

- Throughout this report, phase one and phase two were referred to frequently. It is important to reiterate the relationship between phase one, which was funded exclusively by HART, and this research effort (phase two), which was funded by FDOT through NCTR. For phase one, CUTR worked entirely with HART to calculate life-cycle cost analyses and to perform a route analysis. Several fleet scenarios were also produced to demonstrate the impact of various vehicle combinations. Phase two was designed to utilize the phase one results as a key reference; however, the research plan for phase two was not intended to fully mimic the research methods engaged under phase one.

- This research project did not intend to perform a comparative analysis across participating transit agency bus fleets. Rather, the intent was to gather a sufficient amount of data to calibrate the model and to ensure a robust analysis tool.

- The original scope of work for this project directed CUTR to form a Project Advisory Group comprising representatives from participating transit agencies, as well as the FDOT project manager. Researchers believe the inclusion of this component was vital to the success of the project, and the practical expertise and guidance provided by the group has resulted in a more robust and useful analysis tool than would have been produced under strictly isolated laboratory conditions.

- Familiarity with the following terms and concepts is vital to understanding the function and output of BSeT:

o Constraints - This term refers to required minimum values or quantities. Usually, constraints are discussed in terms of the minimum number of specific bus types required by the BSeT user agency for various reasons, such as vehicle maneuverability, limited access, policy mandates, and other specific needs.

o Constrained share - This term generally refers to the group of buses that must be maintained at a minimum by the 
implementing agency. The analysis result may exceed the minimum required quantity but, the result can never fall below the constrained share value.

0 Unconstrained share - This term refers to the group of buses that may consist of any combination of vehicle sizes so long as the total passenger capacity of the fleet is maintained. The unconstrained share is the source of vehicles that are allocated by the analysis tool.

- While cost analysis results generated by BSeT may vary widely according to the user's data inputs and modifications (if any), the vehicle mix results are generally limited to three possible outcomes, based on the user's overall priorities. Once the qualitative factor analysis has determined the general trend toward one bus type or another, the unconstrained share is assigned entirely to the bus size group that is most likely to satisfy the user's priorities. This outcome is consistent with the original project scope of work, which directed CUTR to devise a tool that aids in the decision-making process. The research product was not intended to generate an optimal fleet mix or to predict deployment patterns on a route by route basis.

- In the event that the analysis of qualitative factors reveals an overall indifference regarding bus size, the model output effectively becomes a cost analysis of the existing fleet. Specifically, the indifferent condition is a signal to the tool that the implementing agency has already achieved a satisfactory fleet configuration. As a result, no alternative fleet configuration is suggested by the output.

- Transit operators are concerned with maintaining a pre-defined operating spare ratio. BSeT does not address operating spare ratios directly; however, the model assumes that the numbers entered into the current fleet composition portion of the analysis include spare vehicles. As such, the tool output can be considered to be inclusive of spare vehicles.

- Because only one of the five participating agencies itemized outside costs separately from maintenance parts and labor costs, this category was not included as a separate variable in BSeT.

- Operator costs were not included in the analysis of the composite bus fleet because the model assumes that there is salary parity between operators of small and large buses.

- None of the agencies observed formal service planning guidelines. 
- BSeT was designed with redundant protections to prevent the loss of data and otherwise unintended modifications.

- All critical dollar amounts referenced in this study were normalized to 2007 dollars, where necessary.

Based on the tasks completed for this research effort, the following areas have been identified for possible future consideration:

- As indicated throughout this report, the model developed for this project was not intended to be a fleet optimization tool or to provide specific route analyses. However, subsequent research efforts could be engaged to develop one or both of these tools as either supplemental modules or as stand-alone products.

- Buses manufactured by the Gillig Corporation comprised 80 percent of the composite bus fleet. This heavy representation is most likely caused by the current Florida state purchasing contract with Gillig, which is effective through 2009. As future procurement agreements are adopted, BSeT will become even more robust from periodic revisions of the default values, which are likely to reflect the addition of vehicles produced by other manufacturers.

- In the event that transit agencies adopt formal service planning guidelines, FDOT should consider revisiting the tool and incorporating the terms into the model, as necessary.

- Formal documentation of customer feedback about bus size and rider comfort was found to be limited, at best. As the use of smaller buses increases, transit agencies would likely benefit by incorporating additional questions related to these areas into customer survey instruments.

- As energy prices continue to rise and interest in alternatively-fueled buses grows stronger, a supplemental component to BSeT could be developed to address these types of vehicles and possibly to compare them to conventional transit vehicles. 


\section{REFERENCES}

1. Hemily, B. and R. King. Transit Cooperative Research Program (TCRP) Synthesis 41: The Use of Small Buses in Transit Service, Transportation Research Board, National Research Council, Washington, D.C., 2002.

2. KFH Group, Inc., MacDorman, L.C., and Laidlaw Transit Services, Inc. TCRP Report 61: Analyzing the Costs of Operating Small Transit Vehicles, Transportation Research Board, National Research Council, Washington, D.C., 2000.

3. Concas, S. and P. Winters. Economics of Travel Demand Management: Comparative Cost Effectiveness and Public Investment. NCTR, FDOT, Tampa, Florida, March 2007.

4. CUTR. Phase One Report: Fixed Route Fleet Composition Analysis \& Recommendations, Hillsborough Area Regional Transit Authority, Tampa, Florida, May 2007. 
(this page intentionally left blank) 


\section{APPENDIX A}


(this page intentionally left blank) 


\section{Table A.1. Florida Transit Agencies: Transit Vehicles Directly Operated in Maximum Service}

\begin{tabular}{|c|c|c|c|c|c|c|c|c|c|c|c|c|c|c|c|}
\hline \multirow[b]{3}{*}{ Agency } & \multicolumn{15}{|c|}{ Vehicles Operated in Maximum Service (VOMS) } \\
\hline & \multirow[b]{2}{*}{2001} & \multirow[b]{2}{*}{2002} & \multicolumn{2}{|c|}{$2002 / 2001$} & \multirow[b]{2}{*}{2003} & \multicolumn{2}{|c|}{$2003 / 2002$} & \multirow[b]{2}{*}{2004} & \multicolumn{2}{|c|}{$2004 / 2003$} & \multirow[b]{2}{*}{2005} & \multicolumn{2}{|c|}{$2005 / 2004$} & \multicolumn{2}{|c|}{$2005 / 2001$} \\
\hline & & & $+1-$ & $\%+/-$ & & $+/-$ & $\%+/-$ & & $+/-$ & $\%+/-$ & & $+1-$ & $\%+/-$ & $+/-$ & $\%+/-$ \\
\hline Bay County Council On Aging Bay Coordinated Transportation (BCCOA) & 4 & 4 & 0 & $0.0 \%$ & 8 & 4 & $100.0 \%$ & 7 & -1 & $-12.5 \%$ & 7 & 0 & $0.0 \%$ & 3 & $75.0 \%$ \\
\hline BOCC, Palm Beach County, Palm Tran, Inc. (PalmTran) & 106 & 106 & 0 & $0.0 \%$ & 106 & 0 & $0.0 \%$ & 105 & -1 & $-0.9 \%$ & 105 & 0 & $0.0 \%$ & -1 & $-0.9 \%$ \\
\hline Broward County Mass Transit Division (BCT) & 203 & 210 & 7 & $3.4 \%$ & 204 & -6 & $-2.9 \%$ & 215 & 11 & $5.4 \%$ & 227 & 12 & $5.6 \%$ & 24 & $11.8 \%$ \\
\hline Central Florida Regional Transportation Authority (LYNX) & 190 & 201 & 11 & $5.8 \%$ & 190 & -11 & $-5.5 \%$ & 195 & 5 & $2.6 \%$ & 197 & 2 & $1.0 \%$ & 7 & $3.7 \%$ \\
\hline City of Tallahassee (TalTran-StarMetro) & 48 & 49 & 1 & $2.1 \%$ & 48 & -1 & $-2.0 \%$ & 49 & 1 & $2.1 \%$ & 49 & 0 & $0.0 \%$ & 1 & $2.1 \%$ \\
\hline Council on Aging of St. Lucie, Inc. (CT) & & 3 & & & 3 & 0 & $0.0 \%$ & 3 & 0 & $0.0 \%$ & 5 & & $66.7 \%$ & 5 & $100.0 \%$ \\
\hline County of Volusia, dba: VOTRAN (VOTRAN) & 45 & 42 & -3 & $-6.7 \%$ & 46 & 4 & $9.5 \%$ & 46 & 0 & $0.0 \%$ & 46 & 0 & $0.0 \%$ & 1 & $2.2 \%$ \\
\hline Escambia County Area Transit (ECAT) & 38 & 32 & -6 & $-15.8 \%$ & 32 & 0 & $0.0 \%$ & 32 & 0 & $0.0 \%$ & 32 & 0 & $0.0 \%$ & -6 & $-15.8 \%$ \\
\hline Gainesville Regional Transit System (RTS) & 72 & 72 & 0 & $0.0 \%$ & 88 & 16 & $22.2 \%$ & 88 & 0 & $0.0 \%$ & 88 & 0 & $0.0 \%$ & 16 & $22.2 \%$ \\
\hline Hillsborough Area Regional Transit Authority (HART) & 171 & 171 & 0 & $0.0 \%$ & 152 & -19 & $-11.1 \%$ & 154 & 2 & $1.3 \%$ & 151 & -3 & $-1.9 \%$ & -20 & $-11.7 \%$ \\
\hline Indian River County Council on Aging, Inc. (IRCCOA) & 8 & 8 & 0 & $0.0 \%$ & 9 & 1 & $12.5 \%$ & 9 & 0 & $0.0 \%$ & & & & & \\
\hline Jacksonville Transportation Authority (JTA) & 145 & 139 & -6 & $-4.1 \%$ & 144 & 5 & $3.6 \%$ & 144 & 0 & $0.0 \%$ & 174 & 30 & $20.8 \%$ & 29 & $20.0 \%$ \\
\hline Lakeland Area Mass Transit District (Citrus Connection) & 25 & 25 & 0 & $0.0 \%$ & 25 & 0 & $0.0 \%$ & 29 & 4 & $16.0 \%$ & 29 & 0 & $0.0 \%$ & 4 & $16.0 \%$ \\
\hline Lee County Transit (Lee Tran) & 43 & 43 & 0 & $0.0 \%$ & 43 & 0 & $0.0 \%$ & 44 & 1 & $2.3 \%$ & 48 & 4 & $9.1 \%$ & 5 & $11.6 \%$ \\
\hline Manatee County Area Transit (MCAT) & 13 & 15 & 2 & $15.4 \%$ & 15 & 0 & $0.0 \%$ & 16 & 1 & $6.7 \%$ & 19 & 3 & $18.8 \%$ & 6 & $46.2 \%$ \\
\hline Miami-Dade Transit (MDT) & 547 & 564 & 17 & $3.1 \%$ & 506 & -58 & $-10.3 \%$ & 663 & 157 & $31.0 \%$ & 751 & 88 & $13.3 \%$ & 204 & $37.3 \%$ \\
\hline Pasco County Public Transportation (PCPT) & 14 & 14 & 0 & $0.0 \%$ & 14 & 0 & $0.0 \%$ & 14 & 0 & $0.0 \%$ & 16 & 2 & $14.3 \%$ & 2 & $14.3 \%$ \\
\hline Pinellas Suncoast Transit Authority (PSTA) & 122 & 136 & 14 & $11.5 \%$ & 138 & 2 & $1.5 \%$ & 141 & 3 & $2.2 \%$ & 147 & 6 & $4.3 \%$ & 25 & $20.5 \%$ \\
\hline Polk County Transit Services Division - Polk County BOCC (PCTS) & 7 & 11 & 4 & $57.1 \%$ & 11 & 0 & $0.0 \%$ & 9 & -2 & $-18.2 \%$ & 11 & & $22.2 \%$ & 4 & $57.1 \%$ \\
\hline Sarasota County Area Transit (SCAT) & 29 & 29 & 0 & $0.0 \%$ & 26 & -3 & $-10.3 \%$ & 26 & 0 & $0.0 \%$ & 28 & 2 & $7.7 \%$ & -1 & $-3.4 \%$ \\
\hline Space Coast Area Transit (SCAT) & 17 & 17 & 0 & $0.0 \%$ & 20 & 3 & $17.6 \%$ & 20 & 0 & $0.0 \%$ & 19 & -1 & $-5.0 \%$ & 2 & $11.8 \%$ \\
\hline
\end{tabular}

Source: Federal Transit Administration National Transit Database (NTD), Years: 2001-2005 
Table A.2. Florida Transit Agencies: Bus Type by Length for Directly-Operated Transit Buses

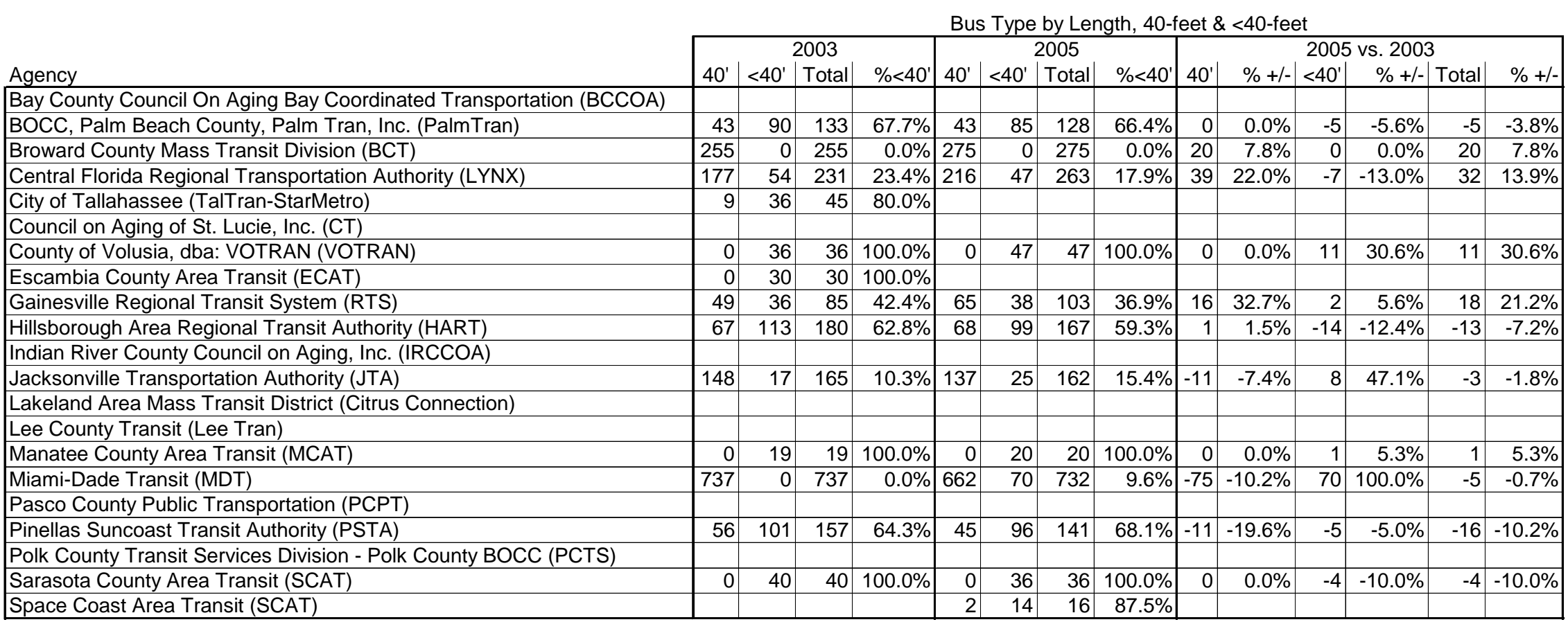

Source: American Public Transportation Association (APTA) Fleet Database, Years: 2003 \& 2005 


\section{Table A.3. Florida Transit Agencies: Potential Working Group Participants}

\begin{tabular}{|c|c|c|c|c|c|c|}
\hline Transit Agency Information & $\begin{array}{l}\text { Central Florida } \\
\text { Regional } \\
\text { Transportation } \\
\text { Authority } \\
\text { (LYNX) } \\
\end{array}$ & $\begin{array}{c}\text { Jacksonville } \\
\text { Transportation } \\
\text { Authority (JTA) }\end{array}$ & $\begin{array}{c}\text { Hillsborough } \\
\text { Area Regional } \\
\text { Transit } \\
\text { Authority } \\
\text { (HART) } \\
\end{array}$ & $\begin{array}{l}\text { Pinellas } \\
\text { Suncoast } \\
\text { Transit } \\
\text { Authority } \\
\text { (PSTA) }\end{array}$ & \begin{tabular}{|c|} 
Board of County \\
Commissioners, \\
Palm Beach \\
County, Palm \\
Tran, Inc. \\
(PalmTran) \\
\end{tabular} & $\begin{array}{c}\text { Gainesville } \\
\text { Regional } \\
\text { Transit } \\
\text { System } \\
\text { (RTS) } \\
\end{array}$ \\
\hline Operating Entity & Authority & Authority & Authority & Authority & County & City \\
\hline Governance & Board & Board & Board & Board & PalmTran & Commission \\
\hline Fixed Routes Operated & 68 & 56 & 50 & 42 & 35 & 36 \\
\hline Service Days/Week & 7 & 7 & 7 & 7 & 7 & 6 \\
\hline Span of Service-Start & 4:15 a.m. & 5:00 a.m. & 5:00 a.m. & 5:00 a.m. & 5:00 a.m. & 6:00 a.m. \\
\hline Span of Service End & 3:05 a.m. & $12: 00$ a.m. & 12:00 a.m. & 12:00 a.m. & 11:00 p.m. & 3:00 a.m. \\
\hline Standard One-way Fare & $\$ 1.50$ & $\$ 0.75$ & $\$ 1.50$ & $\$ 1.50$ & $\$ 1.25$ & $\$ 1.00$ \\
\hline Unlimited Daily Pass & $\$ 3.50$ & no & $\$ 3.25$ & $\$ 3.50$ & $\$ 3.00$ & $\$ 2.00$ \\
\hline Unlimited Monthly Pass & $\$ 38.00$ & $\$ 40.00$ & $\$ 50.00$ & $\$ 85.00$ & $\$ 50.00$ & $\$ 30.00$ \\
\hline Discounts Available (sr, stu, ADA) & yes & yes & yes & yes & yes & yes \\
\hline \multicolumn{7}{|l|}{ UZA-2000 Census (NTD 2005) } \\
\hline City & Orlando & Jacksonville & Tampa-St Pete & Tampa-St Pete & Miami & Gainesville \\
\hline Square Miles & 453 & 411 & 802 & 802 & 1,116 & 77 \\
\hline Population & $1,157,431$ & 882,295 & $2,062,339$ & $2,062,339$ & $4,919,036$ & 159,508 \\
\hline Ranking (465 UZA) & 36 & 44 & 20 & 20 & 5 & 183 \\
\hline \multicolumn{7}{|l|}{ Service Area } \\
\hline Square Miles & 2,538 & 242 & 254 & 226 & 358 & 74 \\
\hline Population & $1,536,900$ & 817,480 & 578,252 & 881,868 & 930,100 & 144,164 \\
\hline \multicolumn{7}{|l|}{ Modal Characteristics - Bus (NTD 2005) } \\
\hline Operating Expenses & $\$ 68,402,819$ & $\$ 51,514,793$ & $\$ 42,349,724$ & $\$ 38,663,558$ & $\$ 36,406,305$ & $\$ 13,823,592$ \\
\hline Fare Revenues & $\$ 16,493,552$ & $\$ 7,391,258$ & $\$ 8,453,598$ & $\$ 8,299,385$ & $\$ 6,554,395$ & $\$ 7,193,151$ \\
\hline Capital Funds & $\$ 30,339,070$ & $\$ 12,237,181$ & $\$ 5,158,239$ & $\$ 20,612,526$ & $\$ 4,525,976$ & $\$ 3,441,863$ \\
\hline Annual Passenger Miles & $148,002,247$ & $60,219,230$ & $53,429,245$ & $47,892,286$ & $51,006,229$ & $26,947,851$ \\
\hline Annual Vehicle Revenue Miles & $13,398,280$ & $10,014,343$ & $6,716,394$ & $8,352,239$ & $6,772,420$ & $2,668,090$ \\
\hline Annual Vehicle Revenue Hours & 949,292 & 611,934 & 542,002 & 569,668 & 409,516 & 235,765 \\
\hline Annual Unlinked Trips & $24,059,369$ & $9,765,763$ & $11,041,918$ & $10,204,222$ & $8,419,477$ & $8,041,803$ \\
\hline Vehicles Available for Maximum Service & 237 & 217 & 188 & 185 & 147 & 108 \\
\hline Vehicle Operated in Maximum Service & 197 & 174 & 151 & 152 & 113 & 88 \\
\hline Average Fleet Age in Years & 6.3 & 8.2 & 5.1 & 6.0 & 4.6 & 11.1 \\
\hline Peak to Base Ratio & 1.11 & 2.60 & 1.34 & 0.97 & 1.33 & 1.16 \\
\hline Percent Spares & $20 \%$ & $25 \%$ & $25 \%$ & $22 \%$ & $30 \%$ & $23 \%$ \\
\hline \multicolumn{7}{|l|}{ Service Efficiency (NTD 2005) } \\
\hline Operating Expense/Vehicle Revenue Mile & $\$ 5.11$ & $\$ 5.14$ & $\$ 6.31$ & $\$ 4.63$ & $\$ 5.38$ & $\$ 5.18$ \\
\hline Operating Expense/Vehicle Revenue Hour & $\$ 72.06$ & $\$ 84.18$ & $\$ 78.14$ & $\$ 67.87$ & $\$ 88.90$ & $\$ 58.63$ \\
\hline \multicolumn{7}{|l|}{ Cost Effectiveness } \\
\hline Operating Expense/Passenger Mile & $\$ 0.46$ & $\$ 0.86$ & $\$ 0.79$ & $\$ 0.81$ & $\$ 0.71$ & $\$ 0.51$ \\
\hline Operating Expenses/Unlinked Pass Trip & $\$ 2.84$ & $\$ 5.28$ & $\$ 3.84$ & $\$ 3.79$ & $\$ 4.32$ & $\$ 1.72$ \\
\hline \multicolumn{7}{|l|}{ Service Effectiveness } \\
\hline Unlinked Pass Trips/Vehicle Rev Mile & 1.80 & 0.98 & 1.64 & 1.22 & 1.24 & 3.01 \\
\hline Unlinked Pass Trips/Vehicle Rev Hour & 25.34 & 15.96 & 20.37 & 17.91 & 20.56 & 34.11 \\
\hline \multicolumn{7}{|l|}{ Fleet Composition (APTA 2005) } \\
\hline 40-foot buses & 216 & 137 & 68 & 45 & 43 & 65 \\
\hline Buses less than 40 -feet & 47 & 25 & 99 & 96 & 85 & 38 \\
\hline Total Buses & 263 & 162 & 167 & 141 & 128 & 103 \\
\hline Percent of buses less than 40 -feet & $17.9 \%$ & $15.4 \%$ & $59.3 \%$ & $68.1 \%$ & $66.4 \%$ & $36.9 \%$ \\
\hline
\end{tabular}

Source: Federal Transit Administration National Transit Database (NTD), Year 2005; American Public Transportation Association (APTA) Fleet

Database, Year 2005 
Table A.4. Florida Transit Agencies: Potential Working Group Participants - Modal Characteristics, Service Efficiency, and Fleet Composition, 2003/2005

\begin{tabular}{|c|c|c|c|c|c|c|c|c|c|c|c|c|}
\hline \multirow[b]{2}{*}{ Modal Characteristics - Bus (NTD) } & \multicolumn{2}{|c|}{$\begin{array}{l}\text { Central Florida Regional } \\
\text { Transportation Authority } \\
\text { (LYNX) }\end{array}$} & \multicolumn{2}{|c|}{$\begin{array}{c}\text { Jacksonville } \\
\text { Transportation Authority } \\
\text { (JTA) }\end{array}$} & \multicolumn{2}{|c|}{$\begin{array}{c}\text { Hillsborough Area } \\
\text { Regional Transit Authority } \\
\text { (HART) }\end{array}$} & \multicolumn{2}{|c|}{$\begin{array}{l}\text { Pinellas Suncoast Transit } \\
\text { Authority (PSTA) }\end{array}$} & \multicolumn{2}{|c|}{$\begin{array}{c}\text { Board of County } \\
\text { Commissioners, Palm } \\
\text { Beach County, Palm Tran, } \\
\text { Inc. (PalmTran) }\end{array}$} & \multicolumn{2}{|c|}{$\begin{array}{l}\text { Gainesville Regional } \\
\text { Transit System (RTS) }\end{array}$} \\
\hline & 2003 & 2005 & 2003 & 2005 & 2003 & 2005 & 2003 & 2005 & 2003 & 2005 & 2003 & 2005 \\
\hline Operating Expenses & $\$ 62,666,486$ & $\$ 68,402,819$ & $\$ 40,134,120$ & $\$ 51,514,793$ & $\$ 30,445,904$ & $\$ 42,349,724$ & $\$ 32,655,094$ & $\$ 38,663,558$ & $\$ 30,518,746$ & $\$ 36,406,305$ & $\$ 10,917,692$ & $\$ 13,823,592$ \\
\hline Fare Revenues & $\$ 13,227,256$ & $\$ 16,493,552$ & $\$ 6,046,611$ & $\$ 7,391,258$ & $\$ 6,653,356$ & \begin{tabular}{|l|}
$\$ 8,453,598$ \\
\end{tabular} & $\$ 7,985,832$ & $\$ 8,299,385$ & $\$ 5,535,671$ & $\$ 6,554,395$ & $\$ 7,398,490$ & $\$ 7,193,151$ \\
\hline Capital Funds & $\$ 13,503,684$ & $\$ 30,339,070$ & $\$ 2,636,860$ & $\$ 12,237,181$ & $\$ 13,588,919$ & $\$ 5,158,239$ & $\$ 13,728,933$ & $\$ 20,612,526$ & $\$ 1,553,444$ & $\$ 4,525,976$ & $\$ 840,833$ & $\$ 3,441,863$ \\
\hline Annual Passenger Miles & $131,858,268$ & $148,002,247$ & $61,723,279$ & $60,219,230$ & $43,832,969$ & $53,429,245$ & $47,165,823$ & $47,892,286$ & $45,199,283$ & $51,006,229$ & $27,153,323$ & $26,947,851$ \\
\hline Annual Vehicle Revenue Miles & $12,986,576$ & $13,398,280$ & $9,333,566$ & $10,014,343$ & $6,219,959$ & $6,716,394$ & $7,657,615$ & $8,352,239$ & $6,573,448$ & $6,772,420$ & $2,408,321$ & $2,668,090$ \\
\hline Annual Vehicle Revenue Hours & 932,284 & 949,292 & 520,438 & 611,934 & 510,698 & 542,002 & 523,013 & 569,668 & 405,668 & 409,516 & 212,034 & 235,765 \\
\hline Annual Unlinked Trips & $21,894,985$ & $24,059,369$ & $8,484,871$ & $9,765,763$ & $9,185,410$ & $11,041,918$ & $9,487,531$ & $10,204,222$ & $7,199,527$ & $8,419,477$ & $8,103,120$ & $8,041,803$ \\
\hline Vehicles Available for $\mathrm{N}$ & 236 & 237 & 171 & 217 & 190 & 188 & 182 & 185 & 141 & 147 & 105 & 108 \\
\hline Vehicle Operated in Maximum Service & 190 & 197 & 144 & 174 & 152 & 151 & 138 & 152 & 114 & 113 & 88 & 88 \\
\hline Average Fleet Age in Years & 6.4 & 6.3 & 8.0 & 8.2 & 4.9 & 5.1 & 5.4 & 6.0 & 4.2 & 4.6 & 10.4 & 11.1 \\
\hline Peak to Base Ratio & 1.04 & 1.11 & 2.15 & 2.60 & 1.32 & 1.34 & 1.02 & 0.97 & 1.18 & 1.33 & 1.18 & 1.16 \\
\hline Percent Spares & $24 \%$ & $20 \%$ & $19 \%$ & $25 \%$ & $25 \%$ & $25 \%$ & $32 \%$ & $22 \%$ & $24 \%$ & $30 \%$ & $19 \%$ & $23 \%$ \\
\hline
\end{tabular}

\section{Service Efficiency (NTD)}

\begin{tabular}{|c|c|c|c|c|c|c|c|c|c|c|c|c|}
\hline Operating Expense/Vehicle Revenue Mile & $\$ 4.83$ & $\$ 5.11$ & $\$ 4.30$ & $\$ 5.14$ & $\$ 4.89$ & $\$ 6.31$ & $\$ 4.26$ & $\$ 4.63$ & $\$ 4.64$ & $\$ 5.38$ & $\$ 4.53$ & $\$ 5.18$ \\
\hline Operating Expense/Vehicle Revenue Hour & $\$ 67.22$ & $\$ 72.06$ & $\$ 77.12$ & $\$ 84.18$ & $\$ 59.62$ & $\$ 78.14$ & $\$ 62.44$ & $\$ 67.87$ & $\$ 75.23$ & $\$ 88.90$ & $\$ 51.49$ & $\$ 58.63$ \\
\hline \multicolumn{13}{|l|}{ Cost Effectiveness } \\
\hline Operating Expense/Passenger Mile & $\$ 0.48$ & $\$ 0.46$ & $\$ 0.65$ & $\$ 0.86$ & $\$ 0.69$ & $\$ 0.79$ & $\$ 0.69$ & $\$ 0.81$ & $\$ 0.68$ & $\$ 0.71$ & $\$ 0.40$ & $\$ 0.51$ \\
\hline Operating Expenses/Unlinked Pass Trip & $\$ 2.86$ & $\$ 2.84$ & $\$ 4.73$ & $\$ 5.28$ & $\$ 3.31$ & $\$ 3.84$ & $\$ 3.44$ & $\$ 3.79$ & $\$ 4.24$ & $\$ 4.32$ & $\$ 1.35$ & $\$ 1.72$ \\
\hline \multicolumn{13}{|l|}{ Service Effectiveness } \\
\hline Unlinked Pass Trips/Vehicle Rev Mile & 1.69 & 1.80 & 0.91 & 0.98 & 1.48 & 1.64 & 1.24 & 1.22 & 1.10 & 1.24 & 3.36 & 3.01 \\
\hline Unlinked Pass Trips/Vehicle Rev Hour & 23.49 & 25.34 & 16.30 & 15.96 & 17.99 & 20.37 & 18.14 & 17.91 & 17.75 & 20.56 & 38.22 & 34.11 \\
\hline
\end{tabular}

Fleet Composition (APTA)

\begin{tabular}{|l}
\hline 40-foot buses \\
\hline Buses less than 40-feet
\end{tabular}

Total Buses

Percent of buses less than 40-feet

Source: Federal Transit Administration National Transit Database (NTD), Years: 2003 \& 2005; American Public Transportation Association (APTA) Fleet Database, Years: 2003 \& 2005 
(this page intentionally left blank) 


\section{Examples Using BSeT}

Three examples of the BSeT analysis are presented below. The first will be constructed to indicate a trend toward large buses, the second an overall need for small buses, and the third will display a condition of indifference. In addition, simple modifications will be made within each sample to demonstrate their impact on the original result. It is important to note that each example presented below is for illustrative purposes only; the numbers contained in the sample and the results are purely hypothetical.

The sample fleet used in each example is displayed in the table below.

Table B.1. Sample Analysis: Sample Fleet

\begin{tabular}{|c|c|c|}
\hline Model Year & Large Buses & Small Buses \\
\hline 2000 & 10 & 10 \\
\hline 2001 & 10 & 10 \\
\hline 2002 & 10 & 10 \\
\hline 2003 & 5 & 5 \\
\hline 2004 & 5 & 5 \\
\hline 2005 & 0 & 10 \\
\hline 2006 & 25 & 0 \\
\hline 2007 & 0 & 10 \\
\hline \hline Totals & 65 & 60 \\
\hline
\end{tabular}

In addition, each sample analysis will establish the following constraints:

- Minimum number of large buses: 10

- Minimum number of small buses: 10

- Average passenger count on large buses across all routes: 15

- Average passenger count on small buses across all routes: 10 


\section{Sample 1: Priorities Met by Large Buses}

Based on the sample fleet and constraints outlined, the results of a qualitative analysis that indicated large buses were best suited to satisfy the priorities of the agency are displayed below.

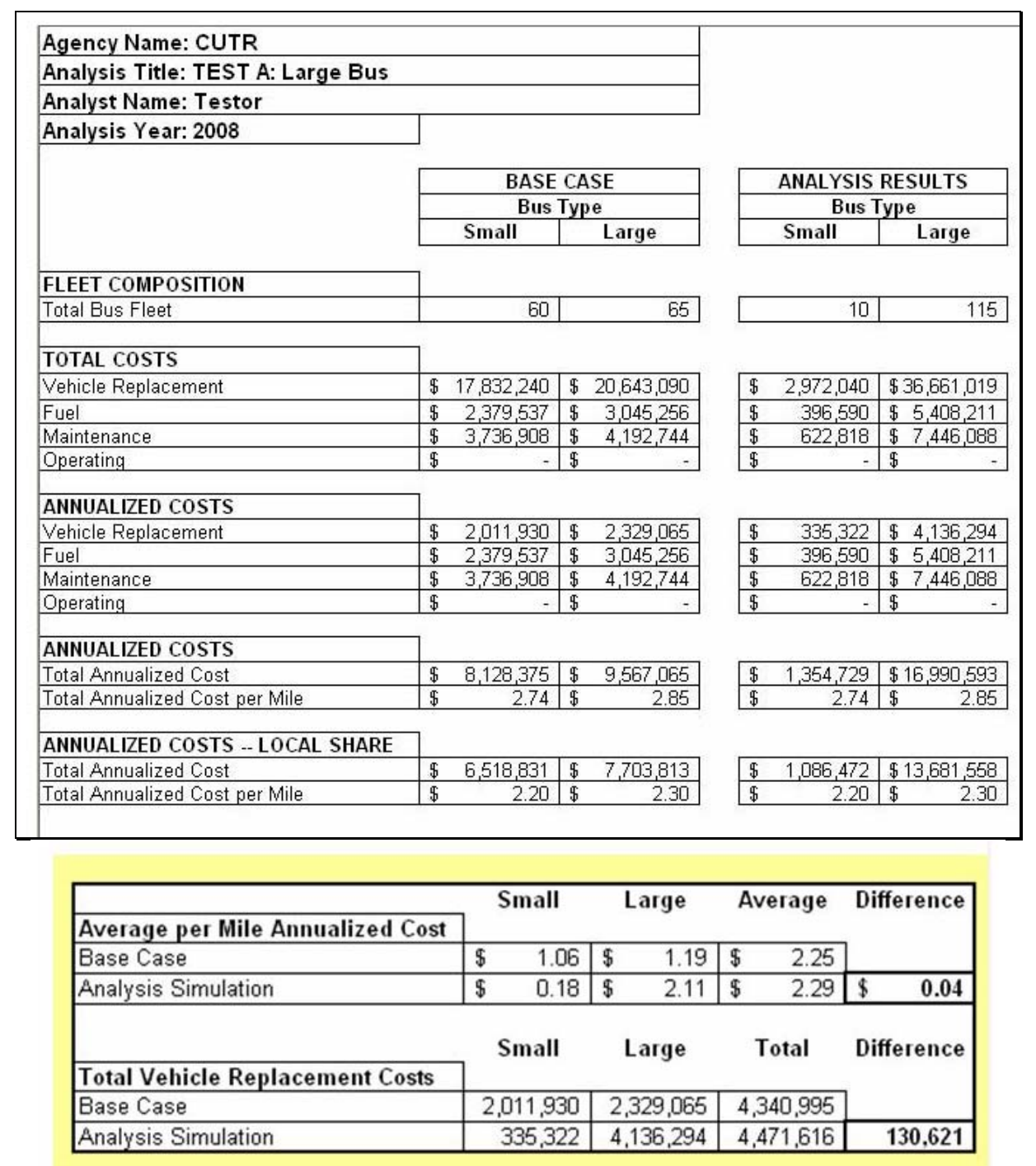

The results of the sample analysis clearly indicate the user's needs are met by large buses. The total fleet size of 125 buses is maintained; however, only the minimum number of small buses is included in the analysis result. The model predicts that the simulated fleet will cost approximately $\$ 0.04$ per mile more to operate on an average annualized basis. Replacement costs are also predicted to be approximately $\$ 130,000$ greater. 
At this point, the sample user decides to modify some of the model parameters. Specifically, the passenger tolerance will be increased to 150 percent for both bus types, and the average annual miles for large buses will be increased to 59,000 miles. The results of the modified analysis are indicated below.

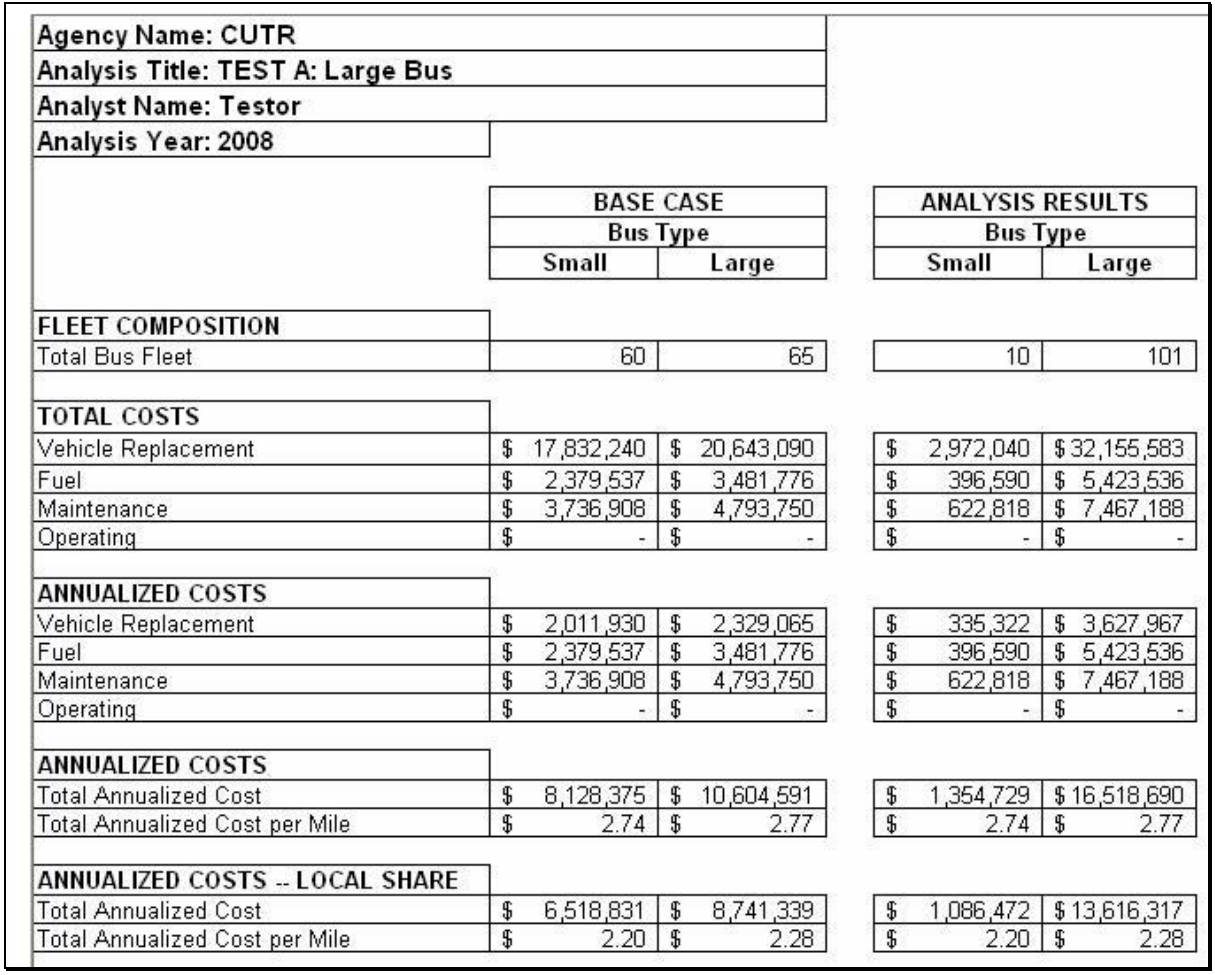

\begin{tabular}{|c|c|c|c|c|}
\hline & \multirow[t]{2}{*}{ Small } & \multirow[t]{2}{*}{ Large } & \multirow[t]{2}{*}{ Average } & \multirow[t]{3}{*}{ Difference } \\
\hline Average per Mile Annualized Cost & & & & \\
\hline Base Case & 1.06 & 1.19 & 2.24 & \\
\hline Analysis Simulation & 0.20 & 2.07 & 2.27 & 0.03 \\
\hline & Small & Large & Total & Difference \\
\hline \multicolumn{5}{|l|}{ Total Vehicle Replacement Costs } \\
\hline Base Case & $2,011,930$ & $2,329,065$ & $4,340,995$ & \\
\hline Analysis Simulation & 335,322 & $3,627,967$ & $3,963,288$ & $(377,706)$ \\
\hline
\end{tabular}

The results of the modified sample analysis clearly indicate the impact of the changes. The total fleet size has dropped to 111 total vehicles, and the total annualized cost per mile for large buses has dropped from $\$ 2.85$ to $\$ 2.77$. Overall, the modified simulation average cost is $\$ 0.01$ less per mile on an annualized basis than the original trial. Additionally, vehicle replacement costs are now almost $\$ 378,000$ less than determined under the base case. 


\section{Sample 2: Priorities Met by Small Buses}

Based on the sample fleet and constraints outlined, the results of a qualitative analysis that indicated small buses were best suited to satisfy the priorities of the agency are displayed below.

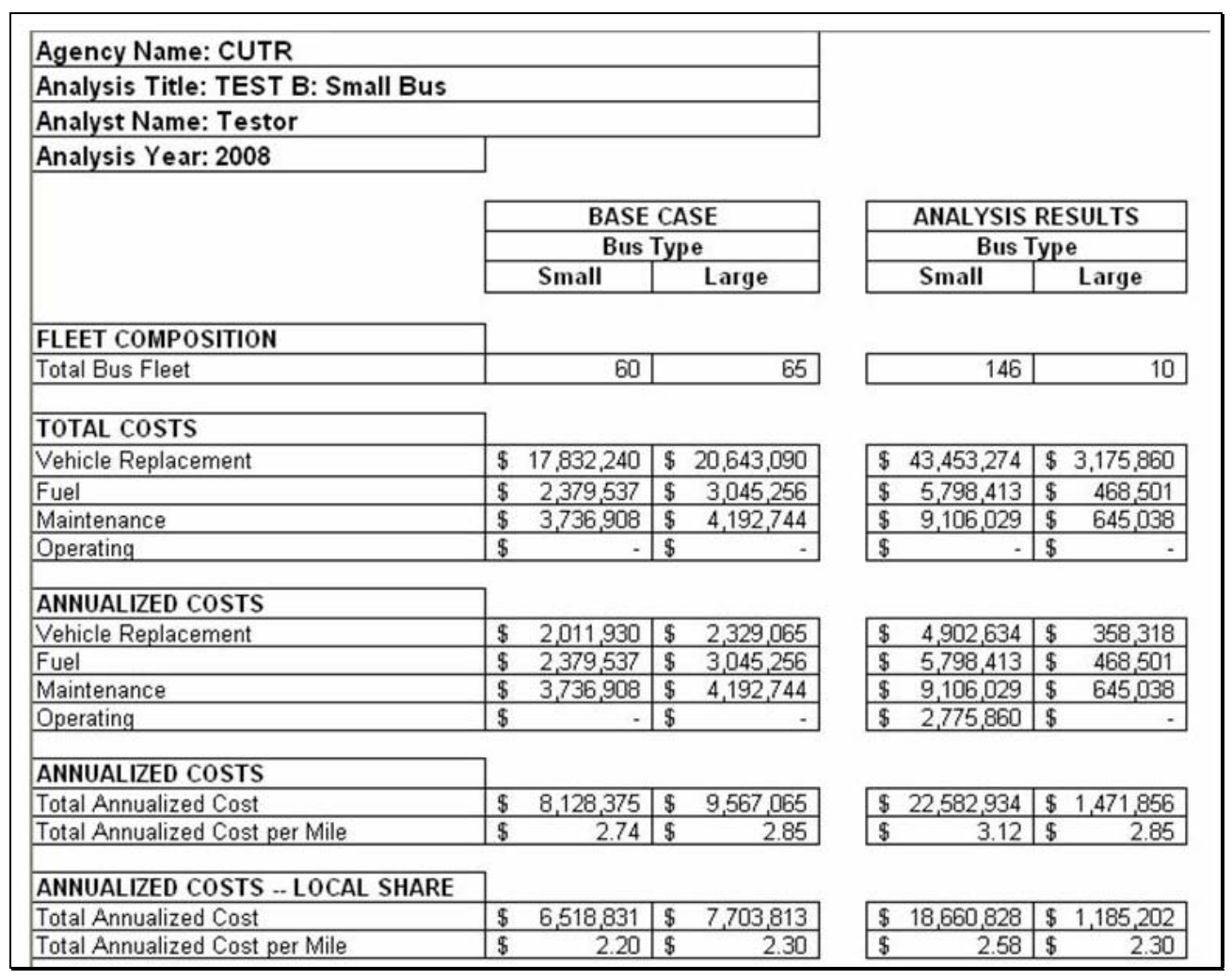

\begin{tabular}{|c|c|c|c|c|}
\hline & \multirow[t]{2}{*}{ Small } & \multirow[t]{2}{*}{ Large } & \multirow[t]{2}{*}{ Average } & \multirow[t]{3}{*}{ Difference } \\
\hline Average per Mile Annualized Cost & & & & \\
\hline Base Case & 1.06 & 1.19 & 2.25 & \\
\hline Analysis Simulation & 2.42 & 0.15 & 2.56 & 0.31 \\
\hline & \multirow[t]{2}{*}{ Small } & \multirow[t]{2}{*}{ Large } & \multirow[t]{2}{*}{ Total } & Difference \\
\hline Total Vehicle Replacement Costs & & & & \\
\hline Base Case & $2,011,930$ & $2,329,065$ & $4,340,995$ & \\
\hline Analysis Simulation & $4,902,634$ & 358,318 & $5,260,951$ & 919,956 \\
\hline
\end{tabular}

The results of the sample analysis clearly indicate the user's needs are met by small buses. The total fleet size has increased to 156; however, only the minimum number of large buses is included in the analysis result. The increased number of buses reflects the model's intent to maintain total fleet capacity. The model predicts that the simulated fleet will cost approximately \$0.31 per mile more to operate on an average annualized basis. Replacement costs are also predicted to be over $\$ 900,000$ greater. 
At this point, the sample user decides to modify some of the model parameters. Specifically, the passenger tolerance will be increased to 150 percent for both bus types, and the average annual miles for small buses will be increased to 60,000 miles. The results of the modified analysis are indicated below.

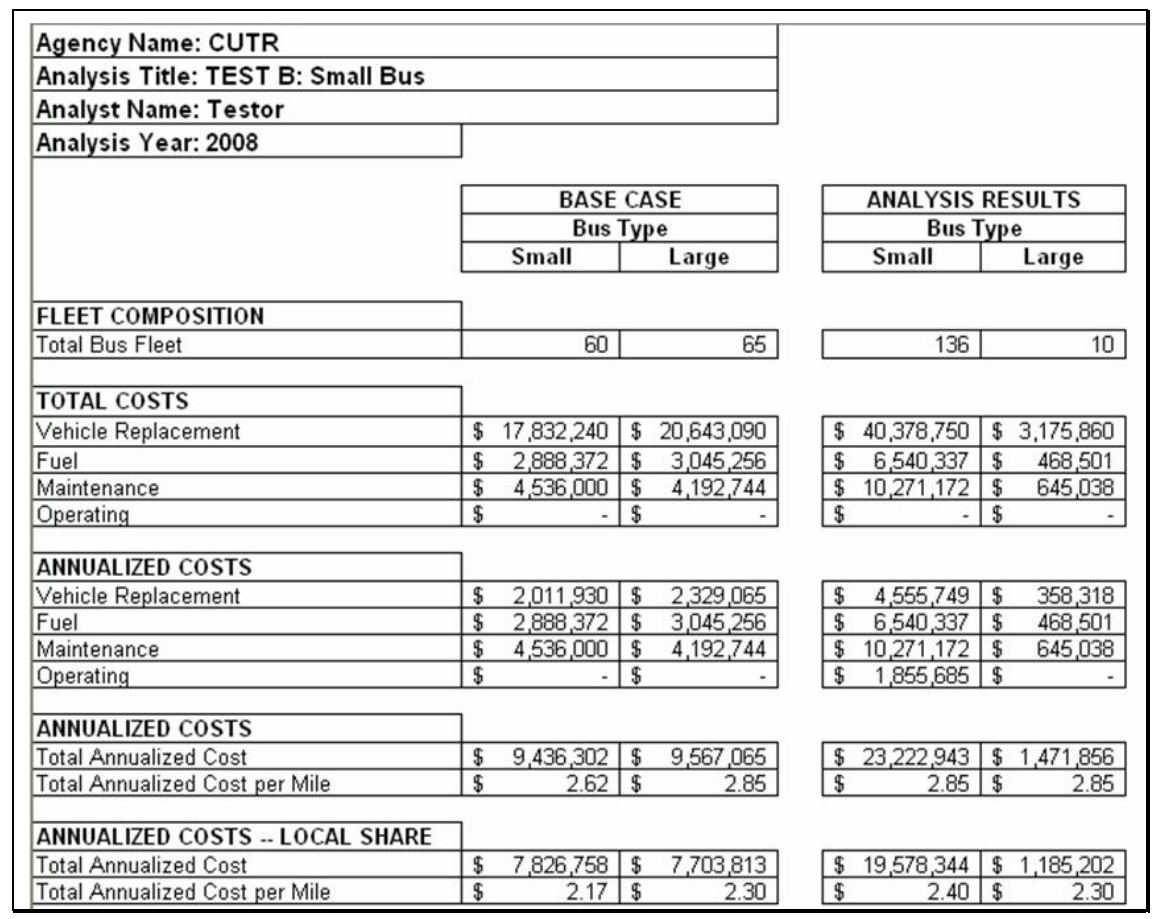

\begin{tabular}{|c|c|c|c|c|}
\hline & Small & Large & Average & Difference \\
\hline Average per Mile Annualized Cost & & & & \\
\hline Base Case & 1.04 & 1.19 & 2.24 & \\
\hline Analysis Simulation & 2.24 & 0.16 & 2.39 & 0.16 \\
\hline & \multirow[t]{2}{*}{ Small } & \multirow[t]{2}{*}{ Large } & \multirow[t]{2}{*}{ Total } & \multirow[t]{2}{*}{ Difference } \\
\hline Total Vehicle Replacement Costs & & & & \\
\hline Base Case & $2,011,930$ & $2,329,065$ & $4,340,995$ & \\
\hline Analysis Simulation & $4,555,749$ & 358,318 & $4,914,067$ & 573,072 \\
\hline
\end{tabular}

Again, the results of the modified sample analysis clearly indicate the impact of the changes. The total simulated fleet size has dropped to 146 total vehicles, and the total annualized cost per mile for small buses has dropped from $\$ 3.12$ to $\$ 2.85$. Overall, the modified simulation average cost is $\$ 0.15$ less per mile on an annualized basis than the original trial. Additionally, vehicle replacement costs have fallen from almost $\$ 920,000$ to less than $\$ 575,000$. 


\section{Sample 3: Indifference Regarding Bus Size}

Based on the sample fleet and constraints defined earlier, the results of a qualitative analysis that indicated neither bus type held a distinct advantage in meeting the needs of the agency are displayed below.

\begin{tabular}{|c|c|c|c|c|}
\hline \multicolumn{3}{|l|}{ Agency Name: CUTR } & & \\
\hline \multicolumn{3}{|c|}{ Analysis Title: TEST C: Indifferent } & & \\
\hline \multicolumn{3}{|c|}{ Analyst Name: Testor } & & \\
\hline \multirow[t]{4}{*}{ Analysis Year: 2008} & & & & \\
\hline & \multirow{2}{*}{\multicolumn{2}{|c|}{$\begin{array}{l}\text { BASE CASE } \\
\text { Bus Type }\end{array}$}} & \multicolumn{2}{|c|}{ ANALYSIS RESULTS } \\
\hline & & & \multicolumn{2}{|c|}{ Bus Type } \\
\hline & Small & Large & Small & Large \\
\hline \multicolumn{5}{|l|}{ FLEET COMPOSITION } \\
\hline Total Bus Fleet & 60 & 65 & 60 & 65 \\
\hline \multicolumn{5}{|l|}{ TOTAL COSTS } \\
\hline Vehicle Replacement & $\$ 17,832,240$ & $\$ 20,643,090$ & $\begin{array}{|ll|}\$ 17,832,240 \\
\end{array}$ & $\$ 20,643,090$ \\
\hline Fuel & $\$ 2,379,537$ & $\$ 3,045,256$ & $\$ 2,379,537$ & $\$ 3,045,256$ \\
\hline Maintenance & $\$ \quad 3,736,908$ & $\$ 4,192,744$ & $\$ 3,736,908$ & $\$ 4,192,744$ \\
\hline Operating & $\$ \quad-$ & $\$$ & $\$$ & \\
\hline \multicolumn{5}{|l|}{ ANNUALIZED COSTS } \\
\hline Vehicle Replacement & $\$ 2,011,930$ & $\$ 2,329,065$ & $\$ 2,011,930$ & $\$ 2,329,065$ \\
\hline Fuel & $\$ 2,379,537$ & $\$ 3,045,256$ & $\$ 2,379,537$ & $\$ 3,045,256$ \\
\hline Maintenance & $\$ 3,736,908$ & $\$ \quad 4,192,744$ & $\$ 3,736,908$ & $\$ 4,192,744$ \\
\hline Operating & $\$ \quad-$ & $\$$ & $\$$ & \\
\hline \multicolumn{5}{|l|}{ ANNUALIZED COSTS } \\
\hline Total Annualized Cost & \begin{tabular}{|l|l|}
$\$$ & $8,128,375$ \\
\end{tabular} & $\$ 9,567,065$ & $\$ 8,128,375$ & $\$ 9,567,065$ \\
\hline Total Annualized Cost per Mile & 2.74 & 2.85 & 2.74 & 2.85 \\
\hline \multicolumn{5}{|c|}{ ANNUALIZED COSTS .. LOCAL SHARE } \\
\hline Total Annualized Cost & 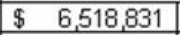 & $\$ 7,703,813$ & 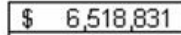 & $\$ 7,703,813$ \\
\hline Total Annualized Cost per Mile & 2.20 & 2.30 & 2.20 & 2.30 \\
\hline
\end{tabular}

\begin{tabular}{|c|c|c|c|c|}
\hline & Small & \multirow[t]{2}{*}{ Large } & \multirow[t]{2}{*}{ Average } & \multirow{3}{*}{ Difference } \\
\hline Average per Mile Annualized Cost & & & & \\
\hline Base Case & 1.06 & 1.19 & 2.25 & \\
\hline Analysis Simulation & 1.06 & 1.19 & 2.25 & $\$$ \\
\hline & \multirow[t]{2}{*}{ Small } & \multirow[t]{2}{*}{ Large } & \multirow[t]{2}{*}{ Total } & \multirow[t]{2}{*}{ Difference } \\
\hline Total Vehicle Repla & & & & \\
\hline Base Case & $2,011,930$ & $2,329,065$ & $4,340,995$ & \\
\hline Analysis Simulation & $2,011,930$ & $2,329,065$ & $4,340,995$ & \\
\hline
\end{tabular}

The results of the sample analysis clearly indicate the user's indifference regarding bus size. The total fleet size has remained the same, and no analysis simulation differences are indicated. 
At this point, the sample user decides to modify some of the model parameters. Specifically, the passenger tolerance will be increased to 150 percent for both bus types, and the average annual miles for both bus sizes will be increased to 55,000 miles. The results of the modified analysis are indicated below.

\begin{tabular}{|c|c|c|c|c|}
\hline \multicolumn{3}{|l|}{ Agency Name: CUTR } & & \\
\hline \multicolumn{3}{|c|}{ Analysis Title: TEST C: Indifferent } & & \\
\hline \multicolumn{3}{|l|}{ Analyst Name: Testor } & & \\
\hline \multirow[t]{4}{*}{ Analysis Year: 2008} & & & & \\
\hline & \multirow{2}{*}{\multicolumn{2}{|c|}{ BASE CASE }} & \multicolumn{2}{|c|}{ ANALYSIS RESULTS } \\
\hline & & & \multicolumn{2}{|c|}{ Bus Type } \\
\hline & Small & Large & Small & Large \\
\hline \multicolumn{5}{|l|}{ FLEET COMPOSITION } \\
\hline Total Bus Fleet & \begin{tabular}{l|l}
60 \\
\end{tabular} & 65 & 60 & 65 \\
\hline \multicolumn{5}{|l|}{ TOTAL COSTS } \\
\hline Vehicle Replacement & $\$ 17,832,240$ & $\$ 20,643,090$ & $\$ 17,832,240$ & $\$ 20,643,090$ \\
\hline Fuel & $\$ 2,647,674$ & $\$ 3,245,724$ & $\$ 2,647,674$ & $\$ 3,245,724$ \\
\hline Maintenance & $\$ 4,158,000$ & $\$ \quad 4,468,750$ & $\$ 4,158,000$ & $\$ 4,468,750$ \\
\hline Operating & $\$$ & $\$$ & $\$$ & $\$$ \\
\hline \multicolumn{5}{|l|}{ ANNUALIZED COSTS } \\
\hline Vehicle Replacement & $\$ 2,011,930$ & $\$ 2,329,065$ & $\$ 2,011,930$ & $\$ 2,329,065$ \\
\hline Fuel & $\$ 2,647,674$ & $\$ 3,245,724$ & $\$ 2,647,674$ & $\$ 3,245,724$ \\
\hline Maintenance & $\$ 4,158,000$ & $\$ 4,468,750$ & $\$ 4,158,000$ & $\$ 4,468,750$ \\
\hline Operating & $\$$ & $\$$ & $\$$ & $\$$ \\
\hline \multicolumn{5}{|l|}{ ANNUALIZED COSTS } \\
\hline Total Annualized Cost & $\$ 8,817,604$ & $\$ 10,043,539$ & $\$ 8,817,604$ & $\$ 10,043,539$ \\
\hline Total Annualized Cost per Mile & $\$ \quad 2.67$ & 2.81 & 2.67 & $\$ \quad 2.81$ \\
\hline \multicolumn{5}{|c|}{ ANNUALIZED COSTS .- LOCAL SHARE } \\
\hline Total Annualized Cost & $\$ 7,208,060$ & $\$ 8,180,287$ & $\$ 7,208,060$ & $\$ 8,180,287$ \\
\hline Total Annualized Cost per Mile & 2.18 & 2.29 & 2.18 & 2.29 \\
\hline
\end{tabular}

\begin{tabular}{|c|c|c|c|c|c|c|}
\hline & Small & \multicolumn{2}{|c|}{ Large } & \multirow{2}{*}{\multicolumn{2}{|c|}{ Average }} & \multirow[t]{2}{*}{ Difference } \\
\hline Average per Mile Annualized Cost & & & & & & \\
\hline Base Case & 1.05 & $\$$ & 1.19 & $\$$ & 2.24 & \\
\hline Analysis Simulation & 1.05 & $\$$ & 1.19 & $\$$ & 2.24 & $\$$ \\
\hline & \multirow[t]{2}{*}{ Small } & \multirow{2}{*}{\multicolumn{2}{|c|}{ Large }} & \multirow{2}{*}{\multicolumn{2}{|c|}{ Total }} & \multirow[t]{2}{*}{ Difference } \\
\hline Total Vehicle Replacement Costs & & & & & & \\
\hline Base Case & $2,011,930$ & & 9,065 & & 0,995 & \\
\hline Analysis Simulation & $2,011,930$ & & 9,065 & & 0,995 & \\
\hline
\end{tabular}

While there continues to be no simulated analysis results and the fleet size and distribution are maintained, the modifications have had an impact. Specifically, the total annualized cost has increased under the modifications, while the total annualized cost per mile has decreased. The sample illustrates the consequences of higher quantities of passengers riding on buses traveling greater distances. 
(this page intentionally left blank) 